\title{
Digital Actuator Technology
}

\section{Ted Quinn, Jerry Mauck, Richard Bockhorst, Ken Thomas}

\section{September 2014}

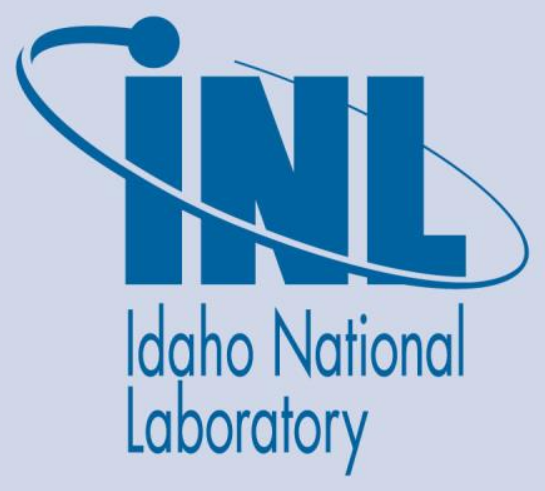

The INL is a U.S. Department of Energy National Laboratory operated by Battelle Energy Alliance 


\section{DISCLAIMER}

This information was prepared as an account of work sponsored by an agency of the U.S. Government. Neither the U.S. Government nor any agency thereof, nor any of their employees, makes any warranty, expressed or implied, or assumes any legal liability or responsibility for the accuracy, completeness, or usefulness, of any information, apparatus, product, or process disclosed, or represents that its use would not infringe privately owned rights. References herein to any specific commercial product, process, or service by trade name, trade mark, manufacturer, or otherwise, does not necessarily constitute or imply its endorsement, recommendation, or favoring by the U.S. Government or any agency thereof. The views 
INL/EXT-14-33132

\section{Digital Actuator Technology}

Ted Quinn, Jerry Mauck, Richard Bockhorst; Technology Resources

Ken Thomas; Idaho National Laboratory

September 2014

Idaho National Laboratory

Idaho Falls, Idaho 83415

http://www.inl.gov

Prepared for the U.S. Department of Energy Office of Nuclear Energy Under DOE Idaho Operations Office

Contract DE-AC07-05ID14517 
The U.S. Department of Energy (DOE) Office of Nuclear Energy (NE) established the Advanced Sensors and Instrumentation (ASI) technology area under the Nuclear Energy Enabling Technologies (NEET) Program to coordinate the instrumentation and controls (I\&C) research across DOE-NE and to identify and lead efforts to address common needs. As part of the NEET ASI research program, the Digital Technology Qualification project was established based on collaboration between Oak Ridge National Laboratory (ANL) and Idaho National Laboratory (INL). This report was prepared under Work Package CT-13IN070307. 


\section{EXECUTIVE SUMMARY}

The nuclear industry has been slow to incorporate digital actuator technology into nuclear plant designs for several reasons, including:

- The high cost of design change modifications to implement them, versus simply replacing them with like-for-like technology when the components fail.

- Digital technology qualification issues, particularly in safety related applications that are susceptible to software common cause failure. This is a concern both for current operating plants as well as new builds.

- General familiarity and comfort with the existing analog technology on the part of the nuclear plant engineering staff, in spite of the superior performance and reduced maintenance costs of the digital replacements.

At the same time, the nuclear industry is under significant cost pressure in the electric marketplace due to the abundance of gas generation. The industry would benefit by investment in new technologies that could lower future operating costs while addressing current obsolescence and reliability issues of the current technologies. However, the industry has been unable to formulate the business cases to take advantage of these labor savings and production reliability improvements.

This report presents the benefits digital actuator technology for four types of actuators that account for the vast majority of control applications in a nuclear power plant: pneumatic control, hydraulic control, motor control, and variable frequency drives. The report describes the common failure modes of the analog actuators as confirmed by actual component failure records from an industry failure data base.

The report discusses the benefits of digital actuators, which are generally found in two main areas. First, the digital technology offers superior operational performance over its analog counterparts, in terms of accuracy, reliability, and maintainability. Also, actuator setup is considerably easier with the digital technology. Second, the cost of maintaining the digital actuators is lower due to simplicity of operation (circuit boards vs. mechanical parts) and onboard diagnostics that greatly improve troubleshooting and repair.

Notwithstanding the benefits of digital actuators, there are certain qualification and licensing challenges that are inherent with digital technology, and these are described in the report. One major qualification impediment for digital sensor implementation is software common cause failure (SCCF). A typical analysis for SCCF, in the form of a Nuclear Regulatory Commission (NRC) regulatory submittal, is presented to demonstrate the difficulty in addressing SCCF for nuclear safety-related designs. It also addresses what options exist to mitigate the SCCF concerns.

The report concludes with a summary of benefits to be gained and challenges to be addressed in pursuing the wide-scale application of digital actuator technology. In particular, it highlights the need for new approaches in digital technology qualification over the only currentlyaccepted approach of presenting a coping analysis for an assumed SCCF. 


\section{CONTENTS}

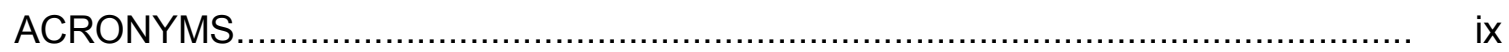

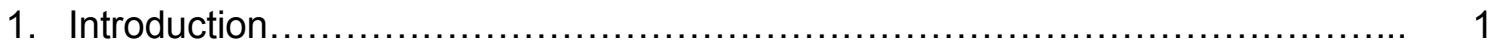

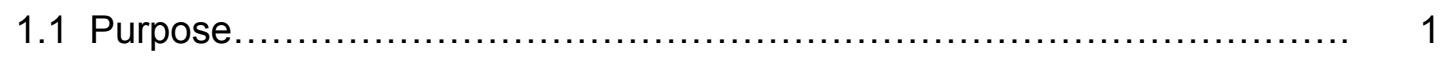

1.2 Scope $\ldots \ldots \ldots \ldots \ldots \ldots \ldots \ldots \ldots \ldots \ldots \ldots \ldots \ldots \ldots \ldots \ldots \ldots \ldots \ldots \ldots \ldots \ldots . \quad 3$

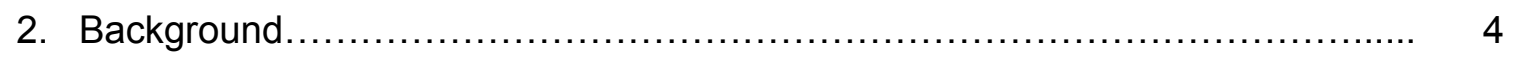

2.1 Why Digital Actuator Technology is Needed............................. 4

2.2 Barriers to Digital Implementation in Nuclear Power Plants................. 4

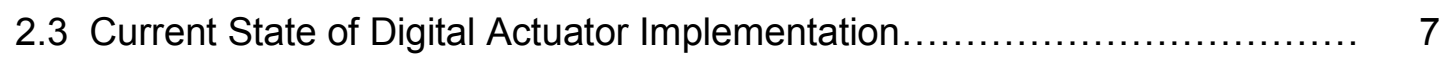

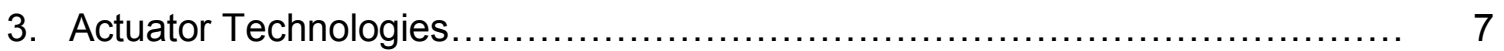

3.1 Pneumatic Valve and Damper Control............................... 8

3.1.1 Analog Pneumatic Control...................................... 8

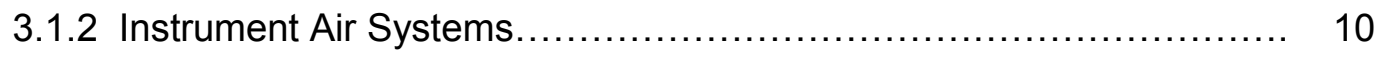

3.1.3 Digital Pneumatic Control..................................... 12

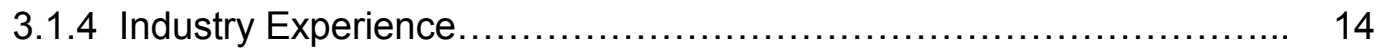

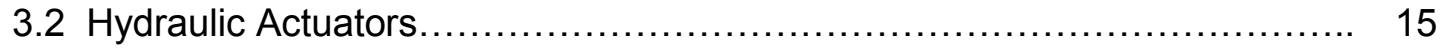

3.2.1 Analog Hydraulic Actuators.................................... 15

3.2.2 Hydraulic Oil Supply System................................. 16

3.2.3 Digital Replacements for Hydraulic Actuators...................... 17

3.2 .4 Industry Experience............................................. 19

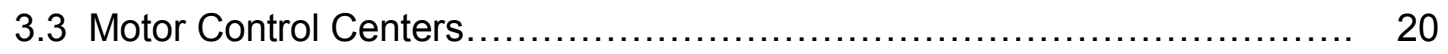

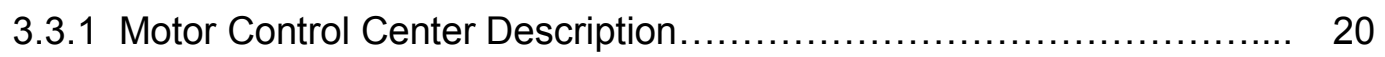

3.3.2 Digital Technology for Motor Control Centers...................... 22

3.3.3 Industry Experience........................................ 22

3.4 Variable Frequency Motor Drives.................................. 23

3.4.1 Variable Frequency Motor Drive Description...................... 23

3.4.2 Digital Technology for Variable Frequency Drives................... 25

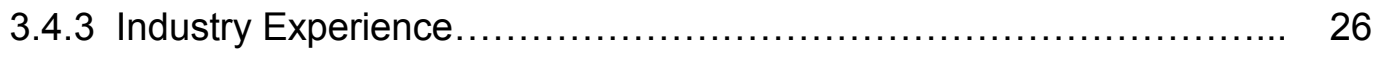


4. Actuator Reliability, Availability, and Maintainability........................ 28

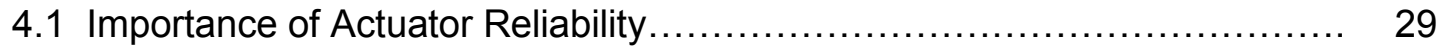

4.2 Example Reliability Calculation - Valve Actuator....................... 30

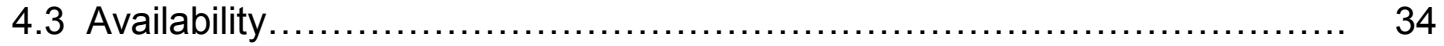

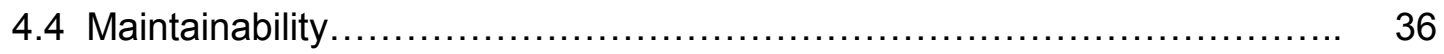

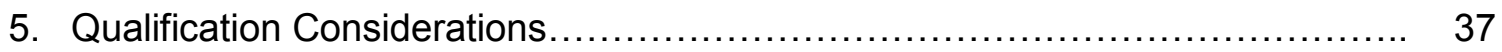

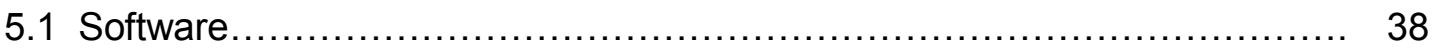

5.2 Environmental, Seismic, and Electromagnetic Compatibility Qualification.... 38

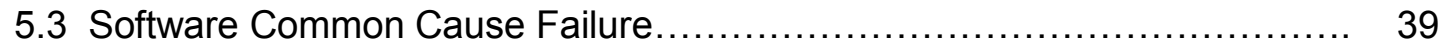

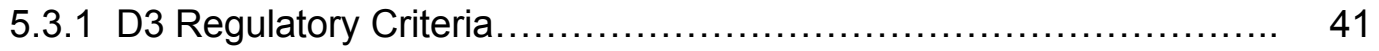

5.3.2 D3 Analysis Process for Digital Actuator......................... 43

5.3.3 Analysis for SCCF within Non-Safety Related Actuators............. 46

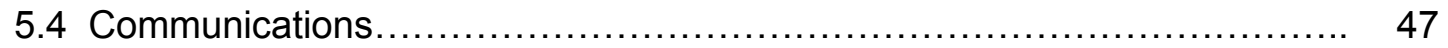

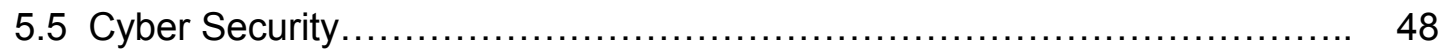

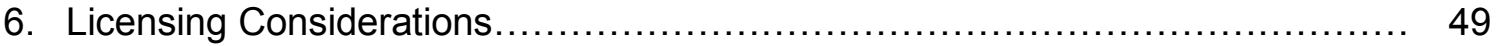

6.1 Nuclear Plant Modifications under Licensee Control..................... 49

6.2 Nuclear Plant Modifications under NRC License Amendment............... 51

6.3 Improvements in Plant Technical Specifications........................ 51

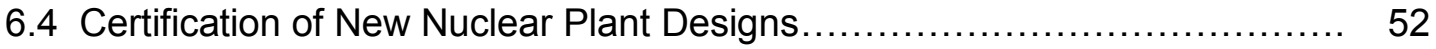

6.5 Summary of Qualification and Licensing Considerations................. 53

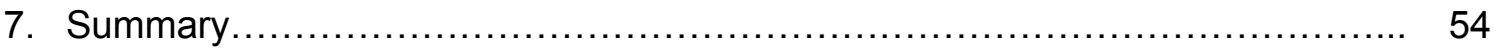

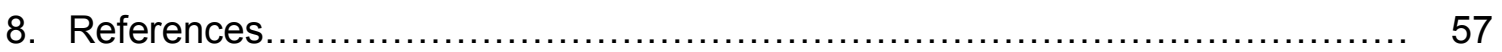

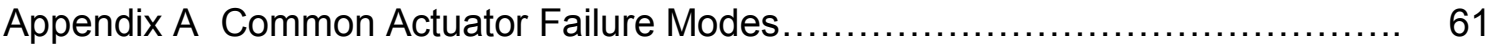

Appendix B Example D3 Evaluation......................................... 63 


\section{FIGURES}

Figure 1 Pneumatic Valve and Damper Circuit...................................... 8

Figure 2 Typical Control Valve Air Supply Arrangement........................... 9

Figure 3 Typical Instrument Air Supply System............................... 10

Figure 4 Example Digital Valve Positioner Block Diagram...................... 13

Figure 5 Exlar Roller Screw Mechanism for Linear Motion........................ 18

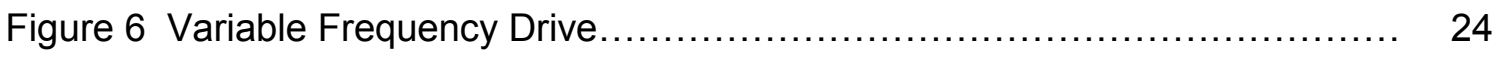

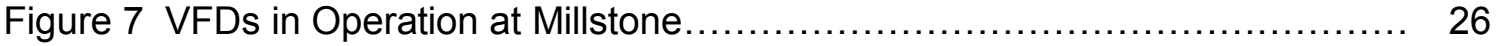

Figure 8 BWR Depicting Recirculation Pump............................... 27

\section{TABLES}

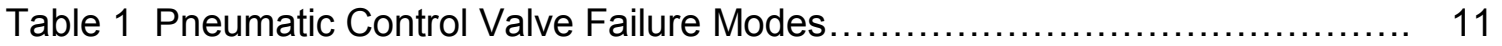

Table 2 Installed Base of VFDs in Nuclear Plants in the U.S $\ldots \ldots \ldots \ldots \ldots \ldots \ldots \ldots \ldots \ldots \ldots \ldots \ldots \ldots$ 


\section{ACRONYMS}

AFS

AFW

ANS

AOO

ATWS

BTP

BWR

CCF

CCP

CCW

CDA

CFA

$\mathrm{COL}$

CW

D3

DAS

DAC

DBA

DCD

DCS

DNB

DNBR

ECCS

$\mathrm{EHC}$

EMC

EMI/RFI

EOP

EPRI

ESD

ESF

ESFAS
Auxiliary Feedwater System

Auxiliary Feedwater

American Nuclear Society

Anticipated Operational Occurrence

Anticipated Transient Without Scram

Branch Technical Position

Boiling Water Reactor

Common Cause Failure

Centrifugal Charging Pump

Component Cooling Water

Critical Digital Assets

Cubic feet per minute

Combined Operating License

Circulating Water

Diversity and Defense-in-Depth

Diverse Actuation Systems

Design Acceptance Criteria

Design Basis Accident

Design Control Document

Digital Control System

Departure from Nuclear Boiling

Departure from Nuclear Boiling Ratio

Emergency Core Cooling System

Electrohydraulic Control

Electromagnetic Compatibility

Electromagnetic and Radio Frequency Interface

Emergency Operating Procedure

Electric Power Research Institute

Electro Static Discharge

Engineered Safety Function

Engineered Safety Function Actuation Systems 


\begin{tabular}{ll}
${ }^{\circ} \mathrm{F}$ & Degrees Fahrenheit \\
FWCS & Feedwater Control System \\
FMEA & Failure Modes and Effects Analysis \\
HFE & Human Factors Engineering \\
HVAC & Heating, Ventilation, and Air Conditioning \\
I\&C & Instrumentation and Control \\
IEEE & Institute of Electrical and Electronics Engineers \\
INPO & Institute of Nuclear Power Operations \\
I/P & Current to Pressure Converter \\
ISA & International Society of Automation \\
ISG & Interim Staff Guidance \\
ITAAC & Inspections, Tests, Analysis, and Acceptance Criteria \\
LBLOCA & Large Break LOCA \\
LOCA & Loss of Coolant Accident \\
LVDT & Linear variable differential transformer \\
mA & Milliamp \\
MCC & Motor Control Center \\
MCCB & Molded case circuit breaker \\
MSLB & Main Steam Line Break \\
MSR & Moisture separator reheater \\
MSSV & Main Steam Safety Valve \\
MTBF & Programmable Logic Controller \\
MTC & Mean-Time-Between-Failure \\
MTTR & Moderator Temperature Coefficient \\
MW & Mean-Time-To-Repair \\
NEI & Megawattt \\
NGNP & Nuclear Energy Institute \\
NPP & Next Generation Nuclear Power Plant \\
NRC & Nuclear Regulatory Commission \\
O\&M & Operation and Maintenance \\
PFD & Probability of Failure on Demand \\
PIE & PLC \\
PM & Postulated Initiating Event \\
\hline
\end{tabular}




$\begin{array}{ll}\text { PRA } & \text { Probabilistic Risk Assessment } \\ \text { PSIA } & \text { Pounds per square inch absolute } \\ \text { PWR } & \text { Pressurized Water Reactor } \\ \text { RCA } & \text { Rod Control Assembly } \\ \text { RCS } & \text { Reactor Coolant System } \\ \text { RIS } & \text { Regulatory Information Summary } \\ \text { RPS } & \text { Reactor Protection System } \\ \text { RRS } & \text { Reactor Recirculation System } \\ \text { RTS } & \text { Reactor Trip System } \\ \text { SAR } & \text { Safety Analysis Report } \\ \text { SER } & \text { Safety Evaluation Report } \\ \text { SFCP } & \text { Surveillance Frequency Control Program } \\ \text { SG } & \text { Steam Generator } \\ \text { SIS } & \text { Safety Injection System } \\ \text { SMR } & \text { Small Modular Reactors } \\ \text { SSC } & \text { System, Structure, Component } \\ \text { STG } & \text { Steam Generator Tube Rupture } \\ \text { SCCF } & \text { Software Common Cause Failure } \\ \text { TI } & \text { Test Interval } \\ \text { UFSAR } & \text { Updated Final Safety Analysis Report } \\ \text { VSD } & \text { Variable Speed Drive }\end{array}$




\subsection{Introduction}

\subsection{Purpose}

This report presents the benefits of using digital actuators in nuclear power plants for component positioning and operation, and describes the challenges in digital technology qualification that are impeding their rate of adoption. The report builds on two previous reports that dealt with sensors and logic processors. These reports are:

1. Digital Technology Qualification (INL/EXT-12-27215) [1]

2. Digital Sensor Technology (INL/EXT-13-29750) [2]

A major theme of these reports is the identification of barriers in the use of digital in an endto-end comprehensive manner or, in other words, from sensor to control system to actuator. This is an important concept in the achievement of the full benefit of digital technology with its superior performance and maintainability characteristics. Too often today, nuclear plant designers implement a modern digital control system capable of high precision control, but then couple it with less-accurate analog sensors and actuators. This effectively negates the benefits of the digital control system in that the analog components tend to dominate the overall system accuracy and reliability.

There are many proven digital actuator product offerings available today and more are being developed. The process industry has made considerable use of them and has proven the benefits in actual field experience. In addition, digital actuators have been used very successfully in conventional power generation. These other industries typically operate on smaller financial margins than nuclear generation, and so the business cases for their upgrades must be sound. Nevertheless, they have been able to incorporate these digital actuator technologies in both new existing facilities. It is also recognized that the qualification requirements for these other industries might be less stringent than that for nuclear application, although it can be argued that process industries have many comparable safety-critical designs.

In any event, the nuclear industry has been slow to incorporate digital actuator technology into nuclear plant designs for several reasons, including:

- The high cost of design change modifications to implement them, versus simply replacing them with like-for-like technology when the components fail.

- Digital technology qualification issues, particularly in safety related applications that are susceptible to software common cause failure. This is a concern both for current operating plants as well as new builds.

- General familiarity and comfort with the existing analog technology on the part of the nuclear plant engineering staff, in spite of the superior performance and reduced maintenance costs of the digital replacements.

In nuclear plant design, many of the large and more expensive components are intended to last for the life of the station, and so the opportunity to replace them occurs only in the case of a premature failure. However, this is not true for actuators. They typically do not last the life of the station and are periodically replaced due to reliability concerns and design specification changes (e.g. more closing force for a valve actuator). 
The replacement opportunity for these actuators represents a decision point in whether to invest in more modern technology that would provide superior operational and maintenance benefits. However, the legacy analog technology remains available at least for the foreseeable future, although this might not always be true. Therefore, nuclear utilities today have the option to replace actuators with like-for-like replacements that avoid design change modification costs and other direct costs such as revising plant testing and maintenance procedures, training modules, etc.

To help the nuclear industry better understand the opportunity represented by digital actuator technology, the report discusses the benefits of digital actuators, which are generally found in two main areas. First, digital technology offers superior operational performance over its analog counterparts, in terms of accuracy, reliability, and maintainability. Also, actuator setup is considerably easier with the digital technology. Second, the cost of maintaining the digital actuators is lower due to simplicity of operation (circuit boards vs. mechanical parts) and on-board diagnostics that greatly improve troubleshooting and repair.

Yet, the application of digital technology has been problematic for the nuclear industry, due to qualification and regulatory issues. With some notable exceptions, the result has been a continuing reluctance to undertake the risks and uncertainties of implementing digital actuator technology when replacement opportunities present themselves. Rather, utilities would typically prefer to accept the performance limitations of the legacy analog actuator technologies in order to avoid potential impacts to project costs and schedules.

To challenge the conventional thinking, this report presents the benefits of digital actuator technology as significant in terms of plant performance and reduced operating cost, and proposes that it is worthwhile to address the barriers currently holding back the widespread implementation of this technology.

In regard to the benefits, this project investigates the advantages of digital actuator technology as it improves performance in the areas of accuracy, reliability, and maintainability. It describes the performance improvement with the digital actuators and asserts that it is very much in the interest of the commercial nuclear industry to find an acceptable solution to the issue of SCCF for digital actuators.

The barriers to implementation are the subject of a related Oak Ridge National Laboratory project for which the goal is to resolve the impediments to qualification of digital technology for nuclear power application to enable more extensive utilization of modern equipment in the full range of I\&C systems at nuclear power plants. [3] More specifically, the project is developing an objective, scientific basis for determining necessary and sufficient mitigation of software common cause failure vulnerabilities.

Together, these projects will demonstrate the application of equipment, strategies, and methodologies to enable more extensive digital technology usage. 


\subsection{Scope}

The scope of this report focuses on major component actuators that are typically found in all control systems of a nuclear power plant. These are actuators are pneumatic control, hydraulic control, motor control, and variable frequency drives. These types of actuators represent the majority of plant applications, covering such components as valves, dampers, motors (and other electrical loads), and pumps.

These actuators are found in all types of nuclear power plants. This includes the current U.S. light water reactor operating fleet, the new builds that are in the licensing and construction process now, small modular reactors (SMRs), and the next generation nuclear plants (NGNP). Even though there are a variety of reactor technologies, the underlying plant systems still consist of the same types of major active components - valves, pumps, dampers, motors, etc. The requirements for actuators for these types of active components remain the same across all of the reactor technologies. In some cases, their qualification criteria differ.

The scope of the qualification and licensing considerations is that set of concerns specific to digital regardless of reactor technology and plant type. These include both the conventional qualifications such as seismic, environmental, and EMC, and the qualification considerations peculiar to digital technology such as cyber security and software common cause failure. In the licensing area, the scope includes the various regulatory processes that are applicable both in general and in particular to digital technology implementation in nuclear power plants.

The organization of the major sections of the report is as follows:

Section 2 Provides background information on why digital actuator technology is beneficial, what the barriers are in implementation, and the current state of digital actuator usage.

Section 3 Provides an overview of current state analog actuator technologies and the particular performance limitations that they have.

Section 4 Describes reliability, availability, and maintainability comparisons of analog vs. digital actuator technologies.

Section 5 Describes certain qualification considerations that are must be addressed for digital actuators to be used in critical areas of nuclear power plants.

Section 6 Describes certain licensing considerations that are somewhat of a challenge with digital technology and that must be addressed in order to take advantage of digital actuators in nuclear power plant (NPP) designs.

Section $7 \quad$ Presents the conclusions of the project and describes future efforts needed to for the wide-spread implementation of digital actuators. 


\subsection{Background}

\subsection{Why Digital Actuator Technology is Needed}

Digital actuator technology has been available to the nuclear industry for many years. During this time, other industries have made extensive use of it to improve the reliability of their operations and to lower costs. In the face of competitive pressure, these other industries have been able to derive positive business cases to invest in these technologies. In fact, such technologies have proven to be a competitive advantage in managing production costs.

Today, the nuclear industry is facing unprecedented cost pressure. On the revenue side, low-cost gas generation is setting market conditions that are challenging many unregulated nuclear power plants with financial viability. Indeed, the closing of Kewaunee Nuclear Station in 2013 was due to the inability to compete in the market place [4]. This plant was operating very well, had no major component issues, and was in good regulatory standing.

On the cost side, nuclear plants today are having to make some major investments to increase safety margins. There is a series of mandatory plant modifications now in progress to address issues arising from the Fukushima accident. This has come on the heels of a long series of previous mandatory plant upgrades related to such issues as security, extensive damage, flood protection, reactor heads, containment sumps, steam generators, and others. Many utilities have elected to invest in plant uprates to increase the power output, and thereby the economic value of their plants. In view of all of these mandatory and elective upgrades, there is a pressing need to reduce operating costs so that the investments are fully recovered and the nuclear plants are positioned for long-term operation.

A major impetus for increased use of digital actuators is that it is a means of reducing operating costs. As discussed in Section 3.0, digital actuators offer performance and maintainability benefits. They offer significant diagnostic and health reporting capabilities that can also reduce plant support costs and provide earlier warning of impending failures. The avoidance of failures that could result in costly plant shutdowns and adverse regulatory actions is a significant indirect cost benefit.

Ironically, many plants have upgraded their plant control systems to digital, which is evidence that they value the operational advantages of digital technology. However, for the most part, these plants continue to use analog actuators on the output side of the digital control systems for reasons that are described in the next section of this report. This greatly limits the overall benefits of the modern digital control systems and leaves operating costs higher than they otherwise would be.

\subsection{Barriers to Digital Implementation in Nuclear Power Plants}

One of the main barriers to widespread implementation of digital actuators is the design and implementation costs to change an analog actuator to digital technology. The cost of a design change modification is relatively high in the nuclear industry due to all of the processes and documentation that must be completed to ensure that the regulatory requirements of the design and licensing bases have been met. In addition to the cost, the number of qualified engineering 
staff is also a limitation. For this reason, most nuclear plants limit the number of modifications that they are willing to take on in a given period of time.

Moreover, the budgets that are allocated to modifications are mostly consumed by mandatory modifications driven by regulatory requirements or deteriorating performance of important plant equipment. In other words, continued operations are in some way threatened. This typically leaves little budget for elective modifications whose merit is based on future cost savings. As long as the plants have an option to replace failing components such as actuators with either the same or like technology, this will be an attractive option. The plants have an "equivalent change" process (meaning the design and licensing bases are not changed) and they can execute this process for a fraction of the cost of a design change.

In order to overcome this barrier, nuclear plants will have to derive business cases that justify the increased modification costs in order to lower the cost of future operations. This will require a thorough examination of the benefits this technology can have across many plant organizations and thereby produce an aggregate benefit analysis based on positive impacts on many plant work activities over the remaining (including extended) life of the plant.

As previously mentioned, the industry has entered an era when comprehensive focus on reducing operating costs is likely to become an imperative. Much of this is driven by external factors such as the price of gas generation and whether expensive regulatory-driven upgrades continue at the present rate. However, digital actuator technology is poised to be a part of the solution, along with many other technology and process improvements that are available. The benefits of this technology as presented in Sections 3.0 and 4.0 will constitute the basis of such a business case.

A second important barrier that must be overcome is the issue of digital technology qualification. Because digital involves electronic components and software, there are qualification requirements that go beyond those for their analog predecessors. Some of these are based on the plant physical environment, such as seismic, environmental (temperature, pressure, high energy spray impingement, radiation), and electromagnetic interference. Electronic components tend to be more sensitive to these phenomena compared to their analog (electro-mechanical) counterparts. In addition, software-based components are susceptible to other types of hazards, including software faults, cyber-attacks, and software common cause failure (SCCF).

For non-safety use of digital actuators, these qualification factors are reasonably manageable as evidenced by a respectable number of implementations (although far short of the potential beneficial usage). The electronics can usually be located in a mild plant environment to address those particular concerns. Also, the consequences of the special software concerns, whether they result in failure or mis-operation, can usually be shown to be bounded by the plant safety analysis, as long as the plant protections systems are not subject to a common cause failure. Therefore, there is opportunity for the industry to pursue broader implementation of non-safety digital actuators based on a plant performance and cost-reduction business case, without undue concern over the qualification issues.

There is general agreement that digital actuators are more reliable due to more precise operation (accuracy) and easier to detect imminent and latent failures (due to embedded 
diagnostic capabilities). Yet, due to the special software concerns, it is very difficult to implement them in safety-related systems. (This measurable improvement in reliability is presented in Section 4.0.) The great irony in the implementation of digital actuators is that the plant systems that need to be the most reliable (i.e. plant protection systems) generally cannot use them due to the qualification issues, while the systems that are less critical from a nuclear safety standpoint can.

This is the challenge for the industry and the regulator: to find a way to use this superior technology where it would do the most good by resolving the qualification barriers to safetyrelated usage. It should be noted that the most difficult issue is that of SCCF, which is a combination of a major technical challenge (determining the reliability of software) and complex regulatory process known as diversity and defense-in-depth (D3) analysis. This requires the assumption that a SCCF occurs within the digital technology and then the proof that the nuclear plant can cope with the failure, considering all applicable events and accidents of the plant safety analysis. The current regulatory framework for SCCF does not provide a means for determining how much diversity in a design is sufficient. It is possible that within given manufacturer's make and model, there could be sufficient diversity to minimize the probability of a SCCF due to other factors, including diverse software development. The manufacturers do not offer these options today because there are no objective criteria for determining how much diversity is enough, and therefore no objective way to credit this diversity in the analysis (as sufficient to preclude a SCCF).

As mentioned previously, a related project is being conducted by the Oak Ridge National Laboratory to address the issue of digital technology qualification, and in particular, the matter of SCCF, in order to develop objective criteria for how much diversity is sufficient in a digital design. The hope is that these two projects together can mount a compelling case for overcoming the barriers to the use of digital actuator technology and encourage plant designers, plant owners, and actuator suppliers to find practical solutions to the current impediments to obtaining these performance improvements.

These qualification issues are discussed in more detail in Section 5.0 and implications for related regulatory processes are discussed in Section 6.0.

Finally, there is the somewhat artificial barrier within the nuclear industry of the tendency to just stay with the proven analog technology to avoid the cost and effort to overcome the first two barriers of difficult cost justifications and unresolved qualification issues. Plant engineers are very busy just keeping the stations running and performing their required activities. Because plant resources are chronically overcommitted, they have to take advantage of any practical ways to manage their workloads. This often means forgoing elective work, regardless of how attractive it might be for the long run. And so, there is very little staff time available to overcome these large barriers to digital actuator implementation when the option to just continue to use the existing analog technology remains available. This, then, is really the overall intent of this report - to make the case that resolving these barriers and providing the basis for compelling business cases will enable a significant improvement in reliability and cost management for the current and future nuclear plants. 


\subsection{Current State of Digital Actuator Implementation}

There is little usage of digital actuators in the nuclear power plants today. It seems to be well behind even the rate of adoption of digital sensors, which are somewhat less of a challenge in the qualification area. In the recent past, there have been several notable implementations of smart positioners for pneumatic valve control, most often for feedwater regulation valves in pressurized water reactors. Likewise, there has been some move to digital systems for variable frequency drives for reactor recirculation pumps in boiling water reactors. There have also been some successful replacements of hydraulic control valves for turbine-driven feedwater pumps and similar auxiliary feedwater pumps. Finally, there is some early usage of digital-based motor control centers and related circuit breakers. All of these examples are discussed in the Industry Experience subsections for the respective actuator types in Section 3.0.

At the present, the momentum in implementing digital actuators is being affected by proposed regulatory requirement changes for digital technologies in general. Until recently, the nuclear industry has operated under certain assumptions on how to address qualification issues for non-safety modifications under Nuclear Regulatory Commission (NRC) regulation 10 CFR 50.59 (see Section 5.1). For example, in some cases, nuclear utilities have dispositioned the SCCF issue by concluding that there is "reasonable assurance that the likelihood of failure due to software is sufficiently low." The NRC has recently initiated a process to review these practices and to potentially develop new regulatory guidance, and in some cases new regulatory requirements. In a related matter, the NRC has issued a draft Regulatory Information Summary [5] that states requirements for implementation of plant components with embedded digital devices for safety-related (and important to safety) applications. It is uncertain how long it will be until these issues are resolved and the industry has a stable regulatory environment for digital implementation.

The effect of this will likely be a slow-down in the implementation of digital actuators and in general, any other digital components. Some utilities have said that they will not pursue these upgrades until the requirements are both settled and determined to be reasonable. This position has been reinforced by at least two recent regulatory findings on embedded digital devices that affect multiple utilities. The resolution of the issues regarding digital technology qualification is of significant importance to the industry if it is to take advantage of the operational and cost benefits of digital actuators.

\subsection{Actuator Technologies}

This section addresses the most common types of actuators used in nuclear power plants that account for the applications that can most benefit from digital technology. They are pneumatic valve and damper control, hydraulic valve control, motor control, and variable speed drives for pump control.

Each actuator type is presented as a comparison between the legacy analog technology and the newer digital technologies. The benefits of the digital technology are found in both the 
operation of the device (accuracy and reliability) and in the maintenance of the devices (early detection of impending failures and diagnostic capabilities to improve troubleshooting).

In some cases, support systems are needed, such as instrument air systems and hydraulic fluid systems. These systems tend to be quite complex and the issues associated with their maintenance and operation are also described. Some digital replacement technologies eliminate the need for these systems altogether.

Finally, two common types of actuators are not addressed, in that the advantages of digital technology replacements are not apparent at this time. They are solenoid actuators and motor operators for valves, or at least as an integral part of the operation. Both of these actuator types are typically used in relatively simple open/close type applications and the role of digital might at best be in providing diagnostics on the health of the devices.

\subsection{Pneumatic Valve and Damper Control}

Pneumatic actuators are used to position air-operated control valves and dampers. The motion of the valve or damper arm is provided either by a sliding stem or a piston (Figure 1). They operate by increasing air pressure on one side of a diaphragm which acts against spring pressure to move the valve stem. If the air pressure is reduced, the spring moves the valve stem in the opposite direction. A piston operated valve works in a similar matter, only using an enclosed piston to push against the spring pressure rather than a diaphragm.

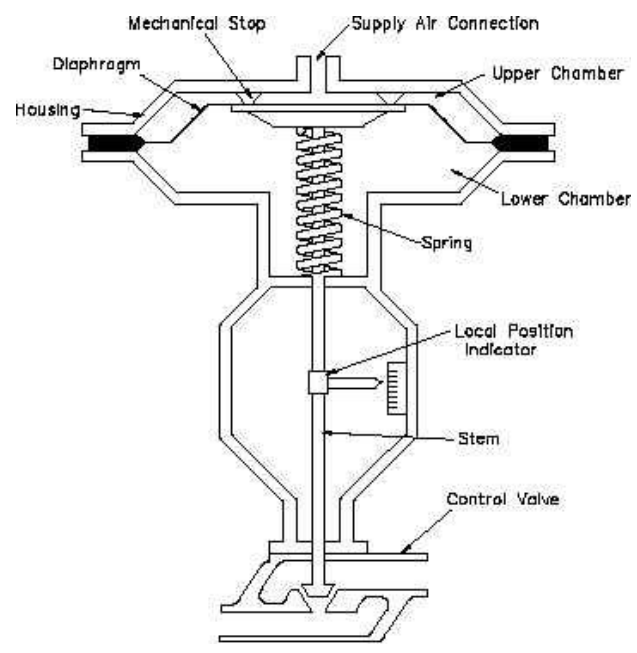

Figure 1. Sliding Stem Pneumatic Actuator

\subsubsection{Analog Pneumatic Control}

In pneumatic control, compressed air is used to provide motive force for various types of displacement mechanisms. A series of devices are used to take air from a regulated supply and then provide the correct amount of air pressure to move the device to the desired position. These can include an air filter, a pressure regulator, a volume booster, an I/P converter, a lubricator, a controller, and a positioner. In some safety-related designs, one or 
two electrically-operated solenoid valves are inserted between the positioner and the control valve to dump the air and let the valve return to its fail-safe position by the spring motion. Two valves are used in safety-related applications - one for each safety actuation train.

Figure 2 provides a typical block diagram of the arrangement of component from the instrument air system to the air-operated control valve. A filter is typically installed to prevent introduction of foreign material into the control components. A pressure regulator reduces the supplied air pressure to the required value. A current-to-pressure converter (I/P) accepts a control signal (typically 4 to 20 milliamps) from an electronic controller and produces a proportional output air pressure (typically 3 to $15 \mathrm{psig}$ ) that is supplied to the positioner. The positioner typically has a separate air supply in addition to the air supplied from the I/P. The output of the positioner is applied to the control valve actuator. The valve position is fed back to the positioner to assist in positioning the control valve to the proper position. There are numerous variants on this arrangement depending on the design requirements. A common variant is that the $\mathrm{I} / \mathrm{P}$ is combined with the positioner as a single unit, but the operation is the same.

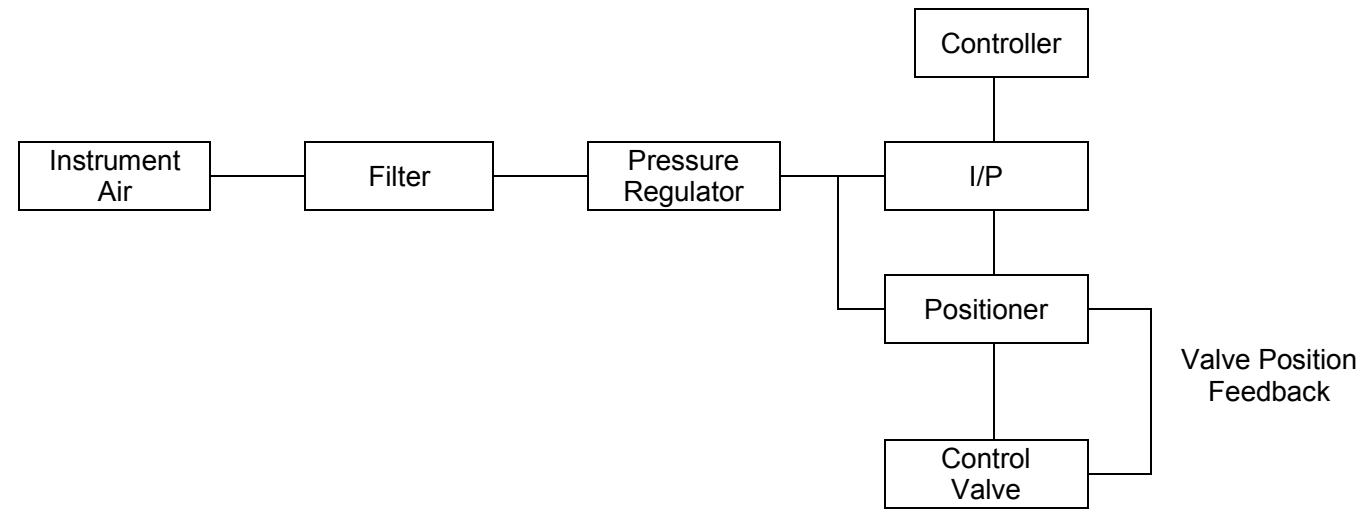

Figure 2 Typical Control Valve Air Supply Arrangement

The instrument air supply is typically 100 psig. The air is filtered and then reduced in pressure and supplied to a current-to-pressure converter (I/P). The I/P typically is provided with a 4-20 milliamp signal from an electronic controller. The I/P modulates a flapper over an air nozzle in proportion to the control signal to vary the output air pressure to between 3 and 15 psig. This air pressure is supplied to a positioner that may perform several functions. A positioner ensures that there is a linear relationship between the signal input pressure from the control system and the position of the control valve. This means that for a given input signal, the valve will always attempt to maintain the same position regardless of changes in valve differential pressure, stem friction, diaphragm hysteresis and so on. A positioner may be used as a signal amplifier or booster. It accepts a low pressure air control signal and, by using its own higher pressure input, multiplies this to provide a higher pressure output air signal to the actuator diaphragm, if required, to ensure that the valve reaches the desired position. Some positioners incorporate an electro-pneumatic converter 
so that an electrical input (typically $4-20 \mathrm{~mA}$ ) can be used to control a pneumatic valve eliminating the need for a separate I/P. Positioners have a feedback loop of valve position back to the positioner.

\subsubsection{Instrument Air Systems}

Figure 3 provides a block diagram of a typical air supply to an air operated control valve. [6] The compressor takes air from the atmosphere and compresses it, typically to 100 psig. Since the compression process heats the air, an after-cooler reduces the temperature of the air. The cooling also causes the humidity of the air to increase and moisture to be generated that is removed by a moisture separator. The receiver provides a storage vessel for the compressed air. Additional filters may be employed to reduce contaminants in the compressed air. Dryers further reduce the humidity of the compressed air. Filters downstream of the dryers provide protection against introduction of desiccant (drying agent) into the instrument air system. There are numerous variants on this arrangement.

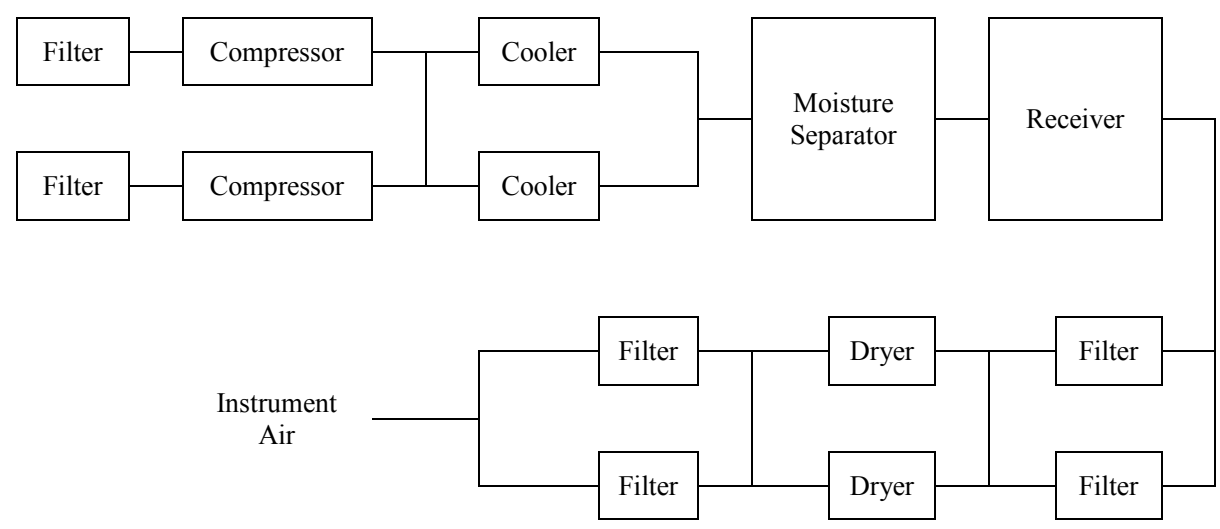

Figure 3: Typical Instrument Air Supply System

In an EPRI-Nuclear Safety Analysis Center publication [7], a review of nuclear industrywide pneumatic system problems indicated that 49 percent of all failure events resulted from contamination in the system, and only 28 percent were attributed to component failures. It is possible some of the component failures also occurred due to contamination in the instrument air system. This means that contaminants are the largest single contributor to instrument air system failures. Table 1 presents the typical failure modes and mechanisms for pneumatic valves.

The principle source of foreign material is rust within the instrument air system and induction of foreign material (primarily dirt) with the air intake. [8] Dirt or rust particles can cause damage to compressor cylinders. Cylinders of non-lubricated compressors are specially honed to a fine finish to reduce the friction coefficient between the piston rings and the cylinder wall surface. Therefore, non-lubricated compressors are more vulnerable to foreign material damage than lubricated compressors.

Compressing and cooling air generates condensate within the instrument air system. Saturated air at atmospheric pressure and $100^{\circ} \mathrm{F}$ contains about 0.4 gallons of water per 
1000 cubic feet of air. If this air is compressed to 100 psig and cooled to $80^{\circ} \mathrm{F}$, the water content in the air will only be about 0.025 gallons per 1000 cubic feet of air. This is equivalent to a removal of 22 gallons per hour for a 1000 CFM capacity compressor. If this water is not consistently removed it can initiate corrosion within the system. Solenoid valves, pneumatically operated valves, pilot valves, and I/P converters are especially vulnerable to failure due to foreign particle incursions.

\begin{tabular}{|c|c|c|c|c|c|}
\hline \multicolumn{6}{|c|}{ Table 1: Pneumatic Control Valve Failure Modes } \\
\hline $\begin{array}{l}\text { Component } \\
\text { type }\end{array}$ & Function & $\begin{array}{l}\text { Failure } \\
\text { Modes }\end{array}$ & $\begin{array}{l}\text { Failure } \\
\text { Mechanism }\end{array}$ & $\begin{array}{l}\text { Effect on } \\
\text { System }\end{array}$ & Comments \\
\hline $\begin{array}{l}\text { Filter } \\
\text { Regulator }\end{array}$ & $\begin{array}{l}\text { Supply } \\
\text { filtered } \\
\text { compressed } \\
\text { air }\end{array}$ & $\begin{array}{l}\text { High } \\
\text { pressure } \\
\text { Low pressure } \\
\text { Erratic } \\
\text { pressure } \\
\text { regulation }\end{array}$ & $\begin{array}{l}\text { Air leaks } \\
\text { Diaphragm } \\
\text { failure } \\
\text { Spring failure } \\
\text { Foreign material } \\
\text { contamination }\end{array}$ & $\begin{array}{l}\text { Consequential } \\
\text { failure of } \\
\text { downstream } \\
\text { components. }\end{array}$ & $\begin{array}{l}\text { Typically } \\
\text { between } 20 \\
\text { and } 50 \text { psig }\end{array}$ \\
\hline $\begin{array}{l}\text { Electro } \\
\text { pneumatic } \\
\text { transducer }\end{array}$ & $\begin{array}{l}\text { Convert an } \\
\text { electronic } \\
\text { control } \\
\text { signal to a } \\
\text { proportional } \\
\text { air pressure. }\end{array}$ & $\begin{array}{l}\text { High } \\
\text { pressure } \\
\text { Low pressure } \\
\text { Erratic } \\
\text { pressure } \\
\text { regulation }\end{array}$ & $\begin{array}{l}\text { Air leaks } \\
\text { Diaphragm } \\
\text { failure } \\
\text { Spring failure } \\
\text { Foreign material } \\
\text { contamination } \\
\text { Force motor } \\
\text { failure }\end{array}$ & $\begin{array}{l}\text { Failure of } \\
\text { valve to } \\
\text { position } \\
\text { correctly }\end{array}$ & $\begin{array}{l}\text { Typically the } \\
\text { control signal } \\
\text { is } 4-20 \\
\text { milliamps } \\
\text { corresponding } \\
\text { to } 3-15 \text { psig }\end{array}$ \\
\hline Positioner & $\begin{array}{l}\text { Provide air } \\
\text { pressure to } \\
\text { valve } \\
\text { actuator to } \\
\text { accurately } \\
\text { position } \\
\text { valve }\end{array}$ & $\begin{array}{l}\text { High } \\
\text { pressure } \\
\text { Low pressure } \\
\text { Erratic } \\
\text { pressure } \\
\text { regulation }\end{array}$ & $\begin{array}{l}\text { Air leaks } \\
\text { Diaphragm } \\
\text { failure } \\
\text { Spring failure } \\
\text { Foreign material } \\
\text { contamination }\end{array}$ & $\begin{array}{l}\text { Failure of } \\
\text { valve to } \\
\text { position } \\
\text { correctly }\end{array}$ & $\begin{array}{l}\text { Positioner } \\
\text { may } \\
\text { incorporate } \\
\text { the functions } \\
\text { of an electro } \\
\text { pneumatic } \\
\text { transducer }\end{array}$ \\
\hline Actuator & $\begin{array}{l}\text { Position } \\
\text { valve }\end{array}$ & $\begin{array}{l}\text { Valve go to } \\
\text { failure } \\
\text { position } \\
\text { Valve go to } \\
\text { position } \\
\text { opposite } \\
\text { failure } \\
\text { position } \\
\text { Erratic valve } \\
\text { operation }\end{array}$ & $\begin{array}{l}\text { Air leaks } \\
\text { Diaphragm } \\
\text { failure } \\
\text { Spring failure } \\
\text { Stem binding }\end{array}$ & $\begin{array}{l}\text { Failure of } \\
\text { valve to } \\
\text { position } \\
\text { correctly }\end{array}$ & \\
\hline
\end{tabular}

In nuclear facilities, if an air operated valve is used in a nuclear safety-related application, an accumulator is typically used to back-up the non-safety related air supply. The accumulator is normally equipped with check valves to assure an air supply is available for the AOV if the normal air supply fails. Foreign material within the system may become lodged on the check valve seat potentially allowing excessive leakage from the accumulator. 
If the service air system is used as a backup to instrument air system gross moisture contamination of the instrument air system can occur unless the cross connection is made prior to dryer pre-filters.

I/P converters are susceptible to air-line contamination, particularly dirt and rust. Due to extremely small ports inside the I/P converter any dirt or rust that enters the device can start plugging ports and causing sluggish response. Filters are installed in the air line just upstream of the I/P converter to mitigate the problem. Plugging of the filter can lead to degradation of the valve performance.

Pneumatic valve operators may have diaphragms made of a neoprene or rubber compound that deteriorates in the presence of hydrocarbon contamination. They may also be exposed to dirt and rust inside the actuator causing the valve to stick.

\subsubsection{Digital Pneumatic Control}

A positioner is a device that accepts a control signal and varies the air pressure applied to the valve actuator until the control valve achieves the position demanded by the control signal. A positioner is used for the following reasons.

- Minimize the hysteresis of the control valve due to packing friction

- Offset variations in valve actuator spring rate

- Improve the valve response time

- Compensate for variations in the internal valve pressure applied to the stem

Figure 4 provides a block diagram of an example digital valve positioner. On the front end, a microprocessor accepts the control signal and adjusts the signal to the I/P based on the output pressure, the supply pressure and the valve position. The I/P provides a pressure signal to a pneumatic relay that amplifies the signal and provides the pressure to the valve actuator.

Digital positioners offer a number of advantages in four fundamental areas.

- High reliability

- Improved operational performance

- Increased productivity and reduce maintenance costs

- On-board diagnostics for early warning of pending failure modes

It should be noted that the use of a digital positioner does not negate the susceptibility to the instrument air quality issues that are described above, although the on-board diagnostics can detect some of the instrument air failure modes.

Since the early 1990's, over a million digital valve positioners have been sold worldwide adding up to billions of operational hours. [9] The modular design of some of the models isolates the field terminal compartment from internal positioner components. Many are designed to function in adverse environmental conditions such as elevated temperatures and high vibration service. 


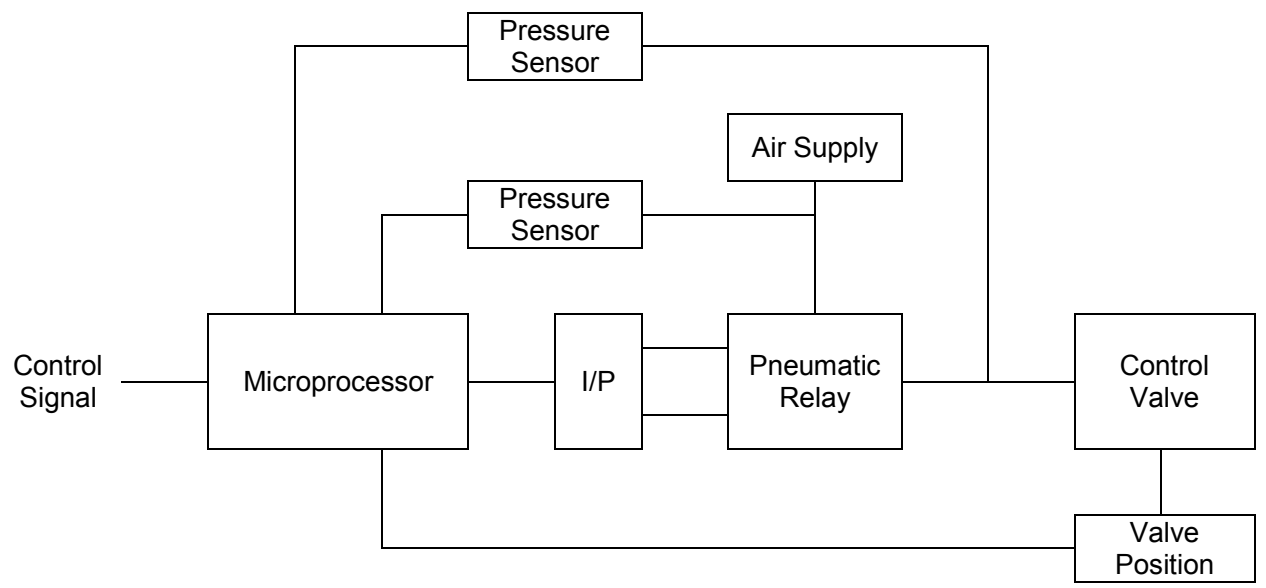

Figure 4 Example Digital Valve Positioner Block Diagram

Operational performance is enhanced through improved accuracy of the digital positioner. The improved accuracy is achieved by enabling consideration of a number of factors digitally to adjust the positioner output pressure. Self-tuning features improve the dynamic response of the associated control valve resulting in better process control. The digital nature of the positioners permit remote diagnostics to be performed routinely or whenever deemed appropriate. These diagnostics have the capability to detect a variety of issues related to the control valve functionality such as the following potential problems.

- air leakage

- valve assembly friction and dead band

- instrument air quality

- loose connections

- supply pressure restriction

- valve assembly calibration.

The availability of diagnostics permits early identification of degradation allowing corrective action to be taken and avoiding an upset condition. The diagnostic capability also facilitates characterization of the valve performance following maintenance on the valve to increase the assurance that the valve will function properly when returned to service.

Implementing digital positioners on critical control valves also enables online partial stroke testing of the control valve without upsetting the normal process control. This testing provides assurance that the control valve will actually move on demand.

Increased productivity and reduced maintenance costs are possible through the following factors.

- remote configuration, calibration and diagnostics

- non-contact feedback technology

- valve position information availability

- remote mounting of positioner

- online valve testing 
- modular design

- inventory reduction

The ability to remotely configure, calibrate, and diagnose the health of the controls may simplify maintenance. Digital positioners have the ability to self-calibrate, potentially eliminating the need to access the valve locally. If the valve is located in a radiological controlled area, personnel radiation exposure may be reduced. Depending on the specific valve location, implementing personnel safety measures such as scaffolding may be avoided if the maintenance can be conducted remotely. If maintenance on a digital valve positioner is required, the modular design of the positioner simplifies the repair.

Some digital valve positioners can be coupled with non-contact valve position sensing to eliminate common problems associated with valve position linkage assemblies. Several designs utilize a magnet assembly to regulate the output of a Hall effect sensor that is proportional to the valve position. Since the magnet is in proximity to the Hall effect sensor but does not contact it, the mechanical linkage is eliminated. This also permits locating the positioner away from the valve if vibration is a problem. With digital valve position indication, the position information may be transmitted to the control room if this information is useful to operations personnel.

A single digital valve positioner model can be used in multiple applications and on most valve assemblies. Using a common positioner may allow a reduction in the spare parts inventory reducing the spare parts inventory expense. The optional integral valve position transmitter eliminates the need for a separate valve position transmitter.

\subsubsection{Industry Experience}

At a Midwestern nuclear unit, digital positioners had been installed on the main feedwater control valves. [10] Several years after the installation, steam leaks developed on two of the valves gradually increasing the instability of the valves. It was decided to implement a common temporary valve packing repair while maintaining the valves in service and the plant online. The digital valve positioners were vital during this process because of the information on the condition of the associated valve during and following the temporary packing repair.

Likewise, a Southern nuclear unit installed digital positioners on the main feedwater and feedwater bypass valves on both units. [11] They installed redundant positioners on the main feedwater valves to assure reliability, and used remote mount models so that the electronic portion of the positioner could be panel mounted with only the feedback device mounted on the valve. They used single positioners on the main feedwater bypass valves. Installation of the digital positioners permitted tuning the control of the steam generator levels to a more stable control. Subsequently, digital positioners were also installed on their main steam to condenser dump valves. These valves must stroke very quickly during a turbine load rejection while exhibiting stable pressure control during start up and shut down operations. Since the digital positioners have higher air volume capability than the previous analog positioners, the utility was able to remove the volume boosters and simplify the 
control scheme used on these valves. This has given the utility the ability to monitor and troubleshoot the valves from a controlled environment while minimizing time out in the field.

At an Eastern nuclear unit, digital positioners have been implemented in a number of applications. [11] Several years ago, the unit experienced a reactor trip where the root cause was determined to be inadequate design of the air supply to the main feedwater bypass valve controls. One of the modifications that were implemented was the installation of digital valve positioners on these valves. As a result of installing the digital valve positioners, the higher flow rates of the new positioners allowed elimination of the volume boosters. The digital positioners are capable of on-line performance diagnostics so that they can monitor performance of the positioner, the valve, and the process. With fewer components to maintain, this predictive approach to maintenance should reduce work load in the future.

At another Eastern nuclear unit, digital positioners were installed on the main feedwater regulating valves. [12] Some initial problems with valve control were investigated using on line diagnostics. It was determined that the valve position linkage was the source of the problem and the valve position was upgraded to a non-contact system. Based on the positive experience of using digital positioners on the main feedwater regulating valves, digital positioners were included in an upgrade of the moisture separator and heater drain controls. These systems have stabilized and the cycling has essentially been eliminated. The moisture separators and heater drains are now working as designed and have improved overall plant efficiency. With stable operation the valves are lasting much longer without having to be maintained. The preventive maintenance (PM's) intervals have been extended from the 18 months to 6-8 years.

At another Southern nuclear unit, redundant digital valve positioners have been installed on the main and bypass feedwater regulating valves, main feedwater pump temperature control and the main steam bypass valves. [12] Due to the local ambient temperature at the main feedwater regulating valves, the positioners were mounted remotely and non-contact valve position monitoring was installed.

All of these modifications are examples of installation of digital valve positioners on critical control valves. The above discussion also applies to air operated ventilation dampers where proportional control is employed.

\subsection{Hydraulic Actuators}

\subsubsection{Analog Hydraulic Actuators}

Hydraulic actuators are similar to pneumatic actuators and are used where more force is needed. Electro-hydraulic actuators have an electric motor-pump set to create the hydraulic pressure, which is then applied to a piston in a cylinder to deliver the actuating force. Often this force is applied against a spring so that any intermediate position of the valve or damper can be obtained by providing the amount of hydraulic force needed to compress the spring to the desired point. The spring also serves to provide a fail-safe 
mechanism in which the spring returns the valve to a desired position (either open or closed) on loss of hydraulic pressure.

Typical examples of hydraulic valve actuators are the governor and throttle valves on the high-pressure section of a large turbine. These valves are used to control the amount of steam flow into the turbine. The hydraulic valve actuators are able to provide precise valve position control in order to make fine adjustments to turbine speed or to megawatt output when the turbine is driving a generator in synchronous conditions. The large springs are able to close the governor and turbine valves very rapidly for emergency conditions (such as following a reactor trip) by venting the hydraulic oil to relax the pressure.

\subsubsection{Hydraulic Oil Supply System}

The design of hydraulic control systems varies widely. Typical common components include the following.

- Reservoir

- Hydraulic pumps

- Actuators

- Filters

- Coolers

- Accumulators

- Trip valve

Most hydraulic control systems incorporate two independent motor driven pumps, each capable of supplying $100 \%$ system capacity. Normally, one pump is in operation with the other in standby. The standby pump starts if there is low pressure in the common discharge header. The actuators modulate the hydraulic pressure to the control valve to position the valve based on the electronic control signal. The trip valves bypass the actuators causing the supplied hydraulic pressure to be relieved allowing the control valve to go to the trip position. EPRI conducted an investigation into the performance of main turbine electro performance at nuclear plants. [13] An analysis of the approximately $50 \mathrm{EHC}$ systemrelated reactor trips provided the following breakdown by components:

$\begin{array}{ll}\text { EHC Pumps } & 8 \\ \text { Trip Devices } & 10 \\ \text { Piping/Tubing/Fittings } & 11 \\ \text { Actuator Components } & 18\end{array}$

As indicated above, actuator components were most often involved in hydraulic control related reactor trips. A breakdown of the actuator components involved in the reactor trips is as follows:

- Six servo valves

- Two limit switches

- Two solenoid valves

- Two linear voltage differential transformers (LVDTs) 
- Six other components

A significant number of piping/tubing, and fitting leaks resulted in reactor trips. Most of the leaks were at the actuators, and in many cases the root cause was attributed to vibration. A review of the various root causes reveals several common factors in many of the reactor trips related to EHC system problems (several events had multiple causes).

- Fluid Contamination

- Maintenance/Operations Errors

- Testing Involved

- Electrical Failure

- Vibration Induced

O-rings must be of the proper size and made of a material compatible with phosphate ester fluid. Vibration is a significant factor in many leaks. Vibration at the EHC pump skids and steam valve actuators stresses tubing and connections, often leading to failure. Vibration at the actuators is also a significant cause of limit switch adjustment problems.

Steam generator feed pumps typically use hydraulic controls somewhat similar to main turbine control systems. A significant difference is that the oil is common with the lubricating oil system. As with pneumatic systems, foreign material contamination of the oil is a primary problem. Wear at pivot points leads to poor speed control.

Oil fire is a significant hazard. To mitigate this risk, a fire detection and mitigation system, such as a deluge system, is typically installed to cover the area exposed to the fire hazard. This is usually a large area in that the oil is pressurized and the spray zone is large. The fire detection and mitigation system must be continually tested and repaired, further adding to the cost of using a hydraulic actuator system.

\subsubsection{Digital Replacements for Hydraulic Actuators}

A viable replacement for analog hydraulic actuators is a digitally-controlled electro-servo actuator, also known as a electro-mechanical linear actuator. An electro-servo actuator is a high-speed electric motor that typically uses a roller screw to achieve fast, accurate linear motion. Due to a number of design features, they are faster than conventional electric actuators that rely on reduction gears to translate motor speed to valve movement. They are more accurate than hydraulic actuators, being able to resolve position within a fraction of a turn of the roller screw using advanced positioning feedback. In addition, the accuracy and repeatability are exceptionally good due to very low hysteresis in the roller screw drive system.

With a digital interface, the electro-servo actuator is able to directly translate a position demand for the plant control system into an actuation signal with no degradation due to loop drift or other types of signal fidelity loss. It is able to self-calibrate by articulating the entire range of motion when first initialized. By contrast, the calibration of a hydraulic actuator is far more complex and time consuming.

Digital communication capability contributes to the overall accuracy of the application when connected to a digital control system, as is becoming more common as nuclear plants 
install distributed control systems. In these situations, the demand (position) signal is communicated in digital form all the way to the electro servo actuator with no signal degradation. This is not true in an analog communication scheme such as a $4-20 \mathrm{~mA}$ current loop. Even though a feedback circuit is used to adjust the signal to the desired process state, there is hysteresis in these components that limits the precision of the positioning. This builds up error in the feedback control circuit and often results in continuous actuator motion or "hunting."

In addition to the operational benefits, there is considerably less maintenance with an electro-servo actuator. Foremost is the amount of maintenance on the oil system itself, which requires filter changes, periodic oil cleaning or replacement, and repair of leaks around fittings and moving parts. There is also significant maintenance required to keep the hydraulic system in good working order, including the hydraulic oil pump, oil cylinder or piston, porting valves, and over-pressure protection devices.

There are a number of operational benefits with electro servo actuators:

- The elimination of hydraulic actuators also removes a significant fire hazard. The high-pressure oil is also a personnel safety concern, requiring protective clothing and special precaution when working around these energized systems.

- They are much easier to install, requiring only the connection of electrical cables rather than hydraulic fluid fittings.

- The footprint of the installation is much smaller. Typically, the entire electro servo actuator fits into the same space as the hydraulic cylinder and does not require the additional space needed for a hydraulic pump, filter, and oil reservoir tank.

- The electro servo actuator is more energy efficient, drawing power only when it is repositioning as opposed to a hydraulic pump, which runs continuously.

- The operation of an electro servo actuator is much quieter than the hydraulic system.

It should be pointed out that electro-servo actuators can also be used as replacements for pneumatic actuators - both for modulating (control) valves as well as open-close applications. In this regards, they can be used to eliminate the need for instrument air usage as described in Section 3.1.

A leading supplier of electro servo actuators for the nuclear power industry is the Exlar Corporation. These actuators incorporate a high performance brushless servo motor with a novel mechanism for converting the motor's rotary power and speed to a highly accurate and reliable linear or rotary motion. A high performance closed loop controller yields both the speed and precise control unachievable by other electric actuators. These electric servo actuators were designed for use on full modulating valves and dampers.

The Exlar design uses a motor wrapped around an inverted roller screw (Figure 5), which is a mechanism for converting rotary torque directly into

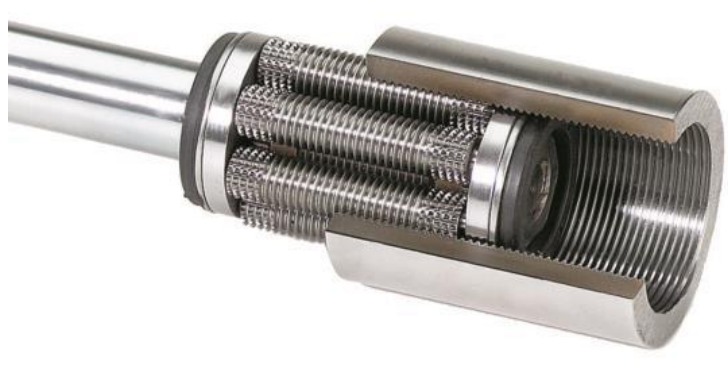

Figure 5. Exlar Roller Screw mechanism for linear motion. 
linear motion. Multiple threaded helical rollers are assembled in a planetary arrangement which converts a motor's rotary motion into linear movement of the shaft. [14]

- Drive motor turns up to 5000 RPM, translating to linear movement up to 40 inches per second. This provides extremely fast response time to complete the desired travel, with little or no overshoot or oscillation. [15]

- Depending on the selected application, one motor revolution is divided into as many as $3,200,000$ incremental positions. The fine resolution of the feedback device results in a continuous position accuracy of roughly 0.001 " when used with a 0.1 " lead roller screw in a linear application. [14]

- Duty cycle is $100 \%$ continuous. [16]

- Design life of hundreds of millions of strokes vs. thousands for most types of electric actuators. [16]

Exlar actuators provides closed loops feedback, eliminating the need for limit switches, torque switches or any mechanical means of feedback found in typical actuators, further extending the life. In addition, the feedback mechanism is integral with the motor shaft and therefore has very little hysteresis. [14]

It accepts a variety of digital communication types, including Ethernet IP, Modbus TCP, and Profinet. It also accepts 4-20 mA input for analog applications. Using a second transmitter, it has the ability to provide precise position information back to the control system or the operator.

Also, there are no limit switches involved as in the case of conventional motor actuators. These require significant maintenance to set up and maintain. [17] Finally, there are diagnostic capabilities with these actuators that reduce troubleshooting and maintenance effort.

Energy consumption is significantly lower for electro-servo actuators as compared to hydraulic actuators. In one particular side-by-side test by the University of Kassel in Germany, hydraulic actuators were compared with electro-servo actuators in a test rig to move a $100 \mathrm{~kg}$ load on an identical workload and duty cycle basis. [18] Over a projected operating time of 6000 hours per year, the energy consumed by the hydraulic operator system (primarily due to the continuously-operating hydraulic pump) would be $3602 \mathrm{kwh}$ whereas the energy consumed for an equivalent electro-servo actuator would $816 \mathrm{kwh}$. In other words, the electro-servo actuator would consume less than $23 \%$ of the energy required by the hydraulic operator. Extrapolated to larger loads and more applications, the energy savings become very compelling for reducing plant operational costs.

\subsubsection{Industry Experience}

There has been limited application of electro servo actuators in the nuclear industry for a variety of reasons. One notable implementation of Exlar electro servo actuators was the feed regulation valves for the turbine driven feedwater pumps at McGuire Nuclear Station. This actuator replaced a hydraulic cylinder that was previously used to modulate a rack and 
cam arrangement that in turn was used to lift a series of poppet valves to control steam flow. This has resulted in considerable setup and maintenance savings for these valves. It has also greatly improved the performance of the feedwater pumps in terms of flow control. [16]

Exlar actuators have also been installed on the main feedwater pump turbines at Calvert Cliffs, Arkansas Nuclear One, and Columbia Generating Station.

Other installations include a feedwater pump retrofit at a Western nuclear utility and the application of Exlar actuators for a Terry Turbine application, which is a single stage steam turbine for emergency feedwater pumps. Many are installed U.S. Navy nuclear ships as well.

As the nuclear industry continues to face cost pressure in the electric market it place, the use of electro servo actuators is one example of where ongoing maintenance costs can be significantly offset by pursuing these component upgrades.

\subsection{Motor Control Centers}

\subsubsection{Motor Control Center Description}

A motor control center (MCC) is an assembly of one or more enclosed vertical metal cabinet sections having a common power bus and principally containing motor control units. Motor control centers are usually used for low voltage three-phase alternating current motors from $208 \mathrm{~V}$ to $600 \mathrm{~V}$.

Each vertical metal cabinet section (bucket) has a power bus and provision for plug-in mounting of individual motor controllers. Each motor controller contains a contactor or a solid-state motor controller, overload relays to protect the motor, fuses or a circuit breaker to provide short-circuit protection, and a disconnecting switch to isolate the motor circuit. Three-phase power enters each controller through separable connectors. The motor is wired to terminals in the controller. Motor control centers provide wire ways for field control and power cables.

Each motor controller in an MCC can be specified with a range of options such as separate control transformers, pilot lamps, control switches, extra control terminal blocks, various types of thermal or solid-state overload protection relays, or various classes of power fuses or types of circuit breakers. A motor control center can either be supplied ready to connect all field wiring, or can be an engineered assembly with internal control and interlocking wiring to a central control terminal panel board or programmable controller.

The performance characteristics of motor control centers are a function of the installed components, the age of the equipment and the environment surrounding the MCC.

Age, adverse environment, and/or vibration can lead to degraded connections within the motor control center. Degraded connections lead to overheating that creates a higher 
potential for fires. Periodic inspection particularly when coupled with thermography can detect degraded connections and enable mitigation of the consequences.

There are several different types of circuit breakers such as magnetic, thermal magnetic and molded case. Magnetic and thermal magnetic are very similar with the primary difference is the addition of a thermal trip function to a magnetic circuit breaker. These breakers are typically capable of remote operation. Molded case circuit breakers are typically used for small loads. If remote or automatic operation is required, a contactor is installed. Age and adverse environmental conditions can cause degradation of circuit breakers and other MCC components. The typical symptom of a degraded circuit breaker is erratic operation possibly resulting in degradation to the electrical protection scheme or failure to close on demand.

Thermal overloads in the MCC provide protection for mechanical overload of the motor and upset electrical supply conditions such as low supply voltage. There are several different types of thermal overload. Their principal function is to detect a high current and interrupt power to the motor before damage occurs. Typically other means of electrical protection are provided for electrical fault conditions. Again, age and adverse environmental conditions can degrade reliable operation of thermal overloads. High ambient environmental temperature can lead to premature tripping of a thermal overload.

Many MCC buckets are equipped with control transformers to provide reduced voltage for the control circuit. Since the transformers are continuously energized. The insulation may degrade over time and cause the transformer to fail possibly resulting in a failure of the load to operate and a possible electrical fire.

MCC buckets are frequently equipped with fuses and fuse holders. Imperfections in the fuse element can cause the fuse to fail over time. Periodic removal and replacement of the fuses can deteriorate the fuse holder, resulting in a degraded connection, increased resistance, fuse heating and premature failure of the fuse.

Relays and contactors are very similar with contactors typically having higher current ratings. Age and foreign material contamination from the environment can cause misoperation of these devices.

Motor control centers can be upgraded with industry leading components, without replacing the structure and bus. Motor control center structures and internal bus work typically have a long life. Their unit racking systems are simple and most likely, in good shape. New direct replacement motor control center units are available for many common vintage and current style MCCs. This approach minimizes outage time and reduces costs associated with having to match existing footprints for the removal and reinstallation of cables. Buckets can be replaced one at a time over an extended period, which provides an overall equipment upgrade on a limited maintenance budget. 


\subsubsection{Digital Technology for Motor Control Centers}

Motor control centers that utilize various digital devices are available from a number of suppliers. Digital motor control centers typically incorporate a digital communication interface and have a number of options available that can improve performance. The current and voltage is continuously digitized and capable of transmission. The benefits are increased reliability, reduced maintenance, remote diagnostics, sequence of events recording, improved electrical protection of the loads, and reduced personnel hazard.

Increased reliability can result from several different available features of digital motor control centers, primarily from the ability to easily perform diagnostics. Since the current and voltage can be monitored for each load trending of these parameters for each load is facilitated. Changes in these parameters may be indicative of a serious problem that can be corrected prior to failure. Motor current signature analysis may also be possible that can broaden the spectrum of problems that may be detected in advance of a failure.

A second feature of digital motor control centers is the ability to perform soft starts of the connected motors. Soft starts reduce the motor inrush current by ramping up the applied voltage on a start avoiding the more severe application of full voltage with the motor at rest.

A third available feature is that solid state overload relays may be used to replace conventional thermal overloads. These relays provide a more accurate assessment of the thermal condition of the motor potentially avoiding unnecessary thermal trips. Additional protection of the load is available through detection of a phase loss, current imbalance, a ground, a stall of the associated motor, or a significant underload condition. Remote operation of the thermal overload relay is an available feature as well as automatic reset of the relay following a thermal overload trip.

Arc flash detection and protection is available with digital motor control centers. Flash detection within the MCC is coupled with incoming current monitoring to determine if a trip of the incoming circuit breaker is appropriate. This may serve to significantly limit the energy of the arc flash assisting in protection of personnel.

\subsubsection{Industry Experience}

A survey of information on digital motor control centers in nuclear power plants resulted in some identification of experience with them. The Aging Management Guideline for Commercial Nuclear Power Plants - Motor Control Centers [19] discusses a number of issues relative to motor control centers that have been identified to be addressed if license extension is to be considered.

One utility had issues with commercial grade dedication of new digital breakers with complex software algorithms installed. Their choice was to replace with digital breakers with much more simple software that could be $100 \%$ tested. The choice of digital breakers with more complexity also brings into play additional issues, such as cyber security. 
Several electrical fires have occurred in MCCs caused by high resistance connection within the bus work connections. These fires typically cause extensive damage to the MCC. Digital MCCs may assist in mitigating problems with bus work connections through internal temperature monitoring.

Molded case circuit breakers (MCCBs) have not functioned properly attributed to high internal temperature. Digital MCCs may assist in mitigating problems with MCCBs by facilitating temperature monitoring within the MCC.

Contactors and relays have failed numerous times, many attributed to prolonged periods of being energized and/or aging. Certain time delay relays have experienced erratic performance. Digital MCCs may substantially reduce problems with control relays by eliminating them from the MCC. Digital MCCs may assist in mitigating problems with contactors by facilitating temperature monitoring within the MCC.

Although there were no issues with control transformers in the Aging Management Guideline [19], it may be possible to eliminate many of them and reducing the heat load within the MCC and mitigating failures of other components within the MCC.

For utilities planning license extension, replacement of buckets with digital MCC components may be cost effective.

\subsection{Variable Frequency Motor Drives}

\subsubsection{Variable Frequency Drive Description}

This section provides an overview and benefits of the use of variable frequency drives (VFD), also known as variable speed drives (VSD), for controlling large pumps in nuclear power plants. Section 3.4.3 provides industry experience on how variable speed drives with digital controls have been incorporated in Boiling Water Reactors (BWR) and Pressurized Water Reactors (PWR) with significant reliability and cost saving results.

Variable frequency drives (VFD) are equipment used to control the speed of machinery, ranging from small appliances to the largest of mine mill drives and compressors. Many industrial processes such as assembly lines must operate at different speeds for different products. When process conditions demand adjustment of flow from a pump or fan, varying the speed of the drive may save energy compared with other techniques for flow control. In this type of control the output speed can be changed without steps over a range. VFD's may be purely mechanical (termed variators), electromechanical, hydraulic, or electronic. The focus of this section will be on the use of VFD's to enhance plant performance and also the benefits of digitally controlled VFD's versus the earlier analog versions.

Process control and energy conservation are the two primary reasons for using a variable speed drive. Historically, VFD's were developed for process control, but energy conservation has emerged as an equally important objective. 
A VFD is a type of adjustable-speed drive used in electro-mechanical drive systems to control $A C$ motor speed and torque by varying motor input frequency and voltage.

For an example, applicable to nuclear plants, a variable speed drive is use to control the recirculation pumps which change the water flow thru the reactor core.

Changing (increasing or decreasing) the flow of water through the core is the normal and convenient method for controlling power from approximately $30 \%$ to $100 \%$ reactor power. When operating on the so-called "100\% rod line," power may be varied from approximately $30 \%$ to $100 \%$ of rated power by changing the reactor recirculation system flow by varying the speed of the recirculation pumps or modulating flow control valves. As flow of water through the core is increased, steam bubbles ("voids") are more quickly removed from the core, the amount of liquid water in the core increases, neutron moderation increases, more neutrons are slowed down to be absorbed by the fuel, and reactor power increases. As flow of water through the core is decreased, steam voids remain longer in the core, the amount of liquid water in the core decreases, neutron moderation decreases, fewer neutrons are slowed down to be absorbed by the fuel, and reactor power decreases.

A typical VFD is shown in Figure 6. A VFD is an electrical system (i.e. inverter) used to control $A C$ motor speed and torque. It provides a continuous range of process speeds compared to a discrete control device such as multiple-speed motors or gearboxes. A VFD controls motor speed by varying the frequency supplied to the motor. The drive also regulates the output voltage in proportion to the output frequency to provide a relatively constant ratio of voltage to frequency $(\mathrm{V} / \mathrm{Hz})$, as required by the characteristics of the $\mathrm{AC}$ motor to produce torque.

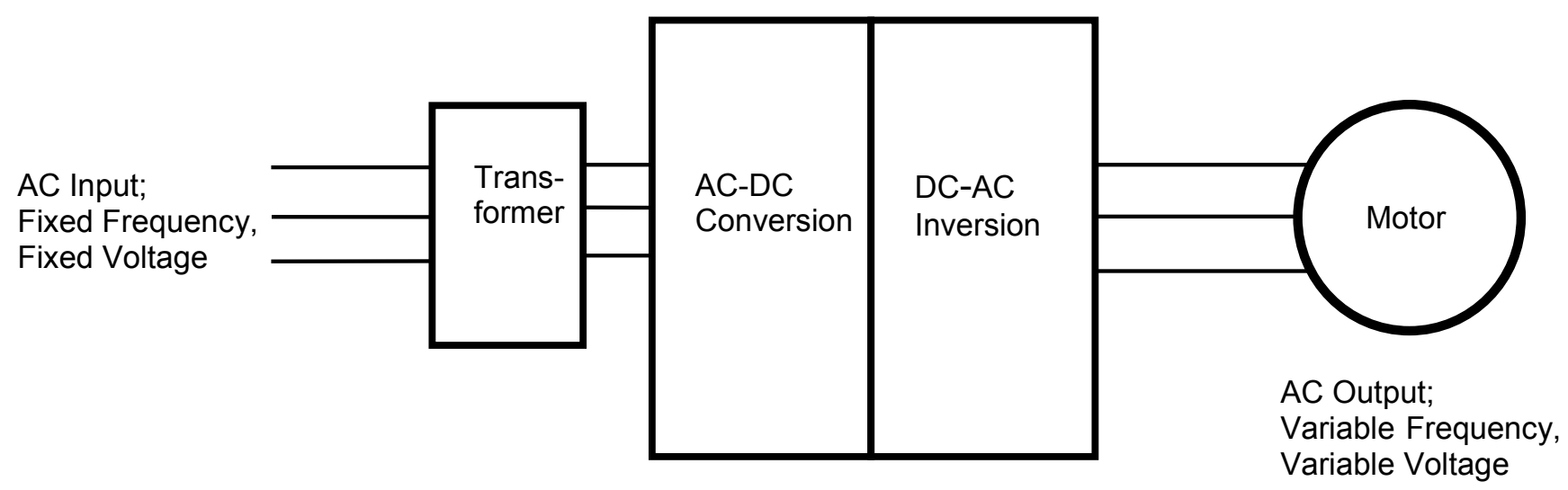

Figure 6 Variable Frequency Drive

Many motors in nuclear plants run at outputs that are higher than required by the plant process:

For example:

- Recirculation pumps and other large pumps have control valves to reduce flow, resulting in a significant loss of energy 
- Cooling water pumps that always run at the same speed, independent from the temperature of the water

- Large air handler fans that have no speed control despite the changing air temperature.

\subsubsection{Digital Technology for Variable Frequency Drives}

The advantages of VFD's in the nuclear industry are many as discussed in a paper published in IEEE PEDS 2011 [20]. Nuclear plants, especially BWR's are including VFD's in their AC power systems in many cases now to improve the reliability, efficiency and enhanced compliance with the Clean Water Act.

The benefits of VFD's can be categorized in the following:

- Higher efficiency and improved power consumption.

VFD's allow the plant operators to operate motors and pumps at the precise speed needed for the process. With the ability to vary motor and pump speed, system efficiency is increased. The enhanced control allows the operators to only consume the energy required for system needs. Compared to fixed-speed pumps with flow controlled via valves, VFD's can provide large savings in power consumption. Improved motor efficiency up to $96.5 \%$ from around $82 \%$ in direct power connections. This can mean 3-4 MW savings across large motors.

- Higher reliability and availability

VFD's have proven to be more reliable than motor-generator (M-G) sets. One nuclear plant reported a four-fold increase in system reliability after the installation of VFD's on their reactor recirculation pump motors.

Also, there is a major benefit in the implementation of redundancy in the design - both redundancy in the logic and redundancy in the sensor strings, which supports single point of failure analyses. New digital VFD's have redundant power cells - which can lose 2 and still maintain $100 \%$ power. If a power cell fails, it swaps over to a good one in 8 cycles with minor loss of RPM.

- Reduced maintenance

VFD's have been shown to reduce maintenance on the motors by reducing parts requirements, eliminating mechanical linkages, scoop tube adjustments and oil handling concerns associated with $\mathrm{M}-\mathrm{G}$ sets.

- Improved flow control in condenser applications

This has the benefit for the $316 \mathrm{~B}$, Clean Water Act rule that plants can reduce flow rate of condenser cooling and not have as much fish impingement. Without VFD's, the pumps are in a fixed control mode, which does not allow for efficiency variation based on inlet temperature changes. Environmental Protection Agency studies have shown that a reduction in fish intrusion is directly proportional to the reduction in flow rate at the intake structure. 
- Soft start

The VFD can be used to "soft start" a motor. The controlled startup minimizes current in rush to motor windings which can extend motor life.

- Elimination of portions of the fire detection and suppression system

As a result of removing M-G sets, this also eliminates the fire detection and suppression system requirements associated with the oil for the clutch with the M-G sets.

- Improvements in fill and vent activities.

Rather than "bumping" RCP motors to sweep out voids, the operators can leave a pump in idle (very low RPM) rather than turning it off. This way, the operators can reduce the number of starts on these very larger RCP motors and extend the life of the motors.

- Reduced water hammer

These dangerous conditions can be reduced due to slower pump motor starts with the VFD.

\subsubsection{Industry Experience}

Applications of VFD's (Figure 7) have been made at multiple plants in a number of systems as follows:

- Reactor Recirculation System (RRS). Replacement of the M-G sets with VFD's provide a much higher degree of flow control for meeting reactor safety margins while optimizing the performance of the plant. Also, the VFD's provide the benefits described above in power savings (Example: 4MW/plant) and extended life for the motors.

- Circulating Water (CW) pumps, to provide more flexibility in flow control based on ultimate heat sink inlet temperature changes and other requirements. This allows reduction in fish kill, enhanced compliance with the Clean Water Act, power savings and extended motor life.

- Refueling Machines. VFD's have been installed in place of fixed speed motors in refueling machines to

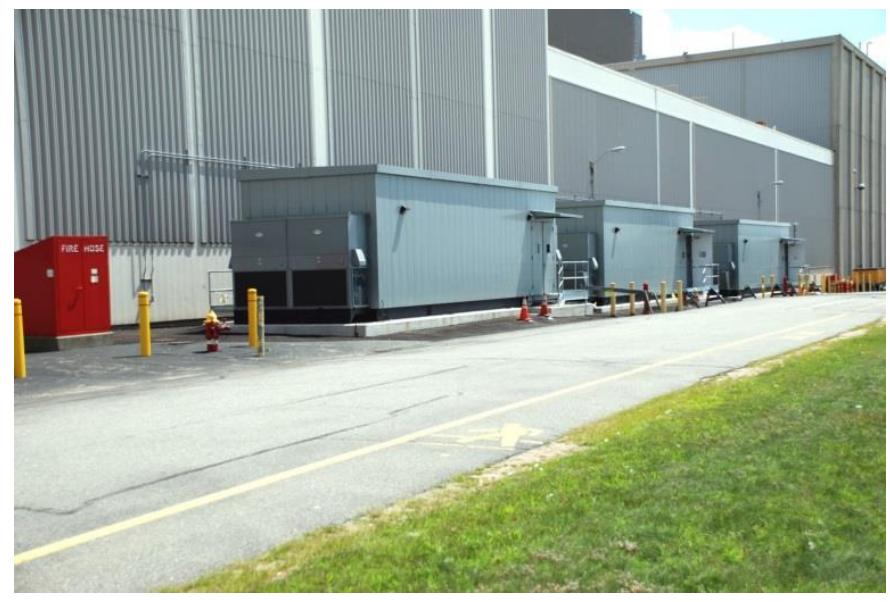

Figure 7. VFDs In Operation at Millstone provide more precise location and moving of fuel rods and extended motor life. Instead of "bumping" a motor to make sure the location is correct, the VSD allows the motor location to be brought to an exact spot. This is critical because the work of the 
refueling machine is almost always on a critical path schedule and any time delays, will be very hard to make up. One plant lost a significant amount of time on the beginning of an outage because the refueling machine motors burned up and required replacement on critical path.

This case study will address the application of variable speed drives (VFD) to Boiling Water Reactors (BWR) and Pressurized Water Reactors (PWR) for improvement in reliability, energy efficiency and enhanced compliance with the Clean Water Act.

A VFD is a type of adjustable-speed drive used in electro-mechanical drive systems to control AC motor speed and torque by varying motor input frequency and voltage.

For an example, applicable to nuclear plants, a variable speed drive is use to control the recirculation pumps which change the water flow thru the reactor core, and also reactor power (Figure 8).

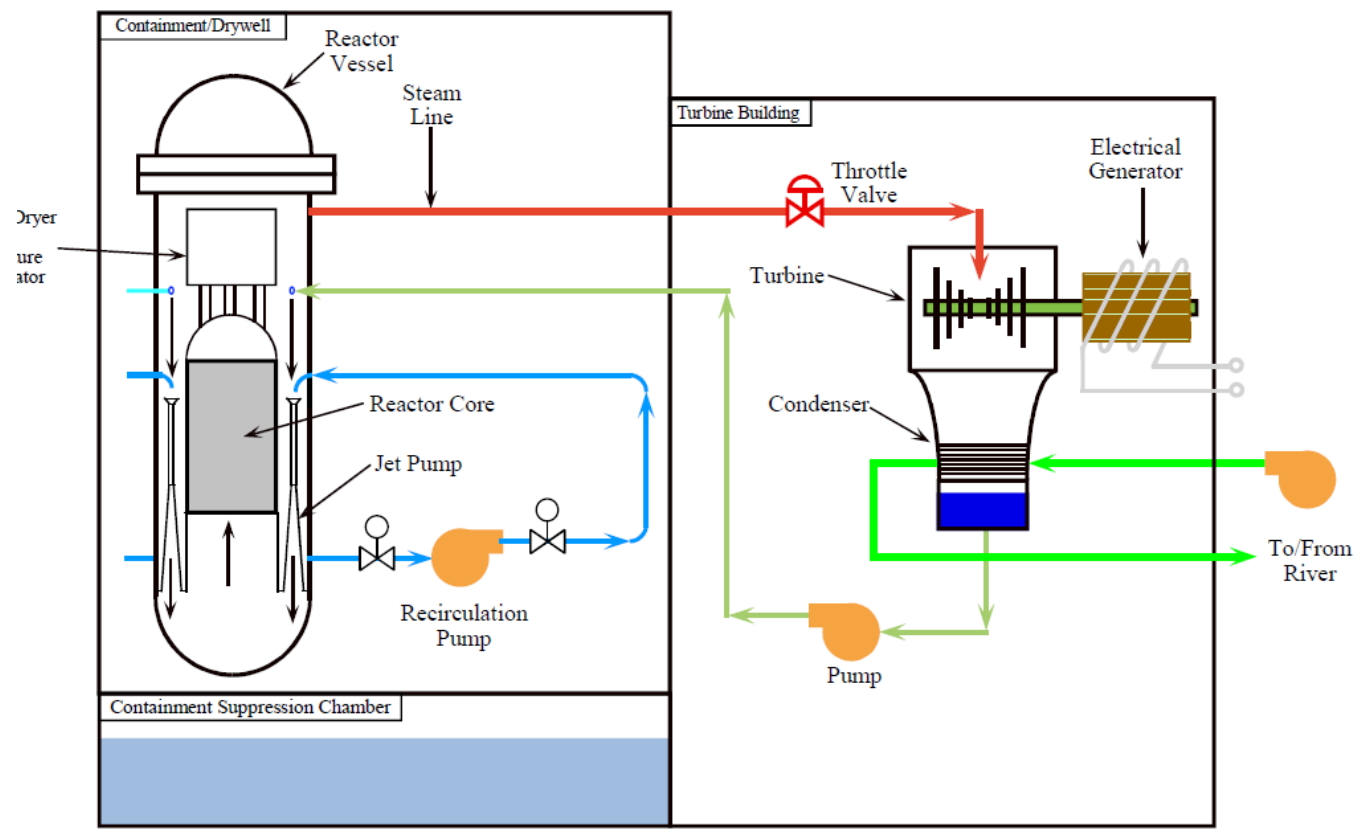

Figure 8. BWR Depicting Recirculation Pump

Changing (increasing or decreasing) the flow of water through the core is the normal and convenient method for controlling power. As flow of water through the core is decreased, steam voids remain longer in the core, the amount of liquid water in the core decreases, neutron moderation decreases, fewer neutrons are slowed down to be absorbed by the fuel, and reactor power decreases.

The benefits from changing from M-G sets to VFD's have been shown in the large number of conversions that have occurred since 1995. Twenty-six reactor recirculation pump VFD's are in operation in BWR's in the U.S. as shown in Table 1 and six VFD's are scheduled for installation in reactor recirculation pumps. Also, 10 Condenser Circulation Water (CCW) VFD's are currently in operation. The benefits from installation of the VFD's are shown in Section 3.4.2 above, resulting in large savings in the annual budget for 
operation of the plants. Also, maintenance of the motor-generator sets has proven to be expensive. One utility had come up to the date of a scheduled maintenance on the M-G sets which would have cost $\$ 1 \mathrm{M}$ per unit, and applied that avoided cost to the installation of the VSDs on multiple units.

TABLE 2: Installed Base of VFD's in Nuclear Plants in the U.S.

\begin{tabular}{|l|l|l|l|}
\hline Plant Name & Plant System & No. of VFD's & Date of Installation \\
\hline Columbia & RRP & 2 & 1995 \\
\hline Browns Ferry \#2 & RRP & 2 & 2003 \\
\hline Browns Ferry \#3 & RRP & 2 & 2004 \\
\hline Browns Ferry \#1 & RRP & 2 & 2007 \\
\hline Hatch \#1 & RRP & 2 & 2009 \\
\hline Quad Cities \#1 & RRP & 2 & 2009 \\
\hline Hatch \#2 & RRP & 2 & 2009 \\
\hline Quad Cities \#2 & RRP & 2 & 2010 \\
\hline Brunswick \#1 & RRP & 2 & 2010 \\
\hline Brunswick \#2 & RRP & 2 & 2011 \\
\hline Limerick \#1 & RRP & 2 & 2012 \\
\hline Dresden \#3 & RRP & 2 & 2012 \\
\hline Limerick \#2 & RRP & 2 & 2013 \\
\hline Millstone \#2 & CCW & 4 & 2009 \\
\hline Millstone \#3 & CCW & 6 & 2010 \\
\hline \multicolumn{1}{|c|}{ Currently Scheduled to be Installed } \\
\hline Dresden \#2 & RRP & 2 & 2014 \\
\hline Peach Bottom \#3 & RRP & 2 & 2015 \\
\hline Peach Bottom \#2 & RRP & 2 & 2016 \\
\hline
\end{tabular}

NOTE: System Designators

RRP - Reactor Recirculation Pumps

CCW- Containment Cooling Water

\subsection{Actuator Reliability, Availability, and Maintainability}

Safety-related actuators must be designed for high reliability using qualified actuator equipment. The reliability of these system configurations to perform their safety functions is demonstrated via a reliability analysis and a Failure Modes and Effects Analysis (FMEA).

The quantitative principles are applicable to the analysis of the effects of component failures on safety system reliability. The principles are applicable during any phase of a system's lifetime. They have the greatest value during the design phase. The importance is to increase the probability that the system will perform its intended function for the environments and the time periods of interest. 
The reliability analysis and the FMEA are performed for protection systems' actuators in conjunction with the remaining portions of the control loop, including the bistable/coincidence and actuating logics.

Nuclear safety is largely dependent on the reliability of the components that make up the important systems of a nuclear power plant. It is therefore a requirement in the design of a nuclear plant to conduct reliability analysis for the certain safety-related components in accordance with IEEE-603 [21] and IEEE-7-4.3.2-2003 [22].

Reliability is defined in IEEE-352 [23] as follows:

The characteristic of an item or system expressed by the probability that it will perform a required mission under stated conditions for a stated mission time. The reliability principles, as stated in IEEE-352, are applicable to the analysis of the effects of components failures on safety system reliability. This is a cornerstone to reactor safety in the regulatory and technical design principles of reactor design around the world.

\subsection{Importance of Actuator Reliability}

The reliability of actuators in a nuclear power plant is highly-important to safe operations. The actuators are the transition devices between the I\&C loops and logic solvers and the plant equipment designed to response to normal, abnormal and emergency events. The actuators perform a key safety function in each application in which they are applied. Without a high reliability in actuator performance, the assurance of safety function cannot be met.

In the earlier years of nuclear power and analog systems, alarms were used to identify system or component level performance degradation. These did not provide indication in all cases of a problem in a component meeting its safety function. The most viable way for analog systems to be checked was during the channel check or calibration which is performed on a refueling interval basis.

Unreliable plant actuators result in excessive maintenance, which is both expensive and can result in maintenance-induced faults. In other words, frequent maintenance on troublesome components can induce further problems as these components are excessively handled, manipulated, and tested. A good example of this is disconnecting instrument tubing over and over, which leads to fitting wear and future tubing leaks. Therefore, unreliable actuators result in more frequent maintenance, which becomes a vicious cycle by providing more opportunity for maintenance-induced faults, due either to component wear or human error.

A search of the Equipment Performance Information Exchange (EPIX) System, maintained by the Institute of Nuclear Power Operations (INPO), confirms that actuator reliability is a common plant problem and the cause of many plant disturbances. The results of this search are found in Appendix A, INPO Common Actuator Failure Modes, which is a sampling of hundreds of relevant actuator problems related to the most common actuator types in nuclear plants. This information confirms that actuator reliability remains a huge concern for safe and productive plant operations. The most common types of failures were:

- $\quad$ Limit Switches 
- Valve Position Feedback Mechanisms

- Pneumatic Volume Booster Gain Settings

- Relays

It is notable that most of these failure causes are related to analog actuators. While current digital actuators do share some of these subcomponents, digital actuator technology eliminates many of these failure modes because they become "detected" in the digital case, where they were "undetected" in the analog case. This underscores the importance of the nuclear industry transitioning to new digital actuator technologies that are not susceptible to these common, chronic problems.

The reliability of actuators is also an input to the system and component level reliability analysis each nuclear plant performs under INPO AP-913, Revision 2. [24] This provides a basis for both validation of existing surveillance and maintenance frequencies originally provided by the vendor, and also provides the basis for surveillance extensions if the reliability of the components can be shown to be adequate. Unreliable actuators thus preclude an opportunity to reduce maintenance workload, conserve spare parts, and reduce overall plant operating costs.

\subsection{Example Reliability Calculation - Valve Actuator}

A quantitative analysis is performed to calculate the predicted reliability or availability (or both) of the equipment to ensure it performs its safety function over an expected surveillance period. A key measure of reliability is the Average Probability of Failure on Demand or PFD avg. The PFD avg is a function of Mean-Time-Between-Failure (MTBF) and the Proof Test (or Surveillance) Interval.

Typically a component supplier will establish the MTBF value for a component based on analysis and operating history and usually follows the processes in the following documents.

- Mil-HDBK-217F, "Reliability Prediction of Electronic Equipment" [25]

- ANSI S84.01-1996 "Application of Safety Instrumented Systems for the Process Industries" [26]

- IEEE 352-1987, IEEE Guide for General Principles of Reliability Analysis of Nuclear Power Generating Station Safety Systems [23]

- IEEE 577-2004, IEEE Standard Requirements for Reliability Analysis in the Design and Operation of Safety Systems for Nuclear Facilities [27]

For the owner-operator, this analysis includes pertinent system interactions and sufficient detail to establish proof testing intervals, which are the same as surveillance testing intervals, consistent with the goals for the system.

Many suppliers base the predicted MTBF upon MIL-HDBK-217F. [25] The vendor has the counts of populations of shipped modules. The failure rate should result in a predicted number of returns of failed modules. Since many vendors track returns and test them for their failure, an actual failure rate can be established and then the vendor can back-calculate the actual MTBF for the population. Actual failure rates for commonly-used analog actuators were not available 
from the suppliers for this purpose. This is not unexpected due suppliers typically not making this data available publically. However, the reliability benefits that can be approximated with typical industry data.

A simple reliability analysis of an analog and digital valve actuator is included in the following. This really shows the increase in reliability that is associated with a distributed control system network due to the higher diagnostics and online monitoring available to minimize downtime and troubleshooting of actuator failures.

Digital System Valve Actuator Reliability Example Calculation

The reliability of a specific actuator design can be quantitatively determined in accordance with IEC 61508 [28] using a Markov Model, including the reliability data for individual components combined in the manner in which they support performance of the safety function. This analysis is based on the proof or surveillance test intervals, repair rates of components, and the plant specific configuration that is performing the safety function. The basic concept in a Markov model is to identify the state of a system and the transitions that occur between such states. A sample calculation using full analysis is provided in the Digital Sensor Technology Report [2]. For this report, a summary analysis is presented with representative numbers assigned based on engineering judgment.

In traditional analog actuator designs, failures of actuators could go undetected until the next scheduled testing at the end of the current surveillance interval. Therefore, the device would be in a latent failure state and it would not operate correctly if called upon for its design basis function. Since the failure might have happened at any time during the surveillance interval, the predicted reliability of the actuation system would have to take this into account. Again, the measure of this is the PFD avg. Surveillance intervals for many safety-critical actuators are often 18 or 24 months, corresponding to a refueling cycle, and therefore the time period over which a failure could go undetected could be quite

A key consideration in the crediting of monitoring is the treatment of what is termed dangerous detected and dangerous undetected failure fractions, which are established to provide input to the Markov reliability model for the device and the associated system. IEC61508 [28] defines these as follows:

Dangerous Detected Failure - A detected failure which has the potential to put the safety actuation system in a hazardous or fail-to-function state. Dangerous detected failures do not include hardware failures and software faults identified during proof testing, represented by the plant's surveillance testing.

Dangerous Undetected Failure - An undetected failure which has the potential to put the safety actuation system in a hazardous or fail-to-function state. Dangerous undetected failures do not include hardware failures and software faults identified during proof testing.

The failure fraction refers to the relative proportion of both the detected and undetected failures, expressed as a fraction of one. Thus, dangerous detected failure fraction of 0.93 means that 93 out of 100 dangerous failures are detected by the monitoring capability. The role of the monitoring capability is to detect as many of the total possible dangerous failures of the system and related devices as possible, with the monitoring credit being proportional to the 
fraction. Note that there are other failures that are designated as safe, meaning they do not threaten the reliability of the system.

A typical reliability calculation depicts all failures for this particular DCS design, separated into those that are dangerous from those that are safe. In addition, those that are detected (by online monitoring) can be separated from those that cannot be detected. Approvals for use of the monitoring credits are obtained from nuclear power regulatory agencies (such as the European TUV).

The example digital system reliability calculation, illustrates the case of a Markov model for a DCS Programmable Logic Controller (PLC) logic solver with an output string using a typical digital valve actuator. The following steps are performed in this analysis utilizing PLC spreadsheets as shown in the Digital Sensor Technology Report. [2]

1) Select the most significant safety actuation function for the configuration using system documentation (Logic Diagrams, I/O Listings and simplified block diagrams). In this case, it is the referenced safety injection (SI) valve actuator.

2) Select the spreadsheet for the PLC configuration (1 out of 2, 2 out of 3, 2 out of 4, etc.). Develop new spreadsheets for special cases (For example Dual 2 out of 3 PLC configuration).

3) Enter I/O module information, proof test interval and mean time to repair into each spreadsheet.

In this particular example, two safety injection (SI) valve actuators are used as parallel redundant divisions so that the on-line monitoring capability can conduct cross-channel checks to verify that the devices are functioning properly. This is just one among many health checks performed by the monitoring capability.

The actual computation is very complex and is performed by a computer program based on the data inputs to the various tables that are found in the calculation. In accordance with the referenced methodology (IEEE-352 and IEC-61508), the reliability values for valve actuator string values (isolation module and temperature transmitters) are combined with the logic controller establish the complete reliability values for the output string and to provide a basis for the required proof testing of the actuator outputs.

As an example of a value for a digital valve actuator, based on experience, the PFD ${ }_{\text {avg }}$ of the digital valve actuator is conservatively set at $1 \times 10^{-6}$ based on a surveillance interval of 14 days. In actuality, the surveillance interval is every few minutes, which is the cycle time for the continuous on-line monitoring. This shows a significant effect on the $P F D_{\text {avg }}$ as a result of the on-line monitoring, because it has a dangerous detected failure fraction of 0.99 .

To be clear, the on-line monitoring capability helps in two distinct ways. It detects almost all of the dangerous failures and it does this check very frequently. Therefore, almost any dangerous failure would be detected immediately and the plant operators could take compensatory action before the device might fail to perform in a possible design basis event. In short, the design is highly reliable. 
As a separate part in the calculation, the PFD avg of the PLC logic solver is also computed and found to be $3.5 \times 10^{-5}$ over 18 months for a fully integrated DCS (PLC logic solver).

The combined PFD avg of the PLC logic solver and digital valve actuator output string are found as follows:

$$
\begin{aligned}
& \text { PFD }_{\text {AVG-TOTAL }}=\text { PFD }_{\text {AVG-LOGIC SOLVER }}+\text { PFD }_{\text {AVG- DIGITAL VALVE ACTUATOR }} \\
& \text { PFD }_{\text {AVG-TOTAL }}=3.50 \times 10^{-5}+1 \times 10^{-6} \\
& \text { PFD }_{\text {AVG-TOTAL }}=3.60 \times 10^{-5}
\end{aligned}
$$

It should be noted that the PFD avg for the digital valve actuator is one orders of magnitude lower than that of the PLC logic solver, meaning that it makes a very small contribution to the total $P F D_{\text {avg. }}$ Again, this is possible only by the use of a digital valve actuator combined with an effective monitoring capability (very high dangerous detected failure fraction).

Analog Valve Actuator Reliability Example Calculation

For comparison purposes, a reliability calculation for a typical analog valve actuator is presented. This valve actuator has a Mean Time Between Failure (MTBF) of 62.50 years as determined by the supplier's experience and represents a highly reliable device. In this case, the proof test or surveillance interval $(\mathrm{TI})$ is 18 months or 1.5 years, based on a normalized plant refueling cycle.

Unlike the digital counterpart, this analog valve actuator does not have the capability to be monitored on-line. And since there is no monitoring capability to perform an automatic crosschannel comparison, a single valve actuator is considered. Therefore, the full dangerous undetected failure fraction must be assumed. Put another way, the dangerous detected failure fraction is 0.00 compared to 0.99 for the digital counterpart. So for this device, no monitoring credit can be given.

On this basis, the PFD avg calculation is somewhat simpler as follows:

$$
\begin{aligned}
& \mathrm{PFD}_{\text {avg }}=(1 / \mathrm{MTBF})^{2} \times \mathrm{TI}^{2} \\
& \mathrm{PFD}_{\text {avg }}=(1 / 62.50)^{2} \times 1.5^{2} \\
& \mathrm{PFD}_{\text {avg }}=5.78 \times 10^{-4}
\end{aligned}
$$

With no on-line monitoring, this is the best $\mathrm{PFD}_{\text {avg }}$ that can be credited to the actuator based on industry standards [21]. The result is also consistent with the reliability values of most of the current analog technology installed in nuclear plants today. In fact, a value of PFD avg in the $10^{-4}$ range is representative of a robust design as stated in IEC-61508 and IEEE-352.

Implications for Improved Valve Actuator Reliability

At the valve actuator level, the PFD ${ }_{\text {avg }}$ is improved by several orders of magnitude by the use of digital valve actuators instead of the analog counterpart. Specifically in this example, the digital valve actuator PFD avg is $1 \times 10^{-6}$ versus the analog valve actuator PFD avg of $5.78 \times 10^{-4}$. Even without the addition of the channel checks, the improvement in the reliability of the valve actuators is dramatic. 
At a system level, this means for the digital valve actuator design, the contribution of the valve actuators to the probability that the system will not function properly on demand is negligible. This is not the case for the analog valve actuator design (with channel checks), where the valve actuators and the logic solver make nearly co-equal contributions to the probability that the overall system will not function properly on demand.

Using the combined numbers from both the digital and analog reliability calculations presented above, the total PFD avg for the SI valve actuator function can be calculated as follows:

$$
\begin{aligned}
& \text { PFD }_{\text {AVG-TOTAL }}=\text { PFD }_{\text {AVG-LOGIC SOLVER (digital) }}+\text { PFD }_{\text {AVG-ANALOG VALVE ACTUATOR }} \\
& \text { PFD }_{\text {AVG-TOTAL }}=3.6 \times 10^{-5}+5.78 \times 10^{-4} \\
& \text { PFD }_{\text {AVG-TOTAL }}=6.14 \times 10^{-4}
\end{aligned}
$$

In this case, the reliability of the total system for this SI function has been degraded to slightly above the level of the analog valve actuator. In other words, the improved reliability of the digital logic solver has essentially been lost and the reliability of the total system, for this SI function, is reduced by over an order of magnitude compared to an all-digital design.

The probability of this SI function failing on demand is roughly twice as high compared to the all-digital design. This illustrates how the reliability benefits of a modern digital control or protection system are substantially negated when combined with traditional analog actuators as the process outputs.

\subsection{Availability}

Availability is a quantitative evaluation of the operational use estimate for any component. The opposite is "unavailability." The concept of availability is related to reliability as presented in Section 4.2. Obviously, the more reliable a component is, the more it is available. However, actual availability as measured by utilities would also be adjusted for the time a component is taken out of service for preventive maintenance and testing when it is actually in good working order (not having to be repaired).

Availability plays a key role in nuclear plant operations today - from the whole plant perspective down to individual components. Frequent analysis is done at every nuclear plant to identify the components with the highest level of "unavailability" so that requests can be made to management for modifications to improve the availability of the component or system.

Availability is defined in IEEE 352-1987 [23] as follows:

The probability that an item or system will be operational on demand.

(1) steady-state availability is the expected fraction of the time in the long run that an item (or system) operates satisfactorily.

(2) transient availability (or instantaneous availability) is the probability that an item (or system) will be operational at a given instant in time. For repairable items, this will converge to steady-state availability in the long term. 
Standards such as IEEE-603 [21] and IEEE 7-4.3.2 [22] provide guidance that a reliability and availability goals should be established. Additionally, availability is analyzed to a high degree, based on plant specific data, following INPO AP-913 Rev 2. [24] In Section 2 of Equipment Reliability Process Instructions, the plant staff is to assemble data based on availability, reliability or condition. Availability is an important performance indicator of system and component health and is typically used to trigger corrective actions if it is not meeting preestablished performance targets. This is also important in NRC space in the area called the NRC's "maintenance rule" or 10 CFR 50.65.

. This states that license holders will monitor the performance of systems, structures, and components to ensure that they are capable of fulfilling their intended functions. When components such as valve actuators have poor availability, they can impact the overall availability of important safety systems, which at a certain point, would be considered noncompliance with the regulation. This could lead to adverse regulatory actions.

A quantitative analysis is performed to calculate the predicted availability of the equipment to ensure it performs its safety function over an expected surveillance period. This is usually provided by the manufacturer and is developed as a typical in the example below.

For the vendor, the analysis is performed at a component level to establish the Mean Time Between Failure (MTBF) value for the component based on analysis and operating history and usually follows the processes referenced in Section 4.2.2. For the owner-operator, this analysis includes pertinent system interactions and sufficient detail to establish proof testing intervals, consistent with the goals for the system.

A simple availability analysis of the typical analog valve actuator from Section 4.2 is provided below. The analog valve actuator has an MTBF of 62.50 years, as noted in Section 4.2.2. The availability is calculated as follows:

$$
\text { Availability }=\frac{\text { MTBF }}{\text { MTBF }+ \text { MTTR }}
$$

Where:

MTBF - Mean Time Between Failures

MTTR - Mean Time to Repair (A common value used for MTTR is 4 hrs.)

Therefore:

$$
\text { Availability vA-Analog }=\frac{62.50 \mathrm{yrs} \times 8760 \mathrm{hrs} / \mathrm{yr}}{(62.50 \times 8760)+4}=\frac{547500}{547504}=99.99926 \%
$$

It should be noted that this is just the availability of the valve actuator (output) and not of the entire actuation loop. The actual loop availability will likely be lower due to the availability of the other components in the loop.

As noted in Section 4.2.2, the reliability and availability of a digital valve actuator can be improved due to continuous on-line monitoring of the health of the device. Again, a MTTR of 4 hours is assumed. Using the example of the same typical digital valve actuator that was 
referenced in Section 4.2.2, the availability can be determined as an inverse relationship of the previously calculated PFD $_{\text {avg }}$ as follows:

$$
\text { Availability }_{\text {TT-Digital }}=\frac{1}{\left(1+1 \times 10^{-6}\right)}=99.99999 \%
$$

The results indicate improvement in availability for the digital valve actuator compared to the analog valve actuator, although both are obviously very good availability numbers. This is because both valve actuators are highly reliable as indicated by their MTBF numbers. The actual availability for an entire actuation loop or string would likely indicate an even greater advantage for the digital valve actuator because it is often the other components in an analog actuation loop that are more prone to failure

\subsection{Maintainability}

Maintainability has a very important role in the operation of nuclear plants today. It is a measure of the required work to keep systems and components in working order, whether they are safety or non-safety systems and components.

There is a very structured program of surveillance testing and preventative maintenance for plant valve actuators. The surveillance testing for safety-related valve actuators consists of multiple levels as required by the plant's Technical Specifications.

For non-safety valve actuators that are not subject to the Technical Specifications, similar surveillances are set up in accordance with good practice and operating experience such that a sufficient degree of reliability is obtained. The Electric Power Research Institute is one source of preventative maintenance templates that are based on best industry practice and experience.

Digital actuator technology offers the potential of significant reduction in surveillance testing. Their self-diagnostic capability may provide justification to eliminate or at least reduce the frequency of the cross channel comparisons. Likewise, digital actuation technology may permit longer intervals between channel calibrations due to the improved long term stability.

In addition, there is corrective maintenance when failures of components occur. Occasionally, modifications to components are required to fix small operational problems or upgrade the components because parts are no longer available.

There is a considerable effort expended the plant support staff to support the instrumentation and control and electrical maintenance program. This is typically the largest technical group in the plant's maintenance organization. In addition, the volume of this work is a key driver to the size of the work planning and scheduling organizations. And, it contributes significantly to the workload of other support functions such as safety tagging, quality control, nuclear risk management, operations support of maintenance, and engineering.

Another significant advantage to less-frequent testing and maintenance is the avoidance of maintenance-induced failures. Unfortunately, an appreciable percentage of valve actuator failures are due to faulty maintenance practices, in spite of all the efforts to control the quality of 
the work. And, just performing work on the devices can cause wear and damage, such as disassembling and reassembling instrument tube fittings, which are then prone to leakage.

The level of training has a large bearing on the ability to have a high degree of maintainability in nuclear plant components. The more complex the new equipment is, the more training is required to ensure that the engineering and maintenance staff have the necessary experience and qualifications to maintain the equipment properly.

In summary, digital valve actuators offer significant benefits in regard to the maintainability of the plant instrumentation and control systems in the areas of plant work reduction, cost reduction, safer operations, and improved job satisfaction. These benefits go on for the life of the nuclear plant and should support the business case the make this transition.

\subsection{Qualification Considerations}

Qualification is the process of demonstrating that a component (actuator) or system meets its specified requirements. The requirements are derived from the design bases of the various systems of the nuclear plant, which in turn rest on system performance objectives, regulatory requirements, consensus standards, and other forms of technical criteria. Certain qualification topics are either specific to, or have special considerations for digital systems, including digital actuators.

Additional burden is imposed on the use of digital actuators in the areas of qualification and licensing due to the fact that they are based on either software or firmware for their processing logic. Software-based digital systems have long been recognized as having failure susceptibilities that are not present with analog counterparts. Also, digital systems reside on electronic components which can be more susceptible to environmental influences than traditional electro-mechanical technology.

The additional burden over what is required for analog actuators is potentially significant and can cause increases in the cost and delays in the implementation schedule. Further work would be helpful in some areas so that the long-term benefits of using digital actuators in nuclear power plants are reasonably available. The major areas of consideration are:

Qualification Considerations:

- Software Quality

- Environmental Effects on Electronics

- Software Common Cause Failure (SCCF)

- Communications

- Cyber Security

The sections below provide a discussion of these qualification and licensing considerations and address issues and concerns that need resolution to encourage greater use of digital actuators. 


\subsection{Software Quality}

Each nuclear plant is required to have a Quality Assurance Program for safety-related systems and components that conforms to 10 CFR 50 Appendix B. In addition, 10 CFR 50.55 $\mathrm{a}(\mathrm{h})$ [29] requires that protection and safety systems comply with IEEE-603-1991. This standard endorses IEEE 7-4.3.2, IEEE Standard Criteria for Digital Computers in Safety Systems on Nuclear Power Generating Stations, as the most general statement of requirements for use of digital in safety-related designs. It, in turn, references a number of other IEEE standards that are concerned with various stages of the software development and implementation life-cycle. IEEE 7-4.3.2 requires a software quality program consistent with the requirements of IEEE/EIA 12207.0-1996 [30] for all software that is resident at run time.

To this end, the nuclear plant's Quality Assurance Plan, established in accordance with 10 CFR 50 Appendix B, "Quality Assurance Criteria for Nuclear Power, Plants and Fuel Reprocessing Plants" [31], must include the quality requirements particular to digital systems.

The NRC's Standard Review Plan, NUREG-0800, Chapter 7, Branch Technical Position (BTP) - 14, entitled Guidance for Software Reviews for Digital Computer-Based Instrument and Control Systems [32], provides a description of the software development process for the programmable based actuators. The software development process is a requirement of the Quality Assurance Program under Appendix B Criterion III, Design Control. A graded approach to the software development process is normally used to take into account the complexity of the software being implemented within the digital based actuator. Simple programs would require less depth when compared to complex programs. However, this is very difficult to judge and can lead to regulatory issues. A conservative position should be taken with respect to the complexity of the software and justification for this decision should be substantial.

\section{2 Environmental, Seismic, and Electromagnetic Compatibility Qualification}

Actuator qualification is composed of three major components:

- environmental (including radiation)

- seismic

- electromagnetic compatibility $(E M C)$ qualification

The environmental, seismic and EMC qualification for digital based actuators is basically the same qualification process as used for the qualification of analog actuators. The objective of equipment qualification is to demonstrate that the safety actuators are capable of performing their designated safety-related functions during and following a postulated event. For actuators, the analysis should determine whether or not they are capable of being used in both normal and accident environments.

Digital actuators typically have a greater sensitivity to environmental factors compared to their analog actuators due to the more sensitive electronic components within the actuator. This can affect where the actuators can be located.

The safety-related actuators must be qualified to the requirements of IEEE Std. 323-2003 [33], as augmented by NRC Regulatory Guide RG 1.209 [34]. When this equipment is to be 
located in a harsh environment where qualified heating, ventilation, and air conditioning (HVAC) is not provided, the qualification is performed by a heat rise test and a subsequent analysis using linear temperature data extrapolation. The analysis must demonstrate, using extrapolated test data, that individual component and equipment temperature specifications are not exceeded within the actuator housing when exposed to the environmental conditions as specified.

In addition, radiation qualification must be performed for actuators located in a harsh environment. The radiation levels are determined by radiation measurements or historical data taken for the respective area. Normally radiation qualification is based only on analysis for mild areas. However, the actuators are typically in areas of the plant that could be exposed to higher levels of radiation during design basis events and it is expected that radiation testing would be performed.

For seismic qualification, a safety-related actuator must be qualified by test, analysis or a combination of both methods in accordance with IEEE Std. 344-2004 [35], as endorsed by NRC Regulatory Guide RG 1.100 [36]. Functional operability tests must be conducted during seismic qualification tests with the equipment energized using simulated inputs and interfaces.

The safety I\&C system actuators are qualified for EMC in accordance with MIL Std. 461E [37] and IEC 61000 Part 4 Series [38] as augmented by RG 1.180 [39]. EMC testing of the equipment is performed for both conducted and radiated signals as follows:

- $E M I / R F I$ emissions

- $\quad$ EMI/RFI susceptibility / immunity

- Surge withstand capability

The tests are performed on each actuator in various modes of operation such that successful completion of the test demonstrates that the safety system function has not been compromised and the equipment performs within its design specifications. The selection of the specific tests and operating envelops (test level, applicable frequency and limitations) is based on RG 1.180. For digital based actuators this could be a harsher environment.

Other EMC testing that needs to be considered are power stability (i.e., surge) and electrostatic discharge.

Due to the difficulty of qualifying digital actuators based on sensitive electronic components for harsh environments, a number of the commercial offerings are available only for mild environments at this time. At the present, the nuclear plant designers and owners are apparently satisfied to continue to use analog actuators in safety-related harsh environment applications rather than pursue this option with the actuator suppliers. This qualification work must ultimately be undertaken by either the actuator suppliers or the plant owners if the full value of digital actuators is to be obtained.

\subsection{Software Common Cause Failures}

The possibility of software common cause failures (SCCFs) of more than one echelon of defense is the primary concern in considering postulated failures within the echelons including 
actuators used for defense-in-depth. These failures can be caused by interdependencies between these echelons. The problem becomes one of specifying the degree of dependencies, as it is impossible to have four completely independent echelons when certain features must be shared due to the commonality of the architecture and personnel. Physical and electrical independence is only one of the dependencies under analysis. The second is the common cause failure (CCF) caused by shared hardware features such as power supplies, actuators or other equipment. The third and the one under consideration in the D3 assessment is shared software between digital based equipment such as actuators that leads to a software common cause failure (SCCF) between and within the echelons. This is of particular concern where actuator software is common for multiple actuators which, in effect, could impact train/division capabilities.

With the use of digital actuators, there is a concern that a SCCF within the actuator could propagate in such a fashion that the acceptance criteria for the transient and accident analyses is not be met. The use of digital actuators presents a somewhat unique concern in that previous diverse designs have all used common (analog) actuators. For the digital actuators, the actuators could prove to be non-diverse within a system and between systems such that they are not available given a postulated SCCF. This would entail the use of diverse actuators for common systems. The selection of digital based actuators with either firmware or programmable software leads to an analysis of the SCCF concern.

This is considered to be the major licensing difference between analog and digital based actuators. The difficulty for analyzing this concern is normally there is only one actuator for each system function which leads to great difficulty in designing a diverse means to counter the SCCF. The diverse actuators design could prove to be difficult to add to an existing plant design and also prove to be cost prohibitive. The licensing process for this concern is discussed below. Because of this, a plant could choose to provide diverse actuators on a per train/division basis where feasible or only use software for the non-safety functions of the actuator. Another solution is to ensure that simple software is used leading to total testability of the signal paths in accordance with NRC guidance. This would eliminate the SCCF concern.

A Diversity and Defense-in-Depth (D3) evaluation must be performed that demonstrates that there is sufficient defense-in-depth and diversity to cope with a postulated SCCF to the safety related digital based actuators in the RTS and ESFAS including, if part of the design, the credited control and Diverse Actuation Systems (DAS). Appendix B of this report is used to show the highlights of a D3 evaluation when the actuators for the Safety Injection System injection vales are modified to be digital based with software used for such things as smart valve positioning, diagnostics, health and overall monitoring of the valve and its actuator. Safety injection system (SIS) injection valves were chosen for this example as it is deemed to be one of the most problematic actuation devices to be digitized since it is necessary for the large break loss-of-coolant accident (LBLOCA) and the required time is much too short to allow for operator manual actions. 


\subsubsection{D3 Regulatory Criteria}

The NRC has established a methodology and acceptance criteria for D3 evaluations that are to be used when digital based systems including actuators are implemented in the RTS and ESFAS at operating nuclear power plants and for new plants. The NRC Branch Technical Position BTP-7-19 [40] and NRC NUREG/CR-6303 [41] document the methodology and acceptance criteria.

1. The applicant/licensee shall assess the defense-in-depth and diversity of the proposed instrumentation and control system to demonstrate that vulnerabilities to common mode failures have adequately been addressed.

2. In performing the assessment, the vendor or applicant/licensee shall analyze each postulated common mode failure for each event that is evaluated in the accident analysis section of the safety analysis report (SAR) using best-estimate methods. The vendor or applicant/licensee shall demonstrate adequate diversity within the design for each of these events.

3. If a postulated common mode failure could disable a safety function, then a diverse means, with a documented basis that the diverse means is unlikely to be subject to the same common mode failure shall be required to perform either the same function or a different function that provides adequate protection. The diverse or different function may be performed by a non-safety system if the system is of sufficient quality to perform the necessary function under the associated event conditions.

4. A set of displays and controls located in the main control room shall be provided for manual, system-level actuation of critical safety functions and monitoring of parameters that support the safety functions. The displays and controls shall be independent and diverse from the safety computer system identified in Items 1 and 3 above.

Items 1, 2, and 3 of the Nuclear Regulatory Commission (NRC) position discussed in BTP-7-19 apply directly to digital actuator modifications to nuclear plants. Item 4 also applies considering that display information is transmitted from the digital actuator.

The acceptance criteria as described in BTP 7-19 are as follows:

1) For each anticipated operational occurrence in the design basis occurring in conjunction with each single postulated CCF, the plant response calculated using realistic assumptions should not result in radiation release exceeding 10 percent of the applicable siting dose guideline values or violation of the integrity of the primary coolant pressure boundary. The applicant should (1) demonstrate that sufficient diversity exists to achieve these goals, (2) identify the vulnerabilities discovered and the corrective actions taken, or (3) identify the vulnerabilities discovered and provide a documented basis that justifies taking no action.

(2) For each postulated accident in the design basis occurring in conjunction with each single postulated CCF, the plant response calculated using realistic assumptions should not result in radiation release exceeding the applicable siting dose guideline values, 
violation of the integrity of the primary coolant pressure boundary, or violation of the integrity of the containment (i.e., exceeding coolant system or containment design limits). The applicant should (1) demonstrate that sufficient diversity exists to achieve these goals, (2) identify the vulnerabilities discovered and the corrective actions taken, or (3) identify the vulnerabilities discovered and provide a documented basis that justifies taking no action.

(3) When a failure of a common element or signal source shared by the control system and RTS is postulated and the CCF results in a plant response for which the safety analysis credits reactor trip but the failure also impairs the trip function, then diverse means that are not subject to or failed by the postulated failure should be provided to perform the RTS function. The diverse means should assure that the plant response calculated using realistic assumptions and analyses does not result in radiation release exceeding 10 percent of the applicable siting dose guideline values or violation of the integrity of the primary coolant pressure boundary.

(4) When a CCF results in a plant response for which the safety analysis credits ESF actuation and also impairs the ESF function, then a diverse means not subject to or failed by the postulated failure should be provided to perform the ESF function. The diverse means should assure that the plant response calculated using realistic assumptions and analyses does not result in radiation release exceeding 10 percent of the applicable siting dose guideline values or violation of the integrity of the primary coolant pressure boundary.

(5) No failure of monitoring or display systems should influence the functioning of the RTS or ESF. If a plant monitoring system failure induces operators to attempt to operate the plant outside safety limits or in violation of the limiting conditions of operation, the analysis should demonstrate that such operator-induced transients will be compensated by protection system function.

(6) For safety systems to satisfy IEEE Std. 603-1991 Clauses 6.2 and 7.2, a safetyrelated means shall be provided in the control room to implement manual initiation of the automatically initiated protective actions at the system level or division level (depending on the design) of the RTS and ESF functions. This safety-related manual means shall minimize the number of discrete operator manual manipulations and shall depend on operation of a minimum of equipment. If a D3 analysis indicates that the safety-related manual initiation would be subject to the same potential CCF affecting the automatically initiated protective action, then under Point 3 of the NRC position on D3, a diverse manual means of initiating protective action(s) would be needed, (i.e. two manual initiation means would be needed). If the safety-related system/division level manual initiation required by IEEE Std. 603-1991 is sufficiently diverse, the diverse (second) manual means would not be necessary (see Section B.1.5, "Manual Initiation of Automatically Initiated Protective Actions Subject to CCF"). If credit is taken for a manual actuation method that meets both the IEEE Std. 603-1991, Clauses 6.2 and 7.2 requirements and a need for a diverse manual means, then the applicant should demonstrate that the criteria are satisfied and that sufficient diversity exists. Note that if 
the diverse means is non-safety, then IEEE Std. 603-1991, Clause 5.6, "Independence," directs the separation or independence of the safety systems and the diverse means

(7) If the D3 assessment reveals a potential for a CCF, then the method for accomplishing the diverse means of actuating the protective safety functions can be achieved via either an automated system (see Section 3.4, "Use of Automation in Diverse Means" below), or manual operator actions that meet HFE acceptability criteria (see Section 3.5, "Use of Manual Action as a Diverse Means of Accomplishing Safety Functions" below).

(8) If the D3 assessment reveals a potential for a CCF, then the method for accomplishing the diverse means of actuating the protective safety functions should meet the following criteria: The diverse means should be:

a) at the system or division level (depending on the design);

b) initiated from the control room;

c) capable of responding with sufficient time available for the operators to determine the need for protective actions even with indicators that may be malfunctioning due to the CCF if credited in the $D 3$ coping analysis;

d) appropriate for the event;

e) supported by sufficient instrumentation that indicates:

1. the protective function is needed,

2. the safety-related automated system did not perform the protective function, and

3. whether the automated diverse means or manual action is successful in performing the safety function.

(9) If the D3 assessment reveals a potential for a CCF, then, in accordance with the augmented quality guidance for the diverse means used to cope with a CCF, the design of a diverse automated or diverse manual actuation system should address how to minimize the potential for a spurious actuation of the protective system caused by the diverse means. Use of design techniques (for example, redundancy, conservative setpoint selection, coincidence logic, and use of quality components) to mitigate these concerns is recommended.

\subsubsection{D3 Analysis Process for Digital Actuators}

A Diversity and Defense-in-Depth (D3) analysis is presented in this report based upon a five-pronged evaluation approach:

1. I\&C architecture review,

2. Diverse Actuator Block establishment,

3. Postulated event analysis concurrent with software common cause failure (SCCF) to each diverse Block, including event categorization, 
4. Review of non-safety, manual actions and display availability for certain events (must not use the digital actuator in question) and

5. Diverse Actuation System (DAS) design or a re-design of the digital actuators. For this case the DAS would consist of a design modification such as the implementation of diverse actuators to counter the SCCF concern.

\section{I\&C Architecture Review}

As the first step in the D3 process, the digital based actuator architecture will be reviewed/analyzed to determine the quantity and identity of all software based I\&C Blocks. This review includes both safety and non-safety I\&C systems. These Blocks will be assembled by system. For most D3 Analysis cases including digital actuators, the lowest Blocks are achieved at the system/actuator level.

\section{Diverse Blocks}

The second step in the D3 analysis process is the review of actuator blocks to determine the degree of diversity within the actuator blocks. By the process of making this selection, the I\&C architecture is reviewed for diversity between the digital actuators used in both safety and non-safety systems and the remainder of the plant software. Diversity is a principle in instrumentation of sensing different variables, using different technology, using different logic or algorithms, or using different actuation means to provide different ways of responding to a postulated event.

The amount of diversity will be determined by using the guidance contained in NUREG/CR-6303, Section 2.5, NUREG-0493 [42] and NUREG/CR-7007 [43]. The principal results of the NUREG research effort have identified and developed diversity strategies, which consist of combinations of diversity attributes and their associated criteria. Technology, which corresponds to design diversity, is chosen as the principal system characteristic by which diversity criteria are grouped to form strategies. The rationale for this classification framework involves consideration of the profound impact that technologyfocused design diversity provides. Consequently, the diversity usage classification scheme involves three families of strategies: (1) different technologies, (2) different approaches within the same technology, and (3) different architectures within the same technology.

Types of diversity have been segregated into six areas: functional, signal, design, equipment, software, and human. These diversity features are intended to be applied to the different instrumentation and control echelons within the overall I\&C architecture.

NUREG/CR-7007 will be used for establishing the final ranking of diversity attributes. These established blocks/modules are intended to represent diverse software and equipment/modules. Upon completion of this step, the diverse blocks will be chosen and the SCCF can be postulated for each set of blocks.

\section{Safety Analysis Concurrent with SCCF}

The actuator blocks will be evaluated to ensure that the safety analysis limits will not be violated given a SCCF to these blocks. The diverse block SCCFs will not be postulated to occur concurrently. As a result, the proposed D3 analysis will then assume: 
(1) A complete loss of common blocks and a re-analysis of the thermal-hydraulic response, the core and fuel response, and the offsite and control room dose consequences for the spectrum of transients and accidents. The D3 effort will evaluate each applicable safety analysis event in conjunction with a postulated SCCF using the guidance provided in BTP 7-19 and its referenced documents. An important point to note is that realistic assumptions will be used during this entire D3 analysis. Each initiating event (single events only) will be evaluated using qualitative deterministic methods. Evaluation results will be presented for all initiating events analyzed

(2) The postulated SCCF that requires the closest attention is the one that will induce a plant transient for which the Class 1E functions, RTS and ESFAS, are needed. The resulting analysis will show that any credible failure of this type does not impair the safety function. The other postulated SCCF is to the non-safety systems where each digital actuator in the non-safety design is postulated to fail and the resulting event is analyzed against the plant safety analysis to determine if the analysis remains enveloped.

(3) If a postulated SCCF to common digital actuators could disable a safety function, then a diverse means, with a documented basis that the diverse means is unlikely to be subject to the same common mode failure should be required to perform either the same function or a different function. The diverse or different function may be performed by a non-safety system if the system is of sufficient quality to perform the necessary function under the associated event conditions. This is more of a concern with actuators in that acceptable diverse means will be more difficult to achieve.

(4) For those events where automatic mitigation (safety or non-safety) is not available, operator manual action times for mitigation will be determined. The USNRC has set a 30 minute time before these manual actions can be credited, thus giving the operator time to recognize the event and the SCCF concern. Times less than 30 minutes will require additional proof of operator capability and, as a result, will be more difficult to gain NRC acceptance. However, depending on the time and system availability, lesser times could prove to be the optimum solution. Pre-discussions with the NRC will aid in this determination. For manual actions, both the manual actuation path and the indications are required to be diverse from the Safety software and accessible to the operator. Again, these manual means will require a path different from the actuators being evaluated.

\section{Review of non-safety, manual actions and display availability for certain events}

For those events falling into Category D (see Appendix B, Section 6) where actuator design features are identified that are susceptible to SCCFs causing events to not be acceptably mitigated, either 1 ) the architecture must be modified to remove the design aspects vulnerable to a digital CCF; 2) compensate for the identified vulnerabilities by implementing a Diverse Actuation System (DAS); or 3) perform a quantitative analysis to demonstrate the resultant plant response to specific anticipated operational occurrences (AOOs) and design basis accidents (DBAs) analyzed in the FSAR meets the applicable 
acceptance criteria. In addition, manual actuation capability can be used for those events where the allowed 30 minute time limit exists. For those events where the manual action time is necessary within the 30 minutes, an individual analysis needs to be performed to demonstrate acceptability and receive NRC concurrence. Events where the required time is less than 30 minutes should be addressed on an individual basis with adequate NRC acceptance in-hand.

For digital actuators, items 1 and 2 in the above paragraph could be combined into one item that would require the installation of diverse actuators on a system/train basis. In addition, manual actuation would, more than likely, use the same digital actuators. Given this, the D3 analysis results would require the installation of diverse actuators in some manner.

\section{DAS Design}

Diverse actuators not impaired by the postulated SCCF should be designed to execute the required RTS and ESFAS actions. In the very unlikely event the Reactor Trip System (RTS) is unavailable due to the SCCF to its digital actuators, then credit would be given to the Anticipated Transient Without Scram (ATWS) system. ATWS architecture is carefully designed to assure that it remains available given an undetermined failure to trip the reactor. However, for the case of the loss of digital actuators, an analysis should be performed to ensure that credit can be given for ATWS system operability.

The quality of the diverse actuators will be at a level similar to the ATWS System (NRC Generic Letter 85-06 [44]. They will be qualified to operate in the projected environment for the postulated event it is required to operate. The software will be qualified to a lower level than the safety software.

The simplicity of the software used within the digital based actuator can become a significant factor in the D3 analysis process. However, to prove simplicity for the D3 analysis, complete testability (all paths used and unused unless terminated) would have to be achieved. Achieving complete testability is discussed more in BTP 7-19. Total testability can be difficult to achieve except for the simplest digital actuator designs, but offers a simpler resolution than the implementation of diverse actuators within multiple systems. Another possible path is to prove that the software is not necessary for the safety function of the actuator. If only portions of the software are non-safety, then the analysis reverts to the safety portions of the software as well as proving the safety and non-safety related software interfaces meet regulatory criteria.

\subsubsection{Analysis Process for SCCF within Non-Safety Related Actuators}

For non-safety related digital actuators, a segmentation analysis should be performed to ensure that the plant Safety Analysis has not been impacted in any manner by a postulated CCF to this set of non-safety digital actuators. The analysis would include a review of the Safety Analysis to determine which events were predicated by only a partial loss of a control system such as the feedwater controls or turbine controls. For this, the upgrade to digital 
actuators would have to ensure that these event initiators have not been compromised by this upgrade. If the initiators are compromised, the modification would have to be redesigned or the event reanalyzed with a different initiator such as a total feedwater loss. In addition, Chapter 7 of the Updated Final Safety Analysis Report (UFSAR) should be analyzed to determine if any credit is given for independent actions of control systems. If this is compromised within Chapter 7 , then the modification should be redesigned or the text in Chapter 7 modified in accordance with existing regulations.

\section{$5.4 \quad$ Communications}

Digital based actuators are able to take advantage of advanced digital communication technology such as HART, Field Bus, ProfiBus, and other such industry standards. However, such usage raises the question of compliance with the NRC's Digital Interim Staff Guidance (ISG) - 04, Communications, because the digital communication links offer certain capabilities that could come into conflict with requirements specified in 10 CFR $50.55 \mathrm{a}(\mathrm{h})$, namely IEEE 603-1991 and IEEE 7-4.3.2, in regard to the requirements of separation and independence of redundant instrument channels. This is applicable to safety digital actuators receiving and transmitting information to monitoring systems regarding status and health for both control and safety systems.

To clarify, the NRC's position is that an ISG does not create requirements, but is a summary of existing requirements and provides guidance to the NRC staff in reviewing licensee designs and design changes subject to those requirements. More importantly, an ISG can be taken as a summary of the NRC's interpretation of those requirements. ISG-04 is composed of four basic areas of interest:

1. interdivisional communications: communications among different safety divisions or between a safety division and a non-safety entity

2. command prioritization: selection of a particular command to send to an actuator when multiple and conflicting commands exist

3. multidivisional control and display stations: use of operator workstations or displays that are associated with multiple safety divisions and/or with both safety and non-safety functions

4. digital system network configuration: the network or other interconnection of digital systems that might affect plant safety or conformance to plant safety analysis assumptions (interconnections among safety divisions or between safety and non-safety divisions should also satisfy the guidance provided for interdivisional communications)

The first and fourth areas are the most applicable to the implementation of digital actuators.

Digital actuators are also subject to the requirements stated in the General Design Criteria of Appendix A to Part 50 of Title 10 of the Code of Federal Regulations [45]. This guidance specifically addresses issues related to interactions among safety trains and between safetyrelated equipment and equipment that is not safety-related. This guidance does address certain aspects of digital control systems that are not safety-related, but which may affect the plant conformance to safety analyses (accident analyses, transient analyses, etc.). As stated above, 
the implementation of digital actuators in non-safety related systems needs to be analyzed to ensure that the safety analysis results are not impacted in any manner.

To maximize the benefit of digital actuators, they should be implemented with digital communications technology. However, the use of the digital communications is encumbered with this additional analysis and potential regulatory review.

\subsection{Cyber Security}

Unlike their analog counterparts, digital actuators must be protected from cyber-attacks. Regulatory requirements for cyber security are found in 10 CFR 73.54, which requires a cyber security program and a cyber security assessment of all digital assets subject to the regulation to determine if any cyber vulnerabilities exist.

The security assessment consists of two parts; computer security and cyber security. Computer security is established during the design phase and primarily uses the guidance provided in NRC Regulatory Guide RG 1.152 [46], which provides guidance for compliance with cyber security requirements during the development life cycle phases such that the digital hardware and software are developed in a secure environment. It is better if this is performed by the digital actuator vendor during the component design and manufacturing process, but could be verified by the licensee or a third party after the design if the right processes were followed and adequate quality records were available for audit. In any case, the nuclear plant licensee is the party that is legally responsible for the accuracy and completeness of this assessment, and therefore must provide oversight of this process.

NRC Regulatory Guide RG 5.71 [47] addresses cyber security for the testing, operational, and retirement life cycle phases, which provides guidance on how to protect critical digital assets (CDA) from cyber-attacks. A CDA is a subcomponent of a critical system that consists of or contains a digital device, computer or communication system or network. In turn, a critical system is an analog or digital technology based system in or outside of the plant that performs or is associated with a safety-related, important-to-safety, security, or emergency preparedness function. These critical systems include, but are not limited to, plant systems, equipment, communication systems, networks, offsite communications, or support systems or equipment, that perform or are associated with a safety-related, important-to-safety, security, or emergency preparedness function.

The industry has developed a template for an industry standard cyber security program to comply with the NRC's cyber security requirements through an effort sponsored and facilitated by the Nuclear Energy Institute (NEI). This was published in a guidance document, NEI 08-09 [48], which was subsequently endorsed by the NRC. NEI 08-09 provides guidance on the necessary elements of a cyber-security plan, how to analyze digital computer systems and networks for cyber-vulnerabilities, and how to establish, implement, and maintain a cybersecurity program.

Safety-related and important-to-safety digital actuators would be categorized as CDAs and would therefore fall under the requirements of the licensee's cyber security program. This will then entail conducting an analysis or potentially-applicable mitigation strategies and 
implementing those that are determined to be appropriate. This then is yet another reason that nuclear plant designers and licensees have been reluctant to use digital actuators in applications that would be subject to these requirements. Therefore, additional efforts are needed by or on behalf of the industry to resolve these issues in a cost-effective manner.

\subsection{Licensing Considerations}

The major areas of licensing considerations are:

- Nuclear Plant Modifications under Licensee Control

- Nuclear Plant Modifications under NRC License Amendment

- Improvements in Plant Technical Specifications

- Certification of New Nuclear Plant Designs

The sections below provide a discussion of these licensing considerations and address issues and concerns that need resolution to encourage greater use of digital actuators.

An NEI/NRC joint task force was recently established to review concerns associated with digital modifications and the licensing process for operating plants. The NRC has stated that since the issuance of Information Notice 2010-10, "Implementation of a Digital Control System under 10 CFR 50.59" [49] was issued, the industry's guidance on performing 50.59 evaluations for digital modifications, NEI 01-01[50], should be updated. New concerns were noted by the NRC with past 50.59 plant reviews and their results. As a result, a series of meetings are being held to discuss revisions to NEI 01-01 and the industry report on which it is based, EPRI TR102348, Revision 1 [51], so that this licensing process can be further clarified. (NEI 01-01 was the co-publication of the Electric Power Research Institute (EPRI) report TR- 102348, Revision 1, Guideline on Licensing Digital Upgrades.) Since these results are not final at this time, the discussions below reflect the current licensing process and the current version of the above documents.

\subsection{Nuclear Plant Modifications under Licensee Control}

In order to upgrade existing analog actuators to digital, a regulatory analysis must be performed to determine under which regulatory process the change must be conducted - either under licensee control or under NRC license amendment (refer to Section 6.2).

The requirements in 10 CFR 50.59 define the criteria that establish when a license amendment is required before implementing plant changes. The criteria of 10 CFR 50.59 apply to actuator modifications for both safety and non-safety systems.

If the criteria are met for the change, no license amendment is required. If not, the change can only be implemented after receiving a license amendment under the requirements and process specified in 10 CFR 50.90 [52]. NEI 01-01 provides guidance to licensees on performing 10 CFR 50.59 evaluations for digital upgrades such as digital actuators. NRC Regulatory Information Summary (RIS) 2002-22 [53] communicates the NRC's endorsement of NEI 01-01 for use as guidance in designing and implementing digital upgrades such as digital 
actuators for instrumentation and control systems. RIS 2002-22 also specifies that statements in the NRC staff's evaluation of NEI 01-01 qualify the NRC staff's endorsement of the report and provide staff positions on several aspects of the design and licensing processes.

One immediate screening criterion for the change is whether the modification requires a change to a nuclear plant's Technical Specifications. Such changes can be made only under a license amendment. Usually such an upgrade would not require a Technical Specification change, as long as the change maintained the same design. In other words, it would be the same design if just the actuators themselves were being upgraded on a like-for-like basis and there were no changes in how the design was configured or functioned (such as changes to the set points or number of channels).

However, if a reduction in the surveillance requirements specified in the Technical Specifications was desired to take advantage of digital actuator capabilities, then a license amendment would be required. (Refer to Section 6.2)

Consideration of software common cause failure (SCCF) is required regardless of the safety significance of the digital actuator. This can be a key factor in determining whether the criteria of 10 CFR 50.59 are met such that a license amendment is not required. Two of the most applicable criteria to this question are:

Criterion 2: Does the activity result in more than a minimal increase in the likelihood of occurrence of a malfunction of a SSC (system, structure, or component) important to safety?

Criterion 6: Does the activity create a possibility of a malfunction of an SSC important to safety with a different result?

In this context, consideration of SCCF involves the determination that failure due to software is "sufficiently low," meaning much lower than other failures that are considered in the nuclear plant's Updated Final Safety Analysis Report (UFSAR). And regarding the possibility of a malfunction with a different result, this is not necessarily a new type of malfunction, but a malfunction that is not bounded by those already evaluated in the UFSAR.

The NEI 01-01 guidance indicates that, for digital upgrades to systems that are highly safety-significant, licensees should perform a defense-in-depth and diversity analysis as part of the design process to ensure that the plant has adequate capability to cope with software common-cause failure vulnerabilities. As discussed in Section 5 and illustrated in Appendix B, non-safety related digital actuator implementations should also be reviewed for any new impact to the safety analysis.

In summary, the guidance of NEI 01-01 must be carefully applied in the upgrade of analog actuators to digital to ensure that the change is made under the correct regulatory process. Due to the special considerations of a software-based plant component, there is extra burden on making this determination and the regulatory consequences of failing to obtain a license amendment when it is required can be quite high. And so, the additional burden and regulatory risk to correctly assess these special digital issues is potentially a factor in the decision to either stay with analog actuator technology or to upgrade to digital replacements. 


\subsection{Nuclear Plant Modifications under NRC License Amendment}

For cases where the 10 CFR 50.59 criteria results in the need for NRC review and approval of the plant change, a license amendment for the nuclear plant must be obtained. The requirements for this are stated in 10 CFR 50.90. Depending on the scope of the license amendment, the process can be lengthy and costly, with no certain outcome as to approval. In fact, there is some risk that the NRC will impose additional design and testing requirements that were not accounted for in the original project estimate.

To ensure a more consistent and predictable license amendment for digital upgrades, the NRC issued Interim Staff Guidance ISG - 6 [54] to provide a detailed approach for all phases of the process. ISG 6 is currently under a pilot project evaluation phase as it is used on a large highly-safety significant digital upgrade at a U.S. nuclear plant. While this upgrade project is not yet complete, ISG-6 is currently available for use by any of the domestic nuclear plants and represents the best regulatory approach for cases where the implementation of digital actuators requires a license amendment.

The need for a license amendment for the upgrade of analog actuators to digital would be a formidable barrier for a number of nuclear utilities, due to the cost, time, and risk involved. Therefore, this is yet another impediment to obtaining the benefits of digital actuators, especially where improved accuracy and reliability could provide improvements in nuclear safety and operating margins. This highlights the importance of the Oak Ridge National Laboratory project to provide objective criteria for how much diversity is sufficient to resolve the SCCF question, and thereby reduce the number of digital actuator upgrades that would potentially require a license amendment.

\subsection{Improvements in Plant Technical Specifications}

One major advantage with the implementation of software-based digital actuators is the ability to use on-line diagnostics including self-monitoring and self-functional operability checks. Digital actuators have the capability to perform self-checks by continuously monitoring outputs and overall health and then automatically annunciating or indicating when actuator problems arise. As a result, traditional test provisions for analog actuators may not be appropriate for the digital actuators because of the differences between the designs where digital actuators can provide the automatic diagnostic design provisions. These diagnostic provisions may be used to lessen the manual testing actions deemed necessary by the technical specifications. This is of great benefit when used in plant programs where the intent is to lengthen a testing cycle such that safety is not impacted but O\&M costs are reduced. This could include channel checks, functional testing and other TS functions.

However, precautions are necessary to ensure that the requirements of the technical specifications are maintained. Unless granted on a generic basis, the approval for surveillance extensions must be granted on a plant-specific basis. The critical area for Technical Specification relief is the crediting of the on-line monitoring feature provided by the digital actuator. This would involve checking the output of the digital actuator to determine if performance criteria are being met. This includes whether or not it is operating inside or outside of acceptable limits and whether or not self-checks are sufficient to replace manual checks of 
the actuator. This can provide relief on channel check frequency or even a total replacement and perhaps relief on the frequency of actuator functional operability, saving a considerable amount of plant personnel time. Of course, this is all dependent on maintaining TS requirements and meeting regulatory requirements.

There are many advantages to this non-intrusive testing credit, including non-intrusive testing, testing performed on a continuous basis, development of long-term trends, decrease in radiation exposure, and a continuous evaluation of the actuator installation and process conditions. However, there are certain features that have to be analyzed, such as the safety level of the on-line monitoring capability, the annunciation of fault conditions or out-of-tolerance conditions either through automatic or manual means, and the bypass and inoperability alarms. Overall, IEEE 603 requirements must be met by the digital actuator installation and consistency must be maintained.

Provisions for digital actuator and network diagnostics as well as the measurement of actuator operability history, is credited in NEI 04-10 Rev 1 [55] to address the extension of surveillance test intervals for equipment covered by Technical Specifications. The NRC has authorized in the SER to NEI 04-10, Rev 1 [56], for changes to frequencies listed in the Technical Specifications to be made in accordance with NEI 04-10, Rev 1. This program establishes a Surveillance Frequency Control Program (SFCP) which ensures that surveillance requirements specified in the Technical Specifications are performed at intervals sufficient to assure the associated Limiting Conditions for Operation are met. The regulatory programs for Maintenance rule (10 CFR 50.65), as well as corrective action programs identified by 10 CFR 50 , Appendix $B$, require monitoring of test failures and require action to be taken. The approach for changing surveillance frequencies uses existing Maintenance Rule guidance as well as NRC Regulatory Guide RG 1.175 [57], to develop risk-informed test intervals for equipment covered by Technical Specifications. In Section 4 of NEI-04-10 Rev 1, Step 7, credit can be taken for benefits of early detection of potential mechanisms (as is provided in digital system online monitoring and diagnostics) and degradations that lead to common cause failures. This and other potential credits are inputs to the risk analysis and Probabilistic Risk Assessment (PRA) for each nuclear plant, which can be used to justify the extension of Technical Specification surveillances.

\subsection{Certification of New Nuclear Plant Designs}

Finally, in the case of a new nuclear plant, the NRC has provided a more streamlined plant licensing process as compared with the process that was used in the first generation of plants which involved first a construction license and then an operating license at the time the plant was completed. This new process is known as a Combined Operating License (COL), for which the requirements are found in U.S. Code of Federal Regulations10 CFR 52. [58]

However, for technical requirements, Part 52 refers to many of the same standards and regulatory guidance that are applicable to the current operating nuclear fleet. This includes the NRC's Standard Review Plan, NUREG-0800, and in particular Chapter 7 for I\&C concerns. Therefore, requirements for qualification of digital designs, including SCCF, remain the same. 
Under Part 52, plant designers apply for approval of a Design Certification Document (DCD), which can be referenced by any prospective plant owner/operator in their application for a COL. Recognizing that a number of design details would not be known at the time of DCD submittal, the NRC provided for concept of Inspections, Tests, Analysis, and Acceptance Criteria (ITAAC), and a special subset of ITAAC known as Design Acceptance Criteria (DAC). This was especially important for digital designs in that certain aspects are not yet known at the time of general plant design certification. This way, the NRC can verify them later in the process to avoid holding up the general design certification.

This concept under Part 52 reduces regulatory risk in the licensing of new nuclear plants because it raises questions about new digital actuators that would not necessarily hold up the overall plant certification, assuming that the outstanding information was granted either DAC or ITAAC status by the NRC.

\subsection{Summary of Qualification and Licensing Considerations}

It is evident that there are substantial burdens in implementing digital actuators that must be overcome if the industry is to obtain the long-term operational benefits of digital actuators. So far, these factors in various combinations have been a significant impediment to the use of digital actuators in both operating plants and new reactor designs, especially for safety-related applications. Non-safety related digital actuators are impacted but to a lesser degree.

The following is a summary of the key areas where the burden needs to be reduced through the efforts of digital actuator suppliers, nuclear plant designers, and nuclear plant licensees if there is to be wide-spread adoption of digital actuators

- Methodologies for determining software quality

- Environmental hardening (temperature, pressure, radiation, electro-magnetic)

- Objective criteria for determining how much diversity is sufficient to alleviate SCCF concerns for both safety and non-safety related digital actuators

- Clear acceptance criteria for special digital concerns such as digital communications and cyber security

- Enhanced guidance for 10 CFR 50.59 evaluations with respect to SCCF

- Proven process for digital license amendments that is consistent and predictable, thereby allowing the reasonable management of project cost, schedule, and risk.

Three positive considerations for digital actuator implementation in the licensing area are noted. There is a proven process under NEI 04-10 for obtaining improvement in Technical Specification surveillance intervals, thereby providing the means to capture the benefit of digital actuators in applications governed by the Technical Specifications.

Also, for new plant designs, the DAC and ITAAC processes reduce regulatory risk to the overall plant certification for qualifying issues that cannot be determined or resolved at the time of Design Certification application. This factor can make it more attractive to pursue the longterm benefits of digital actuators without incurring undue risk to the design certification schedule. 
Thirdly, there is a new NRC/NEI group formed to review and revise NEI 01-01 with the goal of providing clearer guidance on applying 50.59 criteria to digital modifications including digital actuators.

\subsection{Summary}

Digital actuator technologies are available to the nuclear power industry to improve operating performance, improve safety margins, and to reduce costs. These technologies have been proven in other industries and amply demonstrated the performance advantages over the legacy analog counterparts.

The U.S. nuclear power industry is currently under significant cost pressure due to the abundance of low-cost gas generation. The only practical solution to this is to reduce operating and maintenance costs. Therefore, the nuclear industry should take advantage actuator replacement opportunities when they present themselves. These technologies provide benefits in many different aspects of plant operations and support, and they represent an attractive option to contribute to the competitiveness of the nuclear plants.

For new nuclear facilities, including small modular reactors, it would be advantageous for the initial design of the plant systems to use digital actuators, avoiding the cost of later back-fits and ensuring the long-term cost advantages of lower maintenance are realized from the very beginning of commercial operation.

It is evident that there are substantial barriers in implementing digital actuators that must be overcome if the industry is to obtain the long-term operational benefits of digital actuators. So far, these factors in various combinations have been a significant impediment to the use of digital actuators in both operating plants and new reactor designs, especially for safety-related applications. Non-safety related digital actuators are also impacted, but to a lesser degree.

This report outlines the benefits and challenges of introducing digital actuators in the following:

Benefits:

- Improved reliability as documented in Section 4.0 and as shown in the cases for digital positioners, digital electro servo actuators, digital MCC's, and digital variable frequency drives. In all cases, significant improvements have been shown in component-level and system-level reliability with the introduction of digital actuators.

- Cost savings as documented in a number of the case studies in this report. In one case study on introduction of variable speed drives, the savings was estimated at $4 \mathrm{MW}$ because of the higher efficiency of the variable speed drives over the former motorgenerator set and the use of diagnostics to monitor and address vulnerabilities before they threaten to shut down the units. 
- There is a proven process under NEI 04-10 for obtaining improvement in Technical Specification surveillance intervals, thereby providing the means to capture the benefit of digital actuators in applications governed by the Technical Specifications.

- Also, for new plant designs, the DAC and ITAAC processes reduce regulatory risk to the overall plant certification for qualifying issues that cannot be determined or resolved at the time of Design Certification application. This factor can make it more attractive to pursue the long-term benefits of digital actuators without incurring undue risk to the design certification schedule.

Challenges:

- There are certain qualification and licensing considerations that must be addressed in the implementation of digital actuators, particularly in regard to safety-related applications, but also for non-safety applications. One significant barrier to the implementation of digital actuation technology is SCCF under licensing requirements. This is addressed by demonstrating that there is adequate diversity and defense-indepth in the design to accomplish the plant safety functions when SCCF is assumed for all like digital devices. The present state of this consideration is that there are no objective criteria for how much diversity is sufficient to preclude a SCCF. This is the subject of a related project by the Oak Ridge National Laboratory.

- There are some environmental qualification issues with digital actuation technology that must be addressed. These include electromagnetic compatibility, radiation, and temperature. Some digital actuation technology cannot match the environmental qualification of their analog counterparts. The resolution of this problem is somewhat hampered by the lack of market for the digital actuators, providing low incentive to suppliers to improve the environmental qualifications of their digital offerings.

- Methodologies for determining software quality.

- Clear acceptance criteria for special digital concerns such as digital communications and cyber security.

- Enhanced guidance for 10 CFR 50.59 evaluations with respect to SCCF.

- Proven process for digital license amendments that is consistent and predictable, thereby allowing the reasonable management of project cost, schedule, and risk.

Therefore, further work is needed in several areas to promote the widespread use of digital actuator technology.

- A reasonable solution to the SCCF must be found such that all actuators of the same manufacturer and model number do not have to be assumed to fail, and that diverse actuation capability must be provided. The Digital Technology Qualification project at Oak Ridge National Laboratory is an important step in providing objective criteria for how much diversity is enough. There might be an opportunity to collaborate with new nuclear 
plant designers, especially of a SMR design, to see how the use of digital actuators can be accommodated in the addressing SCCF at all levels of digital controls and protection.

- Actuator suppliers need to qualify, and harden if necessary, the digital sensor alternatives, so that they can be used in safety-related applications located in harsh environments. This is primarily an issue of electronic components, on which digital designs depend. Other industry sectors have had success in hardening electronics, notably military and space applications. It is recognized that a market for these improved digital actuators must develop for this to be attractive to the suppliers.

- The industry would benefit by the development of a formal business case related to widespread use of digital actuator technology. This study would need to be performed in the context of an actual nuclear power plant and would capture the plant-wide performance improvement and cost savings related to accuracy, reliability, availability, and maintainability. This report has provided representative examples of performance improvement by digital actuators. The multiplied effect of these performance improvements across the many plant systems should result in appreciable cost savings as well as improved plant performance.

In summary, there is considerable performance improvement available to the industry if digital actuator technology is adopted on a wide-scale. Several barriers must be addressed for this to be a practical option for the nuclear industry. Further work can address these barriers and thereby enable the nuclear power industry to incorporate digital actuators when opportunities are available. 


\subsection{References}

1. Quinn, E., Mauck, J., \& Thomas, K., (2012) Digital Technology Qualification Task 2 Suitability of Digital Alternatives to Analog Sensors and Actuators, INL/EXT-1227215, Idaho Falls, ID: Idaho National Laboratory

2. Quinn, E., Mauck, J., Bockhorst, R., \& Thomas, K., Digital Sensor Technology, issued July, 2013, INL/EXT-13-29750

3. Wood, R., Pullam, L., Smith, C., Holcomb, D., Korsah, K., Muhlheim, M., Common Cause Failure Mitigation Practices and Knowledge Gaps, NEET/ASI/ORNL/TR2012/01, Oak Ridge, TN: Oak Ridge National Laboratory

4. Dominion Resources, Inc. News Release, October 22, 2013, Dominion to Close Kewaunee Power Station

5. U.S. Nuclear Regulatory Commission, Draft NRC Regulatory Issue Summary (RIS), Embedded Digital Devices In Safety-Related System, Systems Important to Safety, and Items Relied on for Safety, Washington, DC, 2013.

6. Compressed Air System Maintenance Guide, EPRI Report TR-1006677, November 2002

7. Pneumatic Systems and Nuclear Plant Safety, EPRI- Nuclear Safety Analysis Center, NSAC-128, October 1988

8. Instrument Air Systems, A Guide for Power Plant Maintenance Personnel, EPRI NMAC Report NP-7079, December 1990

9. Emerson Process Management, DVC6200 Brochure D351908X012 / MZ117 / February 2014

10. Digital Devices as Data Collectors, June 2010 edition of Nuclear Power International By Justin Keim, Supervising Engineer, Wolf Creek Nuclear Power Plant and Bill Fitzgerald, Vice President, Emerson Process Management, Nuclear Business Unit for Fisher Control Valves

11. Digital Devices Deliver for Duke and Millstone by Bill Fitzgerald, V.P. Nuclear Services Business, Fisher Controls; Ryan Printy, AOV Component Engineer, Duke Energy; \& Kevin Cortis, Component Programs, Millstone Station, Valve World, December 2012

12. Digital Field Devices Make Headway and Deliver Results in NPPs By Bill Fitzgerald, Vice President Nuclear Services Business, Fisher Controls, Tim Prestifilippo, I\&C technician, AOV Subject Matter Expert, Southern Nuclear Plant Vogtle and Charles Holden, AOV/MOV Engineer, Ginna NPP, Nuclear Exchange, November 2012

13. Steam Turbine Hydraulic Control System Maintenance Guide, EPRI Technical Report 107069, December 1996

14. B. Boynton, "Technology Transfer Brings New Life to Electric Control Valve Actuation", Exlar Corporation, 2014.

15. Exlar Corporation, Electric Actuator Product Catalog, Roller Screw Technology, p. 2, 2014

16. Exlar Product Brochure, Revolutionary Electro Servo Actuators for Process Control, 2014.

17. Exlar Technology Presentation, “How Does Exlar Technology Differ?”, 2014 
18. C. Pohl, C. Becker, J. Hesselbach, Electro Mechanical Alternatives to Increase the Efficiency of Industrial Systems, University of Kassel, Germany, 2011

19. Aging Management Guideline for Commercial Nuclear Power Plants - Motor Control Centers, Sandia National Laboratories Report SAND93-7069, Ogden Environmental and Energy Services Co., Inc, February 1994

20. IEEE PEDS 2011, Singapore, 5-8 December, 2011, "Variable Speed Pumping in Thermal and Nuclear Power Plants: Frequency Converter versus Hydrodynamic Coupling," Page 228-234.

21. Institute of Electrical and Electronics Engineers, "IEEE Standard Criteria for Safety Systems for Nuclear Power Generating Stations," IEEE Std. 603-1998, Piscataway, New Jersey, 1998

22. Institute of Electrical and Electronics Engineers, "IEEE Standard Criteria for Digital Computers in Safety Systems of Nuclear Power Generating Stations," IEEE Std. 7-4.3.2, 2003, Piscataway, New Jersey, 2003

23. Institute of Electrical and Electronics Engineers, IEEE Guide for General Principles of Reliability Analysis of Nuclear Power Generating Station Safety Systems, IEEE 3521987, Piscataway, New Jersey, 1987

24. Institute of Nuclear Power Operations (INPO), AP-913 Revision 2, Equipment Reliability Process Description, Atlanta, Georgia, December 2007

25. U.S. Department of Defense, MIL-HDBK-217F, Reliability Prediction of Electronic Equipment, Washington, DC, January 1990

26. ANSI S84.01-1996 "Application of Safety Instrumented Systems for the Process Industries"

27. Institute of Electrical and Electronics Engineers, IEEE 577-2004, IEEE Standard Requirements for Reliability Analysis in the Design and Operation of Safety Systems for Nuclear Facilities, Piscataway, New Jersey, 2004

28. International Electrotechnical Commission, IEC 61508 - 2009, Functional Safety of Electrical/Electronic/Programmable Electronic Safety-related Systems, Parts 1 through 6

29. U.S. Code of Federal Regulations, 10 CFR $50.55 \mathrm{a}(\mathrm{h})$, Codes and Standards (Protection Systems), Washington, DC

30. Institute of Electrical and Electronic Engineers, IEEE/EIA 12207.0, Standard for Information Technology- Software Life Cycle Processes, 1996

31. U.S. Code of Federal Regulations, 10 CFR 50 Appendix B, Quality Assurance Criteria for Nuclear Power Plants and Fuel Reprocessing Plants, Washington, DC

32. U.S. Nuclear Regulatory Commission, Standard Review Plan, NUREG-0800, Chapter 7, Branch Technical Position (BTP) - 14 Revision 5, Guidance for Software Reviews for Digital Computer-Based Instrument and Control Systems, Washington, DC, March, 2007

33. Institute of Electrical and Electronics Engineers, "IEEE Standard for Qualifying Class 1E Equipment for Nuclear Power Generating Stations," IEEE Std. 323-2003, Piscataway, New Jersey, 2003

34. U. S. Nuclear Regulatory Commission, Regulatory Guide 1.209, Guidelines for Environmental Qualification of Safety-Related Computer-Based Instrumentation and Control Systems in Nuclear Power Plants, Washington, DC, March 2007 
35. Institute of Electrical and Electronics Engineers, "Seismic Qualification Electric and Mechanical Equipment for Nuclear Power Generating Stations," IEEE Std. 344-2003, Piscataway, New Jersey, 2003

36. U. S. Nuclear Regulatory Commission, Regulatory Guide 1.100, Seismic Qualification of Electrical and Active Mechanical Equipment and Functional Qualification of Active Mechanical Equipment of Nuclear power Plants, Washington, DC, May 2008

37. U.S. Department of Defense, MIL-STD-461E, Requirements for the Control of Electromagnetic Interference Characteristics for Subsystems and Equipment IEC 61000 Part 4, Washington, DC, August 1999

38. International Electrotechnical Commission, IEC 61000 - 2009, Electromagnetic Compatibility, Part 4

39. U. S. Nuclear Regulatory Commission, Regulatory Guide 1.180, Guidelines for Evaluating Electromagnetic and Radio-Frequency Interference in Safety-Related Instrumentation and Control Systems, Washington, DC, October 2003

40. U. S. Nuclear Regulatory Commission, Standard Review Plan, NUREG-0800, Chapter 7, Branch Technical Position (BTP) - 19 Revision 6, Guidance for Evaluation of Diversity and Defense-in-Depth in Digital Computer-Based Instrumentation and Control Systems, Washington, DC, July 2012

41. U. S. Nuclear Regulatory Commission, NUREG/CR 6303, Method for Performing Diversity and Defense-In-Depth Analyses of Reactor Protection Systems, Washington, DC, December 1994

42. NUREG-0493, "A Defense-In-Depth and Diversity Assessment of the RESAR-414 Integrated Protection System," March 1979

43. NUREG/CR-7007, "Diversity Strategies for Nuclear Power Plant Instrumentation and Control Systems," February 2010

44. Generic Letter (GL) 85-06, "Quality Assurance Guidance for ATWS Equipment That Is Not Safety-Related," January 16, 1985

45. U.S. Code of Federal Regulations, 10 CFR 50 Appendix A, General Design Criteria for Nuclear Power Plants, Washington, DC

46. U. S. Nuclear Regulatory Commission, Regulatory Guide 1.152 Revision 3, Criteria for Use of Computers in Safety Systems of Nuclear Power Plants, Washington, DC, July 2011

47. U. S. Nuclear Regulatory Commission, Regulatory Guide 5.71, Cyber Security Programs for Nuclear Facilities, Washington, DC, January 2010

48. Nuclear Energy Institute (NEI), NEI 08-09 Revision 6, Cyber Security Plan for Nuclear Power Reactors, Washington, DC, April, 2010

49. Information Notice 2010-10, "Implementation of a Digital Control System under 10 CFR 50.59," May 2010

50. Nuclear Energy Institute (NEI), NEI 01-01, A Revision of EPRI TR 102348 to Reflect Changes to the 10 CFR 50.59 Rule, Washington, DC, March 2002

51. Electric Power Research Institute (EPRI), TR 102348 Revision 1, Guideline on Licensing Digital Upgrades, Washington, DC, March 2002

52. U.S. Code of Federal Regulations, 10 CFR Part 50.90, Application for Amendment of License or Construction Permit, U.S. Nuclear Regulatory Commission, Washington DC 
53. U. S. Nuclear Regulatory Commission, Regulatory Issue Summary 2002-22, Use of NEI/EPRI Joint Task Force Report, "Guideline on Licensing Digital Upgrades: EPRI TR 102348, Revision 1, NEI 01-01: A Revision of EPRI TR 102348 to Reflect Changes to the 10 CFR 50.59 Rule", Washington, DC, November 2002

54. U. S. Nuclear Regulatory Commission, Interim Staff Guidance, DI\&C-ISG-06, Licensing Process, Washington, DC, January 2011

55. Nuclear Energy Institute (NEI), NEI 04-10 Rev. 1, Risk-Informed Technical Specification Initiative 5b, Risk-Informed Method for Control of Surveillance

56. U.S. Nuclear Regulatory Commission Safety Evaluation Report on NEI 04-10, Rev 1, September 19, 2007

57. U. S. Nuclear Regulatory Commission, Regulatory Guide 1.175, An Approach for PlantSpecific Risk-Informed Decision-making: In-service Testing, Washington, DC, August 1998

58. 10 CFR Part 52, Licenses, Certifications, and Approvals for Nuclear Power Plants, U.S. Nuclear Regulatory Commission, Washington DC 


\section{Appendix A Common Actuator Failure Modes}

During the performance of Maintenance Procedure I-3-L111 it was found that Level Controller (LC) 87 output failed low. Much of the testing had been completed, but following viper testing of LC-111, the LC87 output failed low. LC-87 was replaced and tested satisfactorily. Cause of the failure was not identified.

While Auxiliary Feedwater (AFW) Level Control Valve, FW-2-LCV-110, was controlling Steam Generator (SG) 2-1 level it failed closed and would not open from the control room or the hot shutdown panel. The cause for the valve closing was the absence of a wire loop assembly which does not allow the bias spring to engage and moves the balance beam to the up position. This blocks the low-pressure orifice and produces hydraulic pressure, which closes the valve.

DURING A REVIEW OF COMPETED WORK ORDER 558077-01 IN WHICH A PIC CABINET POWER SUPPLY ALARM WAS RECEIVED ON THE MCB. OPERATIONS INSPECTED PIC CABINETS AND FOUND THIS CARD WITH THE LED NOT LIT. THIS CARD IS THE CONTROLLER FOR PCV-2150A. THE CONTROLLER CARD (PC-2150A) WAS FOUND FAILED WITH A BLOWN FUSE.

At $\sim 0330$, the Unit NSO noticed a slow increase in Reactor water level on the 2-640-26 recorder. Level went from 30-32" to 32-34" over a 4-5 minute period. NSO reduced master fw controller tape setpoint from $\sim 29.5 "$ to $\sim 29 "$. Rx water level decreased and stabilized at $\sim 30-32 "$. About 0430, NSO noticed another change on the recorder from $\sim 30-32$ " to $28-30$ " on a decreasing trend. At this time went to single element control per QCOP 600-12. Notified Shift Manager.

At approximately 0800 hours on September 8, 2008, FCV-1424, the A Train Motor Driven Auxiliary Feedwater (AFW) Pump discharge flow control valve, did not respond as expected during activities associated with procedure PIC-403, CALIBRATION OF ITT TYPE NH91, NH92 NUCLEAR HYDRAMOTORS. FCV-1424 should have opened during Step 8.1.4 of PIC-403 while maintenance personnel were to be listening for unusual noise at the valve. The valve did not open as expected. Trouble-shooting concluded that a loose connector (P1) on flow controller FIC-1424 prevented proper operation of the valve and that the connector likely had not been latched properly. The loose connector was corrected and FCV-1424 was subsequently tested satisfactorily and returned to operable status.

The 2B Steam Generator Train A main feedwater isolation valve (MFIV) HCV-09-2A spuriously stroked closed. The MFIV closure was a result of corrosion of two relays (3Y/671 or 20X/671) located inside the relay box caused by internal water intrusion in the conduits.

During the performance of Maintenance Procedure I-3-L111 it was found that Level Controller (LC) 87 output failed low. Much of the testing had been completed, but following viper testing of LC-111, the LC87 output failed low. LC-87 was replaced and tested satisfactorily. Cause of the failure was not identified.

hile Auxiliary Feedwater (AFW) Level Control Valve, FW-2-LCV-110, was controlling Steam Generator (SG) 2-1 level it failed closed and would not open from the control room or the hot shutdown panel. The cause for the valve closing was the absence of a wire loop assembly which does not allow the bias spring to engage and moves the balance beam to the up position. This blocks the low-pressure orifice and produces hydraulic pressure, which closes the valve.

DURING A REVIEW OF COMPETED WORK ORDER 558077-01 IN WHICH A PIC CABINET POWER SUPPLY ALARM WAS RECEIVED ON THE MCB. OPERATIONS INSPECTED PIC CABINETS AND FOUND THIS CARD WITH THE LED NOT LIT. THIS CARD IS THE CONTROLLER FOR PCV-2150A. THE CONTROLLER CARD (PC-2150A) WAS FOUND FAILED WITH A BLOWN FUSE.

At $\sim 0330$, the Unit NSO noticed a slow increase in Reactor water level on the 2-640-26 recorder. Level went from 30$32 "$ to $32-34 "$ over a 4-5 minute period. NSO reduced master fw controller tape setpoint from $\sim 29.5 "$ to $\sim 29 "$. Rx 
water level decreased and stabilized at 30-32". About 0430, NSO noticed another change on the recorder from $\sim 30-32 "$ to 28-30" on a decreasing trend. At this time went to single element control per QCOP 600-12. Notified Shift Manager.

At approximately 0800 hours on September 8, 2008, FCV-1424, the A Train Motor Driven Auxiliary Feedwater (AFW) Pump discharge flow control valve, did not respond as expected during activities associated with procedure PIC-403, CALIBRATION OF ITT TYPE NH91, NH92 NUCLEAR HYDRAMOTORS. FCV-1424 should have opened during Step 8.1.4 of PIC-403 while maintenance personnel were to be listening for unusual noise at the valve. The valve did not open as expected. Trouble-shooting concluded that a loose connector (P1) on flow controller FIC-1424 prevented proper operation of the valve and that the connector likely had not been latched properly. The loose connector was corrected and FCV-1424 was subsequently tested satisfactorily and returned to operable status.

The 2B Steam Generator Train A main feedwater isolation valve (MFIV) HCV-09-2A spuriously stroked closed. The MFIV closure was a result of corrosion of two relays (3Y/671 or 20X/671) located inside the relay box caused by internal water intrusion in the conduits. 


\section{Appendix B \\ Example D3 Evaluation \\ SIS Analog to Digital Actuators for NPP}

(Note: This example refers to the fictitious Hawke River Nuclear Plant, which is based on a realistic design and licensing basis for a typical three loop PWR nuclear plant.)

\section{Overview}

The Hawke River Nuclear Power Plant (NPP) is replacing the Safety Injection System (SIS) analog actuators used on the injection valves with digital actuators. The plant chosen is a nonexistant three loop pressurized water reactor. The assumption has been made that the digital actuators are fitted on all of the injection valves. The assumed failure is they do not open when necessary and the time-frame for the high head injection to function is very short and it is also assumed that the low-head is inoperable.

A simple diagram for this modification is shown in Figure D-1. This modification was chosen as an example only to show the degree of difficulty in selecting certain actuators to be replaced with digital products. Other system choices would not provide this degree of diversity and defense-in-depth difficulty leading to the conclusion offered later in this appendix. The digital actuator design and configuration is based on standard digital control products and is intended to be diverse from other digital products installed at Hawke River. For this example, the software used with the digital actuators is not designated as "simple" software, is not totally testable and, as a result, is susceptible to Software Common Cause Failures (SCCFs).

The installation of digital-based actuators as discussed above raises a concern of SCCFs and potentially increases the vulnerability of the protection system to CCFs due to software errors. As stated in NUREG/CR-6303:

Common-mode failures (CMFs) are causally related failures of redundant or separate equipment, for example, (1) CMF of identical subsystems across redundant channels, defeating the purpose of redundancy, or (2) CMF of different subsystems or echelons of defense, defeating the use of diversity. CMF embraces all causal relations, including severe environments, design errors, calibration and maintenance errors, and consequential failures.

The NRC has also stated in Branch Technical Position BTP 7-19 (Reference 3):

... that software design errors are a credible source of common-mode failures. Software cannot be proven to be error-free, and therefore is considered susceptible to common-mode failures because identical copies of the software are present in redundant channels of safety-related systems.

By implementing the Safety Injection System (SIS) actuators with a digital platform; a postulated SCCF of redundant elements within these systems could occur in such a manner that events 
discussed in the Hawke River UFSAR Chapter 15 will not meet the applicable acceptance criteria. This appendix investigates the vulnerability of the proposed Hawke River SIS architecture to postulated SCCFs.

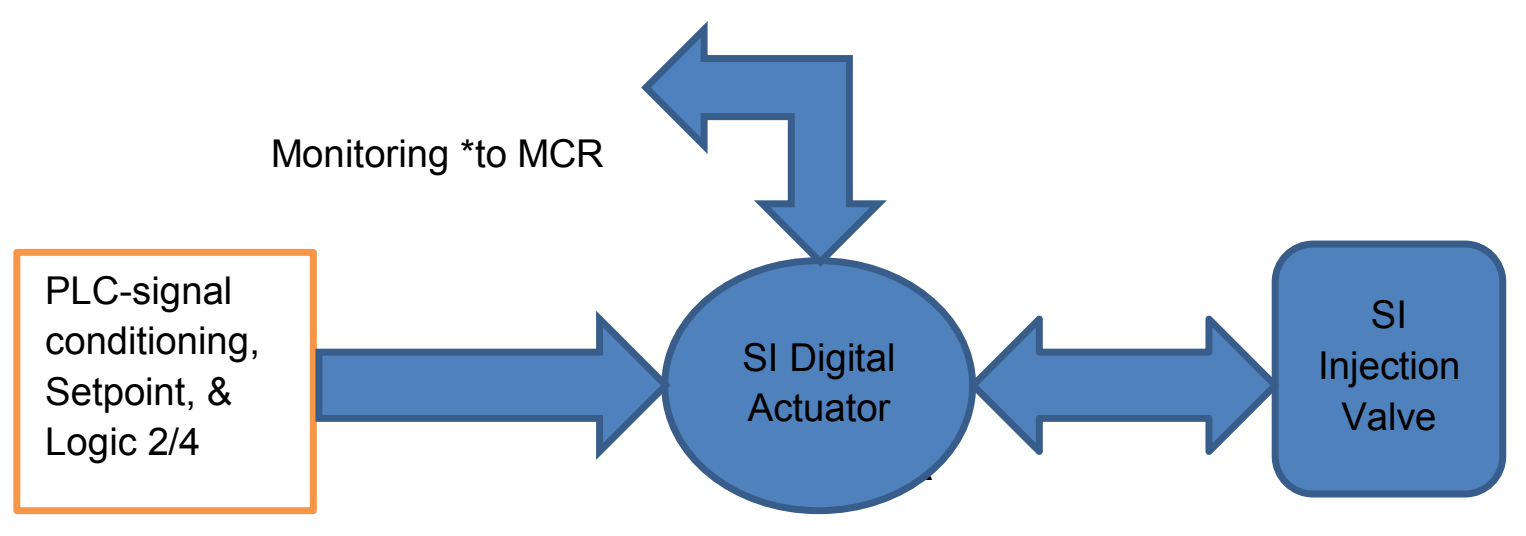

Train A

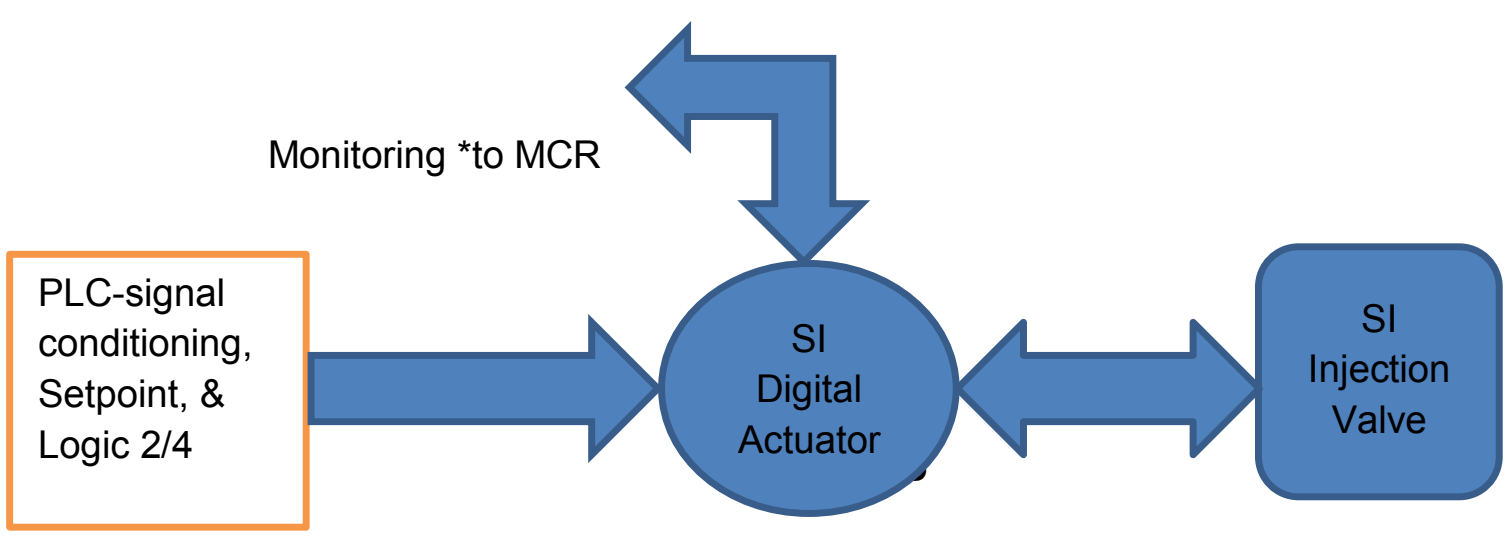

Train B

*Monitoring purpose is for valve position, motor current, temperature, actuator health, voltage, torque, etc.

Figure D-1

\section{Scope}

Diversity is a principle in instrumentation of sensing different variables, using different technology, using different logic or algorithms, or using different actuation means to provide different ways of responding to a postulated event. Types of diversity have been segregated into six areas (NUREG/CR-6303): functional, signal, design, equipment, software, and human. These diversity features are intended to be applied to the different instrumentation and control echelons within the overall I\&C architecture. The digital actuators being used for this upgrade are evaluated for diversity with other digital products installed in the plant. This check is done for 
both safety and non-safety related systems. The diversity evaluation reveals that these digital actuators are diverse from all other digital applications in use at the nuclear plant.

In addition, the actuators are being used in only one echelon, the engineered safety features, so that echelon diversity and interactions are not compromised within the plant.

However, for certain beyond design basis failures, such as a software common cause failure, an evaluation should be performed to demonstrate the ability to safely shutdown the plant using the remaining systems within the echelons of defense. This appendix presents the results of an assessment using this methodology that examines the vulnerability of the digital I\&C replacement project to withstand a postulated SCCF that results in a plant response that does not meet the applicable acceptance criteria. The conclusion section presents the modifications that should be made to the I\&C architecture in order to cope with the postulated digital actuator SCCF.

\section{a. Objectives}

The objective of this D3 assessment is to determine the vulnerability of the Hawke River RPS and ESFAS systems to a postulated actuator SCCF by performing a systematic assessment of the proposed architecture. If design features are identified that are susceptible to SCCFs, either 1) the architecture must be modified to remove the design aspects vulnerable to a digital CCF; 2) compensate for the identified vulnerabilities by implementing a Diverse Actuation System (DAS) that includes diverse Anticipated Transient without SCRAM (ATWS) functions or 3) perform a quantitative analysis to demonstrate the resultant plant response to specific anticipated operational occurrences (AOOs) and design basis accidents (DBAs) analyzed in the Updated Final Safety Analysis Report (UFSAR) meets the applicable acceptance criteria.

\section{b. Regulatory Position}

The NRC has established a methodology and acceptance criteria for D3 evaluations that are to be used when digital based systems are implemented in the RTS and ESFAS at operating nuclear power plants and for new plants. The BTP 7-19 and NUREG/CR-6303 document the methodology and acceptance criteria. As shown in Section 5.3.1 of this report, Points 1, 2, 3, and 4 of BTP 7-19 apply to digital system modifications to operating and new plants.

Conclusions that should be drawn as a result of the D3 evaluation are also listed in this section.

\section{c. Block Selection}

One of the first steps in the D3 evaluation process is the overview of the I\&C architecture and the selection of diverse blocks. By the process of making this selection, the Hawke River I\&C architecture is reviewed for diversity between the digital platforms used in safety and non-safety systems. For this case, the analog actuators of the safety injection system are being replaced by digital actuators with a common software operating system. The design intent is to provide 
digital actuators that are diverse from all other system plant software such that the the selection of the blocks will be a simplified process..

The conservative and best approach for this project (usually for all projects) is to assume that all output functions from the digital actuators are corrupted by a postulated SCCF in the processor and that the actuators can either fail to energize when needed, energize when not needed (spurious actuation) or fail-as-is.

The SIS digital actuators are designated as Block 1since their software is diverse, by design, from all other plant software. The remaining plant systems, both safety and non-safety related, are designated as Block 2. Therefore, Block 1 will be postulated to fail due to the SCCF and Block 2 remains operable to aid in mitigating the event concurrent with the Block 1 failure.

\section{Overview of Hawke River Digital Control System Architecture}

To assist in performing a D3 evaluation, a discussion of the Hawke River I\&C architecture is provided below. The purpose of this description is to gain insight into the four echelons of defense discussed in NUREG-6303. The four echelons of defense are the control systems, the reactor trip system; the engineered safety features actuation systems and the manual and indication systems. Once these placements are made, the postulated software common cause failure (SCCF) will be made to the systems in Block 1 above along with each of the noncoincidental safety analyses events. Credit for safe hot shutdown condition will be given to systems in Block 2 which consists of those systems not affected by the digital actuator SCCF.

Parameters for establishing the echelons and coping systems with the SCCF assumption are varied and discussed in BTP 7-19 as well as NUREG/CR-6303. In this assessment, each of the AOOs and DBAs analyzed in the safety analysis report is examined. If the postulated SCCF could disable a safety function that is required to respond to the event being evaluated, then a diverse means of effective response is necessary. The diverse means may be a safety or nonsafety system, automatic, or manual, if the system is of sufficient quality to perform the necessary function under the associated event conditions or the operator has adequate indications to take manual action within the required time period. In all cases, the digital actuators are only involved in events where the SIS is required as either a primary or back-up system.

\subsection{Control System - Echelon \#1}

The control echelon includes control systems that are responsible for maintaining the plant process variables within the limits assumed in the Hawke River UFSAR Chapter 15 accident analyses. The main function of these non-safety control systems is to actuate the automatic control and monitoring task when the power plant is in normal operation. Additionally, the nonsafety control and monitoring systems also actuates the control and monitoring equipment after an accident to aid in bringing the plant to a safe shutdown condition (hot shutdown and an 
eventual cold shutdown condition). For the D3 evaluation, non-safety control and monitoring systems are normally credited to aid in bringing the plant to a hot shutdown condition.

The non-safety systems placed in Block 2 and available for diverse control functions include the following functions:

1. Pressurizer Pressure Control-Heaters and Sprays

2. Steam Generator Water Level Control (FWCS)

3. Turbine Control

4. Information Display and Control (Echelon 4)

5. Pressurizer Power Operated Relief Valves

6. Main Steam Atmospheric Relief Valves

7. Steam Dump-Condenser

8. Full Length Rod Control System

a. Rod Position Measurement and Indication

b. Rod Control

9. Control Rod Drive Mechanism (non-DCS scope)

10. Pressurizer Level Control Component Cooling Water (part)

11. Essential Service Water

12. Heating Ventilation and Control

13. Chemical and Volume Control System

14. Safety Injection System (part)

15. Residual Heat Removal (part)

16. Pressurizer Level Control

Generally, the operator conducts monitoring and control on the system by the computer information and control system of the Hawke River power plant. When the computer information and control system is not available, the operator will monitor functions on the main control panel and can realize safety trip and safety system actuations by using system level manual controls. These manual controls are diverse and independent from the SI digital actuator software. However, a system level manual actuation for SIS will not go to completion due to the digital valve actuator SCCF. Manual control at a local location is available.

The important point to note regarding the control network is that it is diverse from the safety software used within the digital actuators and, as a result, credit can be given for its continued operation given a SCCF to the SI digital actuators

\subsection{Reactor Trip System - Echelon \#2}

The Hawke River UFSAR describes the automatic reactor trip functions including the manual actuation function associated with the RTS. The RTS is Echelon 2 for this D3 assessment and is placed into Block 2 because the processing and logic software is diverse from the digital actuator software.

The automatic trip functions are as follows: 
1. Power Range High Neutron Flux

2. Intermediate Range High Neutron Flux

3. Source Range High Neutron Flux

4. Power Range High Positive Nuclear Power Rate

5. Power Range High Negative Nuclear Power Rate

6. Overtemperature $\Delta \mathrm{T}$

7. Overpower $\Delta T$

8. Pressurizer Low Pressure

9. Pressurizer High Pressure

10. Pressurizer High Water Level

11. Reactor Coolant Loop Low Flow

12. Reactor Coolant Pump Circuit Breaker Open

13. Reactor Coolant Pump low-low revolution

14. Containment Spray and Containment Phase B Isolation Signal

15. Low-Low Steam Generator Water Level

16. High-High Steam Generator Water Level

17. Steam/Flow Mismatch

18. Turbine Trip Signal

19. Safety Injection Signal

All of the automatic trip functions noted above are operable given the postulated SCCF to Block 1 as the RPS logic software is diverse from the digital actuator software .The manual trip function remains operable even with the postulated SCCF and, as a result is also placed in Block 2.

\subsection{ESFAS - Echelon \#3}

ESFAS is Echelon 3 as discussed in the D3 guidance. The Hawke River UFSAR describes the ESFAS and its vital support systems as follows:

1. Safety Injection System

2. Turbine Trip

3. Feedwater Line Isolation

4. Steam Line Isolation

5. Auxiliary Feedwater System Actuation

6. Containment Spray

7. Containment Isolation (Stage A and B)

8. Containment Fan Coolers Start

9. Emergency Diesel Generator Start

10. Control Room AC System

11. Containment Atmosphere Monitoring System

12. Component Cooling Water Actuation

13. Pressurizer Safety Valves (passive)

14. Main Steam Safety Valves (passive)

These ESF echelon functions include those protection functions that actuate the ESF that assist in maintaining the integrity of the fission-product barriers (cladding, reactor coolant system boundary, and containment boundary). The SIS actuation signals (and the corresponding process instrument variable inputs) are as follows: 
1. Safety injection System

a. Manual

b. Containment high pressure 2

c. High pressure difference among steam lines

d. The steam flow in two lines conforms to the one of the following conditions (bypass allowed if reactor coolant average temperature $<284{ }^{\circ} \mathrm{C}$ ):

- $2 / 3$ steam line low pressure

- $2 / 3$ reactor coolant low-low average temperature

e. Pressurizer low pressure 4 (bypass allowed if reactor coolant pressure is lower than 2000 psi relative pressure)

The SIS digital actuators within the ESFAS echelon will not function properly due to the postulated SCCF. Therefore, this function is placed in Block 1 with the remaining ESFAS functions placed in Block 2.

The following systems are ESFAS support systems and are placed into Block 2:

1. Component Cooling Water System

2. Essential Service Water Supply System (heat removal)

3. Electrical Power Distribution Systems (part)

4. Essential HVAC Systems (safety related)

While not classified as ESFAS the following systems are safety shutdown systems or other necessary systems which are also part of Echelon \#3 and are placed into Block 2. These functions are as follows:

1. Chemical and Volume Control

2. Residual Heat Removal

3. Auxiliary Feedwater with Offsite Power Loss

4. Emergency Diesel Generator Unit

5. Component Cooling Water

6. Service Water (Safety)

From this echelon, the SIS injection function is assumed to fail due to the SCCF to the digital actuators for the injection valves. It is noted that this failure will prevent both automatic and manual operation of the SIS. However, it should be noted that the operator is able to manully close the valves at the local control center for each valve. It is acknowledged that this manual time would be longer than required for system level manual actuation but can be credited if adequate time is available for a postulated event.

\subsection{Manual and Indication - Echelon \#4}

A set of Echelon 2 and 3 system level manual actuations are available and can be credited for acceptable operation given a postulated SCCF to the SI digital actuators. These manual actuations are listed in the above sections and are placed in Block 2 with the exception of SI 
manual actuation. These safety manual actuations while listed in Echelon 2 and 3 above actually comprise part of Echelon 4. In the Hawke River I\&C design, the manual initiation of the reactor trip (Echelon 2) is performed by the scram switches and system level manual initiations. ESFAS (Echelon 3) system and component level manual actuations are performed by manual switch controls.

\subsection{ATWS System (Diverse Actuation System)}

The ATWS condition is the anticipated transient under which the safety rods fail to insert into the core to realize the trip as a result of an unknown common cause failure to the RTS. The ATWS system provides the diverse means to cope with the ATWS transient and provides the necessary mitigation. The SIS digital actuators are not in any ATWS system signal path. The ATWS system is placed in Block 2 and, therefore, its successful operation can be credited in this D3 evaluation.

The ATWS system monitors the main feed water flow to the steam generators, and actuates the auxiliary feedwater system, trips the reactor and provides a turbine trip as well as operating certain steam valves. This actuation signal is provided when the main feed water flow is lower than the set value and the reactor operates at a power level above a set intermediate range level. If the breaker and mechanical parts of the reactor trip system are in an operable condition, the trip will occur as a result of the turbine trip and as a result of the ATWS trip signal to the power control cabinet for the Rod Control System. Regardless, the diverse actuation of the AFW system will aid in bringing the Hawke River plant to a safe shutdown as proven in the generic ATWS analysis.

\section{Diversity Evaluation of the Proposed RPS}

If a postulated SCCF can disable a safety function, BTP 7-19 of the Standard Review Plan Point 3 requires a diverse means of actuation, not subject to the same CCF to perform the same function or an equivalent diverse function. Credit may be taken for any diverse system that performs the safety function or operator action; however, sufficient time must be available for the operator to diagnose the event and initiate action to protect the safety function.

Section 3.5 of BTP 7-19 states in part if manual operator actions are used as the diverse means or as part of the diverse means to accomplish a safety function, a suitable HFE analysis should be performed by the applicant to demonstrate that plant conditions can be maintained within recommended acceptance criteria for the particular AOO or postulated accident. The acceptability of such actions is to be reviewed by the NRC staff in accordance with Appendix 18-A of SRP Chapter 18, "Crediting Manual Operator Actions in Diversity and Defense-in-Depth (D3) Analyses."

"Note: As the difference between Time Available and Time Required for operator action is a measure of the safety margin and as it decreases, uncertainty in the estimate of the difference between these times should be appropriately considered. This uncertainty could reduce the level of assurance and potentially invalidate a conclusion that operators can perform the action reliably within the time available. For complex situations and for 
actions with limited margin, such as less than 30 minutes between time available and time required, a more focused staff review will be performed."

For those events that rely on the subject digital actuator for both primary and backup mitigation (i.e., required manual action by the operator), independent and diverse automation should be provided that is not subject to the postulated CCF.

For the following evaluation of the Hawke River UFSAR events, the acceptance criteria are specified by BTP 7-19:

- For realistic assumption analysis of anticipated operational occurrences (ANS Condition II and III events), the resultant dose must be maintained within 10 percent of the 10 CFR 100 limits and violation of the primary coolant pressure boundary is precluded.

- For realistic assumption analysis of postulated accidents (ANS Condition IV events), the 10 CFR 100 limits must not be exceeded, the primary coolant pressure boundary cannot be violated and the containment integrity (exceeding containment design limits) cannot be violated.

For events that are determined not to require protective action (either automatic or manual) or for events that are bounded by other events, direct comparison to the acceptance criteria is not required. However, for the events that require a realistic assumption analysis to be performed, specific criteria must be developed to demonstrate that requirements of BTP 7-19, above, are met. Therefore, the following criteria are proposed:

ANS Condition II events

- Reactor Coolant System Overpressure: The primary reactor coolant system must not exceed a pressure of 2750 psia, consistent with the UFSAR Section 15.8 ATWS analysis.

- Radiological Dose: Demonstration that fuel failure is precluded through the application of a minimum Departure from Nucleate Boiling ratio (mDNBR) criterion ensures that the primary reactor coolant system activity is maintained within the technical specification limits and subsequently ensures that the limit of 10 percent of the 10 CFR 100 limits are not exceeded.

- $\quad$ The mDNBR must be maintained above the correlation limit value associated with the fuel product implemented in the Hawke River plant and should be consistent with the criteria applied to the UFSAR 15.8 ATWS analysis.

ANS Condition III events

- Reactor Coolant System Overpressure: The primary reactor coolant system must not exceed a pressure of 2750 psia, consistent with the UFSAR Section 15.8 ATWS analysis. 
- Radiological Dose: Demonstration that the fuel failure rate associated with the supporting dose analysis is not exceeded based on best estimate analysis ensures that the radiological consequences of the current licensing basis are not exceeded and subsequently ensures that $10 \%$ of the 10 CFR 100 limits are not exceeded. The fuel failure rate may be calculated based on the results of a DNB calculation during the realistic assumption analysis process assuming that each pin that experiences DNB fails. For Chapter 15 ANS Condition III events in which the licensing basis analysis does not result in fuel failure, the mDNBR must be maintained above the correlation limit value associated with the fuel product implemented in the Hawke River plant (consistent with the criteria applied to the UFSAR ATWS analysis). Additionally, for events where the dose analysis is dependent on a mass release (e.g., steam generator tube rupture), the results of any supporting realistic assumption analysis should demonstrate that the mass release is bounded by the value used as input to the UFSAR dose analysis.

\section{ANS Condition IV events}

- Reactor Coolant System Overpressure: The primary reactor coolant system must not exceed a pressure of 2750 psia, consistent with the UFSAR Section 15.8 ATWS analysis.

- Radiological Dose: Demonstration that the fuel failure rate associated with the supporting dose analysis is not exceeded based on best estimate analysis ensures that the radiological consequences of the current licensing basis are not exceeded and subsequently ensures that the 10 CFR 100 limits are not exceeded. The fuel failure rate may be calculated based on the results of a DNB calculation during the realistic assumption analysis process assuming that each pin that experiences DNB fails. For Chapter 15 ANS Condition IV events in which the licensing basis analysis does not result in fuel failure, the mDNBR must be maintained above the correlation limit value associated with the fuel product implemented in the Hawke River plant (consistent with the criteria applied to the UFSAR ATWS analysis). Additionally, for events where the dose analysis is dependent on a mass release (e.g., steam generator tube rupture), the results of any supporting realistic assumption analysis should demonstrate that the mass release is bounded by the value used as input to the UFSAR dose analysis.

\section{$5 \quad$ UFSAR Chapter 15 Accidents and Events}

The purpose of the following discussion is to demonstrate that in the unlikely event of a SCCF of the proposed digital actuators designated as Block 1, coincident with initiating events analyzed as part of the Hawke River NPP Units 1 and 2 licensing basis, sufficient diverse means (Block 2) for mitigating the event are available to bring the reactor to a safe shutdown condition.

The diversity of the proposed RPS I\&C architecture together with existing diverse protection functions, should ensure that all UFSAR Chapter 15 analysis acceptance criteria continue to be met in the event of credible SIS digital actuator SCCF or design changes should be made. In 
most cases, if an accident were to occur, the plant initial conditions would be less severe than those analyzed for the UFSAR.

Primary and backup protection system signals are provided for most of the events comprising the Hawke River licensing basis. For the purpose of this discussion, a primary protection signal is one upon which the protection function occurs in the licensing basis analysis. Backup protection signals are those expected to occur if the primary signal did not occur.

The Table below identifies the primary and backup mitigating functions where SIS is credited for mitigation in some manner for each initiating event that is analyzed in Chapter 15 . These events represent the full set of events that need to be considered in assessing the impact of the digital actuator modification on the accidents and transients of UFSAR Chapter 15. It should be noted that in accordance with relevant guidance, coincident events are not part of the D3 evaluations due to the low probability of their occurrence at the same time coupled with the postulated SCCF. 


\section{Table 1 Chapter 15 Events and SIS Protection Action Table}

\begin{tabular}{|c|c|c|c|}
\hline $\begin{array}{l}\text { Evaluation } \\
\text { Subsection }\end{array}$ & ANS Condition 2,3,4 Events & $\begin{array}{c}\text { Protection and Safeguards } \\
\text { Action }\end{array}$ & Signals \\
\hline & UFSAR 15.1 Increase in heat rem & val by the secondary system & \\
\hline \multirow{5}{*}{5.1} & \multirow{5}{*}{$\begin{array}{l}\text { Feedwater system malfunction } \\
\text { causing an increase in feedwater } \\
\text { flow (Cond. II) }\end{array}$} & Safety injection & Lo-Lo pressurizer pressure \\
\hline & & \multirow{2}{*}{ Containment Isolation } & Hi-Hi steam generator level \\
\hline & & & SI (Lo-lo pressurizer level) \\
\hline & & \multirow{2}{*}{ AFW Start-up } & Hi-Hi steam generator level \\
\hline & & & SI (Lo-lo pressurizer level) \\
\hline \multirow{4}{*}{5.2} & \multirow{4}{*}{$\begin{array}{l}\text { Accidental main steam system } \\
\text { depressurization }\end{array}$} & Safety injection & Lo-Lo pressurizer pressure \\
\hline & & Containment isolation & SI (Lo-Lo pressurizer pressure) \\
\hline & & AFW start-up & SI (Lo-Lo pressurizer pressure) \\
\hline & & Steam lines isolation & Lo-Lo steam generator pressure \\
\hline \multirow{6}{*}{5.3} & \multirow{6}{*}{$\begin{array}{l}\text { Steam system piping failure (Cond. } \\
\text { IV for large breaks - Cond. III for } \\
\text { small breaks) }\end{array}$} & \multirow{3}{*}{ Safety injection } & $\begin{array}{l}\text { Low compensated steam pressure } \\
\text { and high steam flow }\end{array}$ \\
\hline & & & Lo-Lo pressurizer pressure \\
\hline & & & High containment pressure (MAX2) \\
\hline & & \multirow{3}{*}{ Containment isolation } & $\begin{array}{l}\text { SI (Low compensated steam } \\
\text { pressure + high steam flow) }\end{array}$ \\
\hline & & & SI (Lo-Lo pressurizer pressure) \\
\hline & & & $\begin{array}{l}\text { SI (high containment pressure } \\
(\mathrm{MAX} 2)\end{array}$ \\
\hline
\end{tabular}




\begin{tabular}{|c|c|c|c|}
\hline $\begin{array}{l}\text { Evaluation } \\
\text { Subsection }\end{array}$ & ANS Condition 2,3,4 Events & $\begin{array}{c}\text { Protection and Safeguards } \\
\text { Action }\end{array}$ & Signals \\
\hline & & & $\begin{array}{l}\text { SI (Low compensated steam } \\
\text { pressure + high steam flow) }\end{array}$ \\
\hline & & AFW start-up & SI (Lo-Lo pressurizer pressure) \\
\hline & & & $\begin{array}{l}\text { SI(High containment pressure } \\
(\text { MAX2) }\end{array}$ \\
\hline & & Steam line isolation & $\begin{array}{l}\text { Low compensated steam pressure }+ \\
\text { high steam flow }\end{array}$ \\
\hline & & & Lo-Lo steam generator pressure \\
\hline & & & High containment pressure (MAX3) \\
\hline & & Containment spray & High containment pressure (MAX4) \\
\hline & UFSAR 15.2 Decrease in hea & oval by the secondary system & \\
\hline \multirow{8}{*}{5.4} & \multirow{8}{*}{$\begin{array}{l}\text { Feedwater system pipe breaks } \\
\text { (Cond. IV) }\end{array}$} & \multirow{3}{*}{ Reactor trip } & $\begin{array}{l}\text { SI (low compensated steam } \\
\text { pressure + high steam flow) }\end{array}$ \\
\hline & & & $\begin{array}{l}\text { Low steam generator level }+ \\
\text { steam/feedwater flow mismatch }\end{array}$ \\
\hline & & & Lo-lo steam generator level \\
\hline & & \multirow{2}{*}{ Safety injection } & $\begin{array}{l}\text { Low compensated steam pressure }+ \\
\text { high steam flow }\end{array}$ \\
\hline & & & $\begin{array}{l}\text { High steam lines differential } \\
\text { pressure }\end{array}$ \\
\hline & & \multirow{3}{*}{ Motor driven AFW pumps } & $\begin{array}{l}\text { SI (low compensated steam } \\
\text { pressure }+ \text { high steam flow) }\end{array}$ \\
\hline & & & $\begin{array}{l}\text { SI (high steam lines differential } \\
\text { pressure) }\end{array}$ \\
\hline & & & $\begin{array}{l}\text { Lo-lo steam generator level + low } \\
\text { feedwater flow }\end{array}$ \\
\hline
\end{tabular}




\begin{tabular}{|c|c|c|c|}
\hline $\begin{array}{l}\text { Evaluation } \\
\text { Subsection }\end{array}$ & ANS Condition 2,3,4 Events & $\begin{array}{c}\text { Protection and Safeguards } \\
\text { Action }\end{array}$ & Signals \\
\hline & & T urhing drivon A ГTL numn & $\begin{array}{l}\text { Lo-lo steam generator level + low } \\
\text { feedwater flow }\end{array}$ \\
\hline & & IUrbIne ariven AFV pumps & $\begin{array}{l}\text { Lo-lo steam generator level } \\
\text { (delayed) }\end{array}$ \\
\hline & & Steam line isolation & $\begin{array}{l}\text { Low compensated steam pressure }+ \\
\text { high steam flow }\end{array}$ \\
\hline & & & Low-low steam generator pressure \\
\hline & UFSAR 15.5 Increase in reactor cc & olant inventory & \\
\hline & Inadvertent oneration of safety & & Low pressurizer pressure $+\mathrm{P} 7$ \\
\hline 5.5 & injection during power operation & Reactor trip & High pressurizer pressure \\
\hline & (Cond. II) & & High Pressurizer level + P7 \\
\hline & UFSAR 15.6 Decrease in reactor c & olant inventory & \\
\hline \multirow{9}{*}{5.6} & \multirow{9}{*}{$\begin{array}{l}\text { Inadvertent opening of a pressurizer } \\
\text { power operated relief or safety valve } \\
\text { (Cond. II) }\end{array}$} & \multirow{3}{*}{ Reactor trip } & Low pressurizer pressure $+\mathrm{P} 7$ \\
\hline & & & Overtemperature $\Delta T$ \\
\hline & & & SI (Lo-lo pressurizer pressure) \\
\hline & & \multirow{2}{*}{ Safety injection } & Lo-lo pressurizer pressure \\
\hline & & & High containment pressure (MAX2) \\
\hline & & \multirow[b]{2}{*}{ Containment isolation } & SI (lo-lo pressurizer pressure) \\
\hline & & & $\begin{array}{l}\text { SI (high containment } \\
\text { pressure(MAX2) }\end{array}$ \\
\hline & & \multirow[b]{2}{*}{ AFW start-up (Motor) } & SI (lo-lo pressurizer pressure) \\
\hline & & & $\begin{array}{l}\text { SI(High containment pressure } \\
\text { (MAX2) }\end{array}$ \\
\hline
\end{tabular}




\begin{tabular}{|c|c|c|c|}
\hline $\begin{array}{l}\text { Evaluation } \\
\text { Subsection }\end{array}$ & ANS Condition 2,3,4 Events & $\begin{array}{c}\text { Protection and Safeguards } \\
\text { Action }\end{array}$ & Signals \\
\hline \multirow{5}{*}{5.7} & \multirow{5}{*}{$\begin{array}{l}\text { Failure of small lines carrying } \\
\text { primary coolant outside of } \\
\text { containment (Cond. III) }\end{array}$} & \multirow{2}{*}{ Reactor trip } & Low pressurizer pressure + P7 \\
\hline & & & SI (lo-lo pressurizer pressure) \\
\hline & & Safety injection & Lo-lo pressurizer pressure \\
\hline & & Containment isolation & SI (lo-lo pressurizer pressure) \\
\hline & & AFW start-up (Motor) & SI (lo-lo pressurizer pressure) \\
\hline \multirow{9}{*}{5.8} & \multirow{9}{*}{$\begin{array}{l}\text { Steam generator tube rupture (Cond. } \\
\text { III) }\end{array}$} & \multirow{3}{*}{ Reactor trip } & Low pressurizer pressure $+\mathrm{P} 7$ \\
\hline & & & Hi-hi steam generator level + P7 \\
\hline & & & SI (lo-lo pressurizer pressure) \\
\hline & & Safety injection & Lo-lo pressurizer pressure \\
\hline & & \multirow{2}{*}{ Containment isolation } & SI (lo-lo pressurizer pressure) \\
\hline & & & Hi-hi steam generator level \\
\hline & & \multirow{2}{*}{ Motor driven AFW pumps } & SI (lo-lo pressurizer pressure) \\
\hline & & & Hi-hi steam generator level \\
\hline & & Turbine driven AFW pumps & $\begin{array}{l}\text { Lo-lo coolant pump speed in case of } \\
\text { LOOP }\end{array}$ \\
\hline \multirow{8}{*}{5.9} & \multirow{8}{*}{$\begin{array}{l}\text { Steam generator tube rupture with a } \\
\text { safety valve stuck open (Cond. IV) }\end{array}$} & \multirow[t]{3}{*}{ Reactor trip } & Low pressurizer pressure + P7 \\
\hline & & & Hi-hi steam generator level + P7 \\
\hline & & & SI (lo-lo pressurizer pressure) \\
\hline & & Safety injection & Lo-lo pressurizer pressure \\
\hline & & \multirow[t]{2}{*}{ Containment isolation } & SI (lo-lo pressurizer pressure) \\
\hline & & & Hi-high steam generator level \\
\hline & & \multirow[t]{2}{*}{ Motor driven AFW pumps } & SI (Lo-lo pressurizer level) \\
\hline & & & Hi-hi steam generator level \\
\hline
\end{tabular}




\begin{tabular}{|c|c|c|c|}
\hline $\begin{array}{l}\text { Evaluation } \\
\text { Subsection }\end{array}$ & ANS Condition 2,3,4 Events & $\begin{array}{c}\text { Protection and Safeguards } \\
\text { Action }\end{array}$ & Signals \\
\hline & & Turbine driven AFW pumps & Lo-lo coolant pump speed + P7 \\
\hline \multirow{10}{*}{5.10} & \multirow{10}{*}{$\begin{array}{l}\text { Loss of coolant accident (Cond. IV } \\
\text { for large breaks and intermediate } \\
\text { breaks - Cond. III for small breaks) }\end{array}$} & \multirow[t]{3}{*}{ Reactor trip } & Low pressurizer pressure $+\mathrm{P} 7$ \\
\hline & & & $\begin{array}{l}\text { SI (high containment pressure } \\
(\mathrm{MAX} 2))\end{array}$ \\
\hline & & & SI (Lo-lo pressurizer pressure) \\
\hline & & \multirow[t]{2}{*}{ Safety injection } & High containment pressure (MAX2) \\
\hline & & & Lo-lo pressurizer pressure \\
\hline & & \multirow[t]{2}{*}{ Containment isolation } & $\begin{array}{l}\text { SI (high containment pressure } \\
(\text { MAX2)) }\end{array}$ \\
\hline & & & SI (Lo-lo pressurizer pressure) \\
\hline & & \multirow[t]{2}{*}{ AFW start-up } & $\begin{array}{l}\text { SI (high containment pressure } \\
(\mathrm{MAX} 2))\end{array}$ \\
\hline & & & SI (Lo-lo pressurizer pressure) \\
\hline & & Containment spray & High containment pressure (MAX4) \\
\hline
\end{tabular}




\subsection{Feedwater System Malfunction Causing an Increase in Feedwater Flow (ANS Condition II)}

\section{Realistic assumption Scenario}

Addition of excessive feedwater will result in a decrease in the primary reactor coolant temperature and cause a subsequent increase in core power similar to the Feedwater Temperature Decrease event (UFSAR 15.1.1). Such transients are attenuated by the thermal capacity of the secondary plant and of the reactor coolant system. Overpower (high neutron flux, Overtemperature $\Delta \mathrm{T}$ and Overpower $\Delta \mathrm{T}$ trips) and low pressurizer pressure protection (low pressurizer pressure) prevent any power increase which could lead to a departure from nucleate boiling ratio (DNBR) less than the design limit. Continuous addition of excessive feedwater is prevented by the steam generator hi-hi level trip coincident with the P7 interlock. When the steam generator water levels in the affected loops reach the hi-hi level setpoint, ESFAS actuation results in the automatic closure of the main feedwater isolation valves. The feedwater pump and discharge valves are also closed and the main feedwater pumps are tripped. This prevents continuous addition of the feedwater.

An example of excessive feedwater flow would be the full opening of a feedwater control valve due to a feedwater control system malfunction or an operator error. At power this excess flow causes a greater load demand on the reactor coolant system due to increased subcooling in the steam generator. With the plant at no-load conditions, the addition of cold feedwater may cause a decrease in reactor coolant system temperature and thus a reactivity insertion due to the effects of the negative MTC.

Normal reactor control systems may be credited for functioning and single active failures are not assumed as part of the SCCF analysis. Also, the assumption that the highest-worth Rod Control Assembly (RCA) is stuck out coincident with the reactor trip does not have to be made.

\section{Impact of the SCCF}

The Safety Injection System is not required for this event and, as a result, the subject digital actuator is not part of the mitigation path.

\subsection{Accidental Main Steam Depressurization (ANS Condition II)}

Note that the evaluation of this event is for the zero power condition. The UFSAR provides the appropriate justification to demonstrate that the at power condition is bounded by the analysis of the Excess Load Increase event documented in the UFSAR.

\section{Realistic assumption Scenario}

This event is defined as an inadvertent opening of a single turbine bypass valve, atmospheric steam dump valve or main steam safety valve (MSSV). This accident results in an initial increase in steam flow, which results in an increase in the heat extraction rate and a 
consequential reduction in primary system temperature and pressure. In the presence of a negative MTC, the primary system cooldown results in an insertion of positive reactivity and subsequent decrease in shutdown margin. Since the initial steam generator water inventory is greatest at no-load, the magnitude and duration of the reactor coolant system cooldown may be less for steam line release occurring at a just-critical or low power core condition. Additionally, the steam flow is assumed to decrease during the accident as the steam pressure decreases.

Because the UFSAR event is initiated from the zero power condition, only ESFAS functions are available to limit the consequence of the main steamline depressurization event by actuation of the safety injection system, main feedwater isolation and main steamline isolation. Additionally, the shutdown banks are assumed to be fully inserted in the core in an $\mathrm{N}-1$ configuration (most reactive rod is stuck in the fully withdrawn position) and the passive accumulators would be available. Therefore the reactor is assumed to be in the tripped state and the reactor trip system is not credited for actuation during the event. Additionally, a single active failure in the ESFAS of one train of the Safety Injection system is assumed.

For the realistic assumption scenario considered here-in, neither the stuck rod nor the single failure assumptions are required to support the SCCF evaluation. In addition, safety injection flow rates and boron concentration levels based on realistic assumption plant data may be assumed. The additional energy stored by various metal structures in the reactor may also be credited to attenuate the primary reactor coolant system cooldown.

At the zero power condition, protection against an accidental depressurization of the Main Steam System may be provided by safety injection system actuation, main feedwater isolation and main steamline isolation. Therefore, the operators may have to manually align by using local control the safety injection valves impacted by the actuator SCCF or wait for the RCS pressure to decrease to the passive accumulator injection setpoint.

For an accidental depressurization of the main steam system the DNB design limits are not exceeded. The radiological consequences of this event are not limiting in comparison to the steam line break event.

\section{Impact of Postulated SCCF}

A review of the results of the safety analysis presented in the UFSAR indicates that the reactor is not maintained below a critical condition throughout the event. However, the analysis credits automatic safety injection actuation on lo-lo pressurizer pressure at 170 seconds (2.8 minutes), which delivers boron to the core and limits the reactivity transient. Based on the use of a realistic assumption modeling approach to address the SCCF, the elimination of the stuck rod assumption may provide sufficient margin to prevent a return to critical condition without the need to rely on boron delivery through actuation of the safety injection system. Further, the severity of the inadvertent opening of a MSSV is bounded by the results for MSLB. A realistic assumption quantitative safety analysis approach could demonstrate that acceptable results are attained without a need for safety injection. 


\subsection{Steam System Piping Failure (ANS Condition IV)}

\section{Realistic assumption Scenario}

The main steam system piping failure is the consequence of a rupture of a main steam line; the most conservative assumption is the double ended guillotine break that leads to the greatest cooldown. The steam release arising from a rupture of a main steam line results in an initial increase in steam flow, which decreases during the accident as the steam pressure decreases and the steam generator coolant inventory is depleted. This results in an increase in the primary-to-secondary heat transfer rate and a consequential reduction in primary reactor coolant system temperature and pressure. In the presence of a negative MTC, the cooldown results in an insertion of positive reactivity. Initiated from an at-power condition, a steamline rupture will result in an increase in core power due to the positive reactivity insertion. The power increase will continue until either an equilibrium condition is reached or a reactor trip occurs. The UFSAR Section 15.1 .5 analysis assumes that the most reactive Rod Control Assembly (RCA) is stuck in its fully withdrawn position after reactor trip, which reduces the scram reactivity worth and increases the possibility of a post-trip return-to-power. Ultimately, the analysis demonstrates that the event is terminated by the delivery of boric acid through safety injection actuation.

If the reactor were at hot zero power conditions at the time of the break, a continued cooldown would normally result in safety injection actuation. In the presence of a negative moderator temperature coefficient, the cooldown results in a reduction of core shutdown margin due to a positive reactivity insertion from the negative MTC. The cooldown is attenuated by feedwater isolation initiated through automatic or manual means by the operator. An automatic steamline isolation signal will either terminate the cooldown, if the break occurs downstream of the main steamline isolation valve (MSIV), or limit the blowdown to one steam generator if the break is between the steam generator and the MSIV. In the event that the break occurs between the steamline exit nozzle and the MSIV, the steam release will eventually be terminated due to the equalization of the pressure in the faulted steam generator and containment or due to the depletion of the coolant inventory in the faulted steam generator.

The RTS and ESFAS both function to limit the consequences of a steamline rupture event by actuation of reactor and turbine trips, the safety injection system, feedwater isolation and steamline isolation. Additionally, the passive accumulators provide the capability to add coolant inventory and boron to the reactor coolant system in the event that steamline rupture results in a large cooldown and depressurization of the reactor coolant system. With respect to the realistic assumption evaluation, the conservative safety analysis assumptions such as a stuck RCA, conservative reactivity feedback effects, the worst single failure or minimum safety injection pump performance do not have to be considered to address the postulated SCCF. This lessens the concern of achieving an over power condition at full power or a return to power from a zero power condition. 
With the postulated SCCF, the guidance of BTP 7-19 allows for the normal operation of control systems. The feedwater control system may be assumed to be aligned for proper operation and to be available for Steam Generator level control. Additionally the pressurizer pressure control system (heaters and spray) is credited to reduce the rate of depressurization. Overall, the combined response of the feedwater and pressurizer pressure control systems improves the margin to fuel damage (DNBR) should a return to power be predicted.

\section{Impact of Postulated SCCF}

Since the zero power case is initiated from a post-trip condition there is no impact of the SCCF on RTS actuations. However, safety injection, either automatic or manual, cannot be credited. Additionally, neither the assumption of a stuck rod nor the conservatism built into the reactivity feedback parameters have to be considered given the realistic assumption nature of this evaluation. This lessens the concern of a post-trip return to power following a steam line rupture. This additional negative reactivity will offset the positive reactivity inserted by the primary system cooldown so that a return to power after a reactor trip is reduced and high local power density near the stuck rod is removed. As such, the DNB margin would be greater than the UFSAR case.

For the steamline rupture initiated from the full power condition, the postulated SCCF will cause the SIS injection valves to fail. Like the zero power case, the realistic assumption quantitative safety analysis evaluation can credit the conservatism built into the reactivity feedback parameters, which may help reduce the magnitude of the resultant overpower condition.

\subsection{Feedwater System Pipe Break (ANS Condition IV)}

\section{Realistic assumption Scenario}

A major feedwater system pipe break is defined as a break in a feedwater line large enough to prevent the addition of sufficient feedwater to the affected steam generator to maintain shell side fluid inventory. If the break is postulated in a feedwater line between the check valve and the steam generator, fluid from the steam generator may also be discharged through the break. Further, a break in this location could preclude the subsequent addition of auxiliary feedwater to the affected steam generator. The resulting depressurization induces a reversal of steam flow from the two unaffected steam generators to the failed one. A fraction of the auxiliary feedwater spills through the break until the auxiliary feedwater system line to the affected steam generator is isolated. (A break upstream of the feedwater line check valve would affect the Nuclear Steam Supply System only as a loss of feedwater to a single steam generator.) Depending upon the size of the break and the plant operating conditions at the time of the break, the break could cause either a reactor coolant system cooldown (by excessive energy discharge through the break) or a reactor coolant system heatup. The maximum potential reactor coolant system cooldown resulting from feedwater line break is bounded by the secondary pipe rupture and is evaluated in the UFSAR, steam system piping failure. Therefore, as safety injection would not be actuated or required to mitigate the postulated heat-up event, no further evaluation is considered herein. 


\subsection{Inadvertent Operation of the Safety Injection System (ANS Condition II)}

An Inadvertent Safety Injection event results in an unplanned or unneeded addition RCS inventory through operation of the safety injection system. This event is currently discussed in the UFSAR and is an ANS Condition II event. The application of digital actuators to the Safety Injection system will not result in a change to the consequences of the event presented therein, as it assumes a worst case scenario with respect to the RCS inventory increase. Additional studies associated with the reliability of the proposed digital actuators would have to be performed to determine whether or not the application of the digital actuators may result in an increase in event frequency, such that the event may need to be reclassified as an ANS Condition III event.

\subsection{Inadvertent Opening of a Pressurizer Power Operated Relief or Safety Valve (ANS Condition II)}

\section{Realistic assumption Scenario}

An accidental depressurization of the reactor coolant system could occur as a result of an inadvertent opening of a pressurizer power operated relief or safety valve. This event results in a rapidly decreasing reactor coolant system pressure through either the relief or safety valve. The event is terminated by a reactor trip and stabilization of the RCS through inventory make-up supplied by the Safety Injection system. The UFSAR event credits automatic rod control to maintain core power and the chemical and volume control system to maintain the pressurizer level, as these actions prolong and worsen the consequences of the event due to delaying the reactor trip.

As the DNB concern is mitigated by a reactor trip on low pressurizer pressure and the reactor trip setpoint is above safety injection setpoint, a SCCF associated with the safety injection valve actuators would not impact the primary response of the RTS. Therefore, the DNBR response would not be expected to be impacted by a failure that resulted in preventing the delivery of Safety Injection. With respect to stabilization of the RCS pressure, if Safety Injection were not available, the RCS pressure would decrease to the actuation setpoint of the passive Accumulators. Once the accumulator setpoint is reached, borated RCS make-up inventory would be injected that stabilize the RCS pressure decrease.

\section{Impact of SCCF}

Because the results of the core response are not impacted by the unavailability of Safety Injection, the DNBR acceptance criterion would continue to be met. However, with the need to rely on either manual operator action to align the appropriate SI valves or ensure that the accumulators can mitigate the pressure transient, it is suggested that a realistic assumption quantitative safety analysis be performed to demonstrate that the reactor can be placed in a stable shutdown condition. 


\subsection{Failure of Small Lines Carrying Primary Coolant Outside Containment (ANS Condition II)}

\section{Realistic assumption Scenario}

There are no instrument lines connected to the reactor coolant system that penetrate containment. There are however, grab sample lines and one letdown line that penetrates containment. The grab sample lines are provided with normally closed isolation valves on both sides of the containment wall and are designed in accordance with the requirements of GDC-55.

Any release rate of these lines is within the capability of the reactor makeup system. It would not result in ESF system actuation. Furthermore, frequent operation of the automatic makeup system will provide the operator with some indication of the level of reactor coolant. Other indication signals are accumulator tank level and pressure indicators, volume control tank low level indication and alarm, containment sump level indicators, core exit thermocouples (high reading), and stem leak-off alarms.

\section{Impact of SCCF}

The Safety Injection System is not required for this event and, as a result, reliance on the digital actuator is not part of the mitigation path.

\subsection{Steam Generator Tube Rupture (ANS Condition III)}

\section{Realistic assumption Scenario}

The accident examined is the complete severance of a single steam generator tube. Timely operator response is required to terminate the primary-to-secondary break flow and to ensure that the ruptured steam generator does not fill with water and flood the main steam lines. This criterion is important because the main steam lines and safety valves are not designed for liquid flow.

The accident is assumed to take place at power with the reactor coolant contaminated with fission products corresponding to continuous operation with a limited amount of defective fuel rods corresponding to the Technical Specification limits. The accident leads to an increase in contamination of the secondary system due to leakage, at the Technical Specification limits, of radioactive coolant from the reactor coolant system. Discharge of activity can take place through the atmosphere via the Atmospheric Steam Dump Valves and/or MSSVs. Failure of an Atmospheric Steam Dump Valve in the open position is not assumed to occur for the realistic assumption SCCF evaluation discussed below.

It is considered that the assumption of a complete severance of a tube is conservative and using realistic assumptions, not likely to occur. The more probable mode of tube failure would be one or more minor leaks of undetermined origin or a longitudinal split. Break sizes less that the complete severance of a tube would result in lower break flow rates and subsequently provide the operators with more time to diagnose and mitigate the event. Activity in the Steam and Power Conversion System is subject to continual surveillance and an accumulation of minor 
leaks which exceeds the limits established in the Technical Specifications is not permitted during unit operation.

The major concern associated with the steam generator tube rupture and a concurrent SCCF is the potential for the overfill condition in the faulted steam generator exceeding that analyzed in the UFSAR safety analysis. Because the current UFSAR analysis predicts steam generator overfill, the Atmospheric Steam Dump Valves have been qualified for water relief. Additionally, it is noted that the MSSVs are not qualified for water relief. Further discussion of the event assuming a SCCF is presented, below.

The operator is expected to determine that a steam generator tube rupture has occurred, and to identify and isolate the ruptured steam generator on a restricted time scale in order to minimize the contamination of the secondary system and to ensure the termination of the radioactive release to the atmosphere from the ruptured steam generator. Sufficient independent and diverse indications, alarms, procedures, controls and event specific simulator training are provided to enable the operator to carry out these functions satisfactorily.

Consideration of the indications provided at the control board, together with the magnitude of the break flow, leads to the conclusion that the accident diagnostics and isolation procedure can be completed such that pressure equalization between the primary and secondary can eventually be achieved and break flow terminated within approximately two hours using the conservative assumptions presented in the UFSAR.

Operator actions in response to an SGTR are assumed to follow plant specific emergency procedures and related procedures of any EOPs. Required operator action times modeled in the plant specific UFSAR Chapter 15 analysis are typically based on plant specific operator training sessions in the simulator following the EOPs.

Assuming normal operation of the various plant control systems, the following sequence of events is typically initiated by a tube rupture:

1. Pressurizer low pressure and low level alarms are actuated and charging pump flow is increased to maintain pressurizer level. On the secondary side, there is a steam flow/feedwater flow mismatch prior to reactor trip as the feedwater flow to the faulted steam generator is reduced due to the break flow being supplied to that generator.

2. Decrease in pressurizer pressure due to continued loss of reactor coolant inventory leads to the generation of a reactor trip signal. Following this, the operator terminates normal feedwater supply and manually initiates auxiliary feedwater (AFW).

3. Continued loss of reactor coolant inventory may result in a reactor trip signal being generated by either Low Pressurizer Pressure (with P7 interlock), Hi-Hi Steam Generator level (with P7 interlock) or a Safety Injection signal. The resultant plant cooldown following a reactor trip leads to a rapid decrease in the pressurizer level, and the safety injection actuation signal, initiated on low-low pressurizer pressure, follows soon after the reactor trip. The safety injection system should inject borated water to the reactor coolant system via the two centrifugal charging pumps (CCPs). The safety injection actuation signal automatically causes the termination of the normal feedwater 
supply and the initiation of the Auxiliary Feedwater System (AFS). While injection of RCS inventory is assumed to not be available due to the SCCF associated with the injection valve actuators, all other mitigating functions generated by the Safety Injection signal are assumed to be available.

4. The reactor trip automatically trips the turbine. Excess steam would be relieved through the Atmospheric Steam Dump Valves. The MSSVs would also lift if required to maintain the secondary system pressure within the acceptance criteria. The MSSVs are not qualified for water relief and would therefore be assumed to fail once the steam generator reached an overfill condition per the UFSAR analysis.

5. Following the reactor trip, the continued action of AFW provides a heat sink, which dissipates the decay heat.

The immediate symptoms of a tube rupture accident, such as falling pressurizer pressure and level and increased charging pump flow, are also symptoms of small steamline breaks and loss of coolant accidents. Therefore, it is important for the operator to identify the accident as a steam generator tube rupture in order to execute the correct recovery procedure. The steam generator tube rupture event can be uniquely identified by alarms from the condenser off gas, steam generator blowdown, or main steamline radiation monitors. In addition, following reactor trip, the narrow range water level will rise more rapidly in the faulted steam generator than in the other steam generators due to the primary-to-secondary break flow.

Following identification of the event as a steam generator tube rupture, the operator responses depicted in the UFSAR are required to terminate the primary-to-secondary break flow and to terminate the event.

\section{Impact of SCCF}

The primary concerns for the steam generator tube rupture (SGTR) event are 1) the release of radioactive contamination from the reactor coolant system to the secondary systems and ultimately to the environment, and 2) overfill of the ruptured SG beyond that considered in the UFSAR dose analysis. The primary means of protection is operator response to the symptoms with manual actions to isolate the ruptured $S G$ and terminate the primary to secondary release.

With the confirmation of the validity of abnormal secondary system radiation levels, the operator would be required to actuate SI which would not cause injection due to the postulated SCCF to the digital actuators. The diagnostic charts in the emergency procedures would guide the operator to the appropriate emergency procedure for a steam generator tube rupture, based on secondary radiation monitors having abnormal indications. This emergency procedure will guide the operator through mitigation of the event. Several functions available to provide indications of this event are steam generator blowdown and main steam line radiation monitors. Steam generator wide range level indications will also be available to provide the operator with indication of a steam generator tube rupture event. Other indications that can be used are pressurizer level; reactor coolant system depressurization, main steam safety valve position, and/or steam generator blowdown radiation monitor alarms (and indicator lights).

For evaluating the impact of SCCF on this event, the limiting single active failure (manual termination of auxiliary feedwater from the control room, which delays termination by 15 
minutes) does not have to be considered given the realistic assumption approach applied to the SCCF evaluation. From the limiting case shown in the UFSAR Chapter 15 analysis, automatic reactor/turbine trip, ECCS function, main feedwater isolation, and auxiliary feedwater initiation are credited on the appropriate protection signals with minimum delay for the auxiliary feedwater initiation.

ECCS during the SGTR performs two functions. It compensates for the leak flow rate and maintains reactor coolant system inventory. It also helps to maintain reactor coolant system subcooling. If the reactor coolant system subcooling criteria in the EOPs are not met, the operator should proceed into the Emergency Contingency Actions involving a SGTR scenario which has not been analyzed. It is recognized that the UFSAR analysis applies an assumption of maximum ECCS performance, which acts to maximize the break flowrate and subsequently maximize the resultant offsite dose calculations. For the case where ECCS is not available due to the injection valve actuator SCCF, it is expected that the RCS pressure will naturally drift down the point where it equalizes with the pressure in the faulted steam generator, ultimately resulting in terminating the break flow sooner than in the UFSAR analysis. Additionally, hot leg saturation would be a concern without the delivery of ECCS to help maintain and control RCS pressure. It is noted that the EOPs directly monitor RCS subcooling and provide mitigating strategies when hot leg saturation is approached, specifically tripping of the RCPs.

For the low power SGTR event, ample time should be available for the operator to manually isolate main feedwater and trip the reactor due to the smaller primary-to-secondary pressure and temperature differences. Additionally, the ability to maintain subcooling in the core is eased due to the low power level. Diverse indications are available that indicate the need for these actions. Therefore a realistic assumption quantitative analysis is suggested to ensure that sufficient time exists for manual operator action, define whether or not the Atmospheric Steam Dump Valves are required to mitigate a steam generator overfill condition, ensure that the accumulators can provide a sufficient capability to maintain primary reactor coolant system inventory and subcooling, and define any required diverse automatic RTS and ESFAS functions if insufficient time is available to credit operator action.

For the full power SGTR event, ECCS flow is required to be actuated by manual operator actuation within approximately 10 minutes of identification of the SGTR event. Therefore, a realistic assumption quantitative analysis should be performed to address the situation where automatic SIS injection is not available and ensure that the resultant mass release used in the UFSAR dose analysis remains bounding.

\subsection{Steam Generator Tube Rupture with a Safety Valve Stuck Open}

Per the guidance provided in BTP 7-19, the limiting failure does not have to be assumed concurrently with the event and the postulated SCCF for the SCCF evaluation. As a result, the Steam Generator Tube Rupture event with a Stuck Open Main Steam Safety Valve does not require evaluation in the Diversity and Defense In-Depth SCCF analysis. 


\title{
5.10 Loss of Coolant Accident (LOCA) (ANS Condition III for Small Breaks, ANS Condition IV for Large Breaks and Intermediate Breaks)
}

\author{
Realistic assumption Scenario \\ A Loss of Coolant Accident (LOCA) is the result of a pipe rupture of the reactor coolant system \\ pressure boundary. The UFSAR discusses a spectrum of break sizes. The limiting break \\ location is in the cold leg piping for all break sizes. The UFSAR discusses large break LOCAs \\ and small break LOCAs separately, because the phenomena and analysis methods are \\ different for these break classifications.
}

The acceptance criteria for this event are from 10CFR50.46 and are:
a. The calculated peak fuel element clad temperature should be below $1204^{\circ} \mathrm{C}$.
b. The amount of fuel element cladding that reacts chemically with water or steam should not exceed $1 \%$ of the total amount of Zircaloy/Zirlo in the reactor.
c. The localized cladding oxidation should be less than $17 \%$.
d. The core must remain in a coolable geometry at all times.
e. Long term cooling of the core should be ensured.

The analyses described in the UFSAR show that the above criteria are satisfied for Hawke River for the complete spectrum of break sizes. The limiting large break LOCA is a double-ended guillotine break in the cold leg. The limiting small break LOCA is in the cold leg. The large break LOCA results in higher peak cladding temperatures than the small break LOCA. Hence it is the limiting event supporting the design basis of the ECCS.

The large break LOCA also is the limiting event for the peak pressure analysis in the containment and supports the design basis for the containment function.

The UFSAR LOCA analyses assume a loss of offsite power concurrent with break initiation and a single failure of a low head safety injection pump. The analyses also assume conservative initial and boundary conditions. Qualitatively, the sequence of events for a LOCA will not be significantly different with more realistic accident assumptions. The main change is that a loss of offsite power does not need to be assumed in a realistic scenario. The reactor coolant pumps would not be tripped at the beginning of the accident, and the operator would trip them when the appropriate setpoint (subcooling margin) is reached as dictated by the EOPs.

In a realistic scenario, for large break LOCAs, the reactor coolant system will depressurize rapidly immediately after break initiation. A reactor trip signal will be initiated by a low pressurizer pressure signal. This will be followed quickly by a safety injection actuation signal, which activates the ECCS. The reactor coolant pumps continue to operate until the operator trips them on a loss of subcooling margin. The rapid depressurization results in core voiding, which introduces substantial negative reactivity in the core causing a rapid power decrease. The UFSAR analysis assumes that control rods do not insert for this accident, demonstrating that the negative reactivity introduced by core voiding is more than sufficient to decrease reactor power to manageable levels. The accumulators begin injecting water when the reactor coolant 
system pressure drops to about 600 psia. The core is maintained in a shutdown condition due to boron delivery from both the ECCS and the accumulators.

In the UFSAR analysis, because of the assumed loss of offsite power, there is a delay for the diesels to come up to speed. This causes a small delay in ECCS injection. In any case the High Pressure ECCS injection begins first followed by the Low Pressure ECCS injection. The UFSAR analysis indicates that peak cladding temperatures in the core are reached in the time period of 2 to 3 minutes after break initiation. The core temperature increase is arrested primarily due to the water injected by the Low Pressure ECCS injection system. Subsequently, the core is refilled as the Low Pressure ECCS injection system continues to inject water. The injected ECCS water is borated, and this provides sufficient negative reactivity to maintain the core subcritical. Beyond this time, long term recovery procedures will be active and this maintains the core filled and in a coolable geometry. These longer term recovery actions, such as switchover to ECCS recirculation from the containment sump, are manual operator actions based on the plants emergency operating procedures. These long term actions are well beyond the manual ESFAS action times considered herein and therefore beyond the scope of the SCCF evaluation.

As contrasted with the large break, the blowdown phase of the small break occurs over a longer time period. For very small breaks, the charging pumps can make up water to maintain the reactor coolant system at its initial operating condition, until the operator responds to the event and initiates an orderly shutdown. The UFSAR notes that for Hawke River, one charging pump can provide makeup flow to the reactor coolant system to maintain the system pressure at the normal operating pressure.

For larger small breaks, the reactor coolant system depressurizes resulting in a reactor trip on low pressurizer pressure and safety system activation on low-low pressurizer pressure. Prior to the reactor trip, it is possible for the power to increase slightly. This is because there can be a small positive reactivity insertion due to the nature of the moderator density reactivity coefficient. As density continues to decrease the reactivity becomes more negative and the power decreases. As the depressurization continues, if the break size is small enough, high pressure injection from the ECCS provides sufficient makeup. In this case, the reactor coolant system pressure stabilizes and there is no resultant core uncovering. For the larger end of the small break spectrum, the depressurization continues. As the reactor coolant system continues to depressurize further, the low pressure ECCS injection initiates and provides continued core cooling. At a pressure of approximately 600 psia, the cold leg accumulators begin to inject borated water. Meanwhile, it is possible for the core to void partially and exhibit some fuel rod heatup. However, for all small breaks, the combination of ECCS and accumulator injection provides sufficient water supply to maintain the mixture above the top of the core. Eventually, similar to the large break LOCA which is discussed below, long term recovery procedures are established following the EOPs.

\section{Impact of SCCF}


A concurrent event such as a loss of offsite power is not assumed for the SCCF analysis; therefore, the reactor coolant pumps are not assumed to trip at the inception of the accident. The primary automatic RTS trip signal is low pressurizer pressure for the LOCA events. The backup reactor trip signals are containment high-pressure safety injection and OTDT. The primary ESFAS safety function is provided by the ECCS to provide safety injection on a low-low pressurizer pressure signal. The SIS fails to inject water for all size breaks into the reactor due to the SCCF of the digital actuators. However, the auxiliary feedwater actuates.

The current UFSAR analysis does not credit the shutdown control rod banks. The reactor power is decreased initially due to the large negative reactivity introduced by core voiding, and the core is maintained subcritical at later times due to Boron injection from the ECCS and accumulators. For the larger end of the small break spectrum and the intermediate breaks, the cases initially result in core voiding and subsequent Boron delivery from the ECCS and accumulator actuation. In the initial phase of a small break LOCA, due to the moderator density coefficient, the reactor power would increase slightly. This power excursion is mitigated by the negative Doppler reactivity provided by an increase in fuel temperature. As the small break LOCA event progresses, with an attendant decrease in reactor coolant system pressure, the moderator density decreases, and combined with the negative fuel temperature coefficient, provides sufficient negative reactivity to begin decreasing reactor power. Since offsite power is available, the reactor coolant pumps continue to operate, providing forced coolant flow through the core. The reactor coolant pumps are tripped if the operator is directed to do so as directed by the EOPs. However, prior to tripping the pumps, the operator would manually trip the reactor if an automatic trip signal were not generated. This should not result in violations of the realistic assumption acceptance criteria.

If ECCS flow cannot be automatically established, there will be a significant effect on the large break LOCA scenario. The UFSAR analysis shows that the peak cladding temperatures are reached in a short period of time (1 to 2 minutes) after break initiation. This means that ECCS actuation is required in a similar 1 to 2 minute time frame to mitigate the event and provide a coolant source to begin recovery the core water level. Also, the rate of cladding temperature increase will be slightly lower based on a set of realistic assumptions, power distribution peaking factors and decay heat. Nevertheless, further evaluation is needed to determine whether the time available for the operator to diagnose and respond to this event is sufficient to maintain the peak cladding temperatures within acceptable limits. It is likely that the operator must act within the first minute following event initiation to provide successful mitigation for this event. (System level manual SIS injection actuation is impaired due to the SCCF for the digital actuators. However, the operator can manually operate each valve from a local control station.) This will prove to be the limiting case and will require implementation of a design change to successfully mitigate the LBLOCA event.

\section{Diverse Mitigating Functions for FSAR Chapter 15 Accident Analyses}

The evaluation considered that the plant response to the postulated initiating events (PIE) concurrent with a postulated CCF can be addressed by one of the following approaches. These 
approaches can be categorized in different ways but for this evaluation, the following four categories were chosen:

\begin{abstract}
Category A - The Safety Injection System is not required to be actuated in the event, resulting in no impact from the postulated digital actuator SCCF or the event is not considered in the SCCF evaluation because multiple failures would be required in order for the event to occur.

Category B - The event is terminated successfully by actuation of RTS and/or ESFAS or an alternate, independent, diverse system through either automatic or manual actions. The events credited with mitigation through the use of manual actions for mitigation were deemed acceptable and placed into this category if an engineering analysis determined there was sufficient time and available indications available.
\end{abstract}

Category C - The event is bounded by another event.

Category D - Further work is required to demonstrate successful event mitigation, such as quantitative analysis, event simulations, additional justifications, or plant modifications. The final results of this work action would be to change the Category D items to Category B either by the acceptance of a manual actuation(s) or the addition of the proper diverse mitigation functions through a diverse actuation system (DAS).

Indicators and alarms for events requiring operator manual action are provided by highly reliable components. Should an event occur, these indicators and alarms will be available to alert the operator so that timely and appropriate operator action for the applicable events can be taken in accordance with plant procedures. The following criteria were used to consider if operator manual action was credible:

- The postulated digital actuator SCCF and its effects do not impair controls or displays necessary for operator action,

- Sufficient information is available for the operator to determine the action required, and

- Sufficient time is available for operator analysis, decisions and action.

Table 2 below shows the resulting Category $D$ for each event. For this example, only the Category $D$ events are shown in Table 2. With the exception of the LBLOCA, these events could be placed into Category $B$ by using a more detailed quantitative analysis showing positive results. However, the LBLOCA event requires design changes as noted above. All the Hawke River events described will continue to meet established acceptance criteria using realistic assumption assessments with equivalent protection or mitigation functions providing design changes are made as recommended. 


\section{Table 2 Category D- Chapter 15 Events Requiring Further Analysis}

\begin{tabular}{|c|c|c|c|}
\hline No. & $\mathrm{PIE}$ & PRIMARY PROTECTION & $\begin{array}{l}\text { DIVERSE } \\
\text { PROTECTION* }\end{array}$ \\
\hline 5.2 & $\begin{array}{l}\text { Accidental Main Steam System } \\
\text { Depressurization }\end{array}$ & $\begin{array}{l}\text { Safety Injection } \\
\text { Containment Isolation } \\
\text { AFW } \\
\text { Steam Line Isolation }\end{array}$ & $\begin{array}{l}\text { SI-Low-Low Press } \\
\text { SI } \\
\text { SI } \\
\text { Lo-Lo STG Press }\end{array}$ \\
\hline 5.3 & Steam System Piping Failure & $\begin{array}{l}\text { Safety Injection } \\
\text { Containment Isolation } \\
\text { AFW } \\
\text { Steam Line Isolation } \\
\text { Containment Spray }\end{array}$ & $\begin{array}{l}\text { Low Compensated } \\
\text { SP } \\
\text { SI } \\
\text { SI } \\
\text { Low Compensate SP } \\
\text { Hi Containment } \\
\text { Pressure } \\
\end{array}$ \\
\hline 5.6 & Opening PSV & $\begin{array}{l}\text { Reactor Trip } \\
\text { Safety Injection } \\
\text { Containment Isolation } \\
\text { AFW Start-up }\end{array}$ & $\begin{array}{l}\text { SI - Low-Low } \\
\text { Pressurizer Pressure }\end{array}$ \\
\hline 5.8 & SGTR & $\begin{array}{l}\text { Reactor Trip } \\
\text { Safety Injection } \\
\text { Containment Isolation } \\
\text { Motor driven AFW pumps }\end{array}$ & $\begin{array}{l}\text { Manual Operator } \\
\text { action } \\
\text { SI - Low-Low } \\
\text { Pressurizer Pressure }\end{array}$ \\
\hline 5.10 & $\begin{array}{l}\text { LOCA (Large, intermediate and } \\
\text { small) }\end{array}$ & $\begin{array}{l}\text { Reactor Trip } \\
\text { Safety Injection } \\
\text { Containment Isolation } \\
\text { AFW Start-up } \\
\text { Containment Spray }\end{array}$ & $\begin{array}{l}\text { SI - Low-Low } \\
\text { Pressurizer Pressure }\end{array}$ \\
\hline
\end{tabular}




\section{Conclusions}

The Hawke River licensing basis safety analyses were evaluated to determine which events required the SIS for primary or backup protection actuations. Those events identified as requiring the SIS for primary/secondary protection system response were then evaluated to determine if a timely diverse means of automatically mitigating the transient was available or annunciators and indicators were available to allow the operator to diagnose the event and manually bring the plant to a safe shutdown condition in a timely manner. Manual actuations for the SIS can only be considered at the local valve control as the system level manual mitigation path required use of the digital actuators which are postulated to have failed due to the SCCF. This evaluation yielded 5 Category $D$ events causing concern and requiring more detailed quantitative evaluations. However, the LBLOCA event will prove to be bounding as discussed below.

The Hawke River D3 evaluation documented herein has demonstrated that there is a concern with sufficient diversity and defense-in-depth to cope with a postulated SCCF to the SIS digital actuators. It has been determined that, with a postulated SCCF there are not adequate defenses and diversity in the SIS architecture to meet the applicable acceptance criteria. The LBLOCA will prove to be the limiting case and cannot be successfully mitigated without a design change to cope with the postulated SCCF.

This change should be one of the following:

1. Software for the digital actuators be completely testable (simple software) in accordance with NRC guidance such that a SCCF possibility is eliminated

2. Diverse digital actuators would be needed for each SIS Train to eliminate concurrent SCCFs to both digital actuators.

3. Either maintain the current analog actuators or replace them (if available) with new analog actuators which are not susceptible to the SCCF concern.

When considering realistic assumption and the design of the digital actuators, it is determined that the proposed Hawke River digital I\&C architecture will meet the BTP 7-19 acceptance criteria with the implementation of one of the three options noted above.

Each initiating event requiring SIS was evaluated using qualitative deterministic methods. Based on the evaluation herein, it is expected that the acceptance criteria as discussed in the qualification section of this report will be met for all evaluated PIEs when the actuator design modification as discussed above is implemented. That this conclusion applies to the proposed SIS design is demonstrated in the evaluations shown in this appendix, which assumes that a SCCF disables the digital actuation portion of the SIS design while all other systems, including ATWS and the other SIS functions, are not susceptible to the same SIS digital actuator SCCF and remain available to perform the required functions. 